\title{
PADRÕES DE VARIABILIDADE ESPACIAL E TEMPORAL DA PRODUÇÃO EM UM POMAR JOVEM DE LARANJA HAMLIN
}

Francisco José de Oliveira Parise

Engenheiro Agrônomo

Orientador: Prof. Dr. CARLOS ALBERTO VETTORAZZI

Tese apresentada à Escola Superior de Agricultura "Luiz de Queiroz", Universidade de São Paulo, para obtenção do título de Doutor em Agronomia, Área de Concentração: Irrigação e Drenagem.

P IR A C I C A B A

Estado de São Paulo - Brasil

Fevereiro - 2004 


\section{ERRATA}

PARISE, F. J. de O. Padrões de variabilidade espacial e temporal da prodúção em um pomar jovem de laranja Hamlin

$\begin{array}{lllll}\text { p. } & \text { item } & \text { linha } & \text { onde se lê } & \text { leia-se } \\ 83 & 4.2 & \text { oitava } & \text { área de projeção da copa } & \text { Desconsiderar a linha } \\ 86 & 4.3 & \text { décima } & \text { vôo 1 b altura } \ldots & \text { Desconsiderar a linha } \\ 86 & 4.3 & \begin{array}{l}\text { décima } \\ \text { sexta }\end{array} & \cdots \mathrm{y}=1,0112 \mathrm{e}^{0,0038 x} \ldots\end{array}$
$86 \quad 4.3$ décima $\quad \ldots$ linear $\ldots 0,36 \quad 0,12 \quad$ exponencial $y=0,7732 \mathrm{e}^{0,00052 \mathrm{x}}$ nona $\quad 0,0069 \quad \ldots 0,27 \quad 0,07 \quad 0,023$

87 4.3 vigésima vôo 1 b̉

altura infravermelho linear sexta $\mathrm{y}=0,0104 \mathrm{x}-0,1873 \quad 18$ $0,36 \quad 0,12: 0,0069$

$92 \quad 4.4 \begin{aligned} & \text { décima } \\ & \text { quinta }\end{aligned}$

$y=0,0167 x+27,744$

975 prımeira $\quad$ Sob ... $\quad$ Desconsiderar o parágrafo

$98 \quad 5 \quad$ primeira A resposta espectral ... $\quad$ Desconsiderar o parágrafo

98 . 5 décima A explicação $\ldots$ Desconsiderar o parágrafo terceira 


\section{Dados Internacionais de Catalogação na Publicação (CIP) DIVISÃO DE BIBLIOTECA E DOCUMENTAÇÃO - ESALQ/USP}

Parise, Francisco José de Oliveira

Padrōes de variabilidade espacial e temporal da produção em um pomar jovem de laranja Hamlin / Francisco José de Oliveira Parise. - - Piracicaba, 2004.

107 p. : il.

Tese (doutorado) - Escola Superior de Agricultura Luiz de Queiroz, 2004.

Bibliografia.

1. Laranja Hamlim 2. Pomar 3. Produção vegetal 4. Sensoriamento remoto 5. Variabilidade espacial 5. Variabilidade temporal I. Título

CDD 634.31

Wermitida a copia total ou parcigl ieste documento desde que citada a fonte -0 autor 
A Omar Ali Shah e a minha querida esposa Magali, presentes em todos os momentos. 


\section{AGRADECIMENTOS}

Ao Departamento de Engenharia Rural da Escola Superior de Agricultura "Luiz de Queiroz" - Universidade de São Paulo pela oportunidade de cursar o programa de pós-graduação em Irrigação e Drenagem.

A Coordenação de Aperfeiçoamento de Pessoal de Nível Superior (CAPES) pela concessão da bolsa de estudo.

Ao Prof. Dr. Carlos Alberto Vettorazzi pela orientação e incentivo, mas, principalmente, pela paciência e tolerância.

Ao Prof. Dr. Rubens Ângulo Filho pelas sugestões, suporte técnico e condescendência.

Aos Prof. Francisco de Assis Alves Mourão Filho e José Paulo Molin pelas sugestões e condescendência.

Aos Prof. Durval Dourado Neto, Luiz Roberto Angelocci e Nilson Augusto Villa Nova pelas sugestões e incentivo.

Ao engenheiro agrônomo Márcio Frascino Müller de Almeida pela disponibilidade, sugestões, esclarecimentos e suporte técnico.

Ao Sr. Nelson da Silva pela disponibilidade, esclarecimentos e ajuda.

A Antonio Aparecido Ribeiro pelo incentivo e ajuda.

A Antonio Aparecido Perin pelos esclarecimentos e ajuda.

A Rosalino Mendes de Souza e sua equipe de colhedores, José Felício, Claudinei da Silva, Irival Araújo, Paulo Sérgio de Lima, Luis Evangelista, Terezinha da Silva, Maria de Lurdes dos Santos, Gilberto da Silva, Maria Ramos da Cruz, Maria de Fátima Pereira, Odair Bento, Jalmir Camargo, Genário da Silva, Natalina da Silva, Itarcil Antonio, Paulo Cezar Martins, Pedro de Oliveira, José Maurílio de Andrade, 
Antonio José de Oliveira, José Orioni Tristão, Antonio Venâncio de Moura Neto, Moacir de Souza, João Ferreira de Oliveira, Maria de Fátima de Menezes, Gildeone José da Silva, José Morato de Moura, Adão de Oliveira pela possibilidade de levantamento dos dados de produção.

Ao engenheiro agrônomo Maurício Antonio Coelho Filho e ao engenheiro agrícola Alexandre Cândido Xavier pelas sugestões e incentivo.

Ao técnico em informática Jefferson Lordello Polizel do Laboratório de Métodos Quantitativos do Departamento de Ciências Florestais pelo suporte técnico na aquisição das imagens aéreas.

Aos funcionários do Departamento de Engenharia Rural e da Divisão de Biblioteca e Documentação da Escola Superior de Agricultura "Luiz de Queiroz" Universidade de São Paulo pelo suporte técnico.

Aos amigos Alcester e Adriana, Sérgio e Graziela, Vanoli e Rosa, Eder, Diniz, Ronalton, Luis Campeche e Nádia pelo convívio nesses anos em Piracicaba.

A Marie e minha irmã Maria Ligia pela presença constante e aos meus irmãos Maria Lúcia e Fernando pelo incentivo.

Enfim, a todos aqueles que, de forma direta ou indireta, colaboraram para a realização deste trabalho. 


\section{SUMÁRIO}

Página

LISTA DE ABREVIATURAS E SIGLAS .................................................. viii

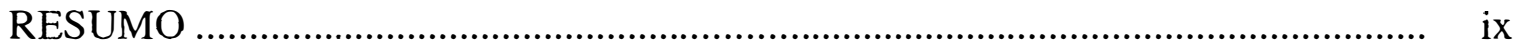

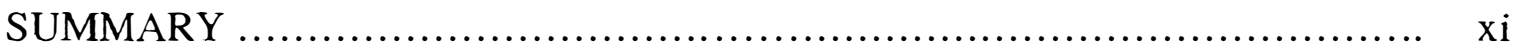

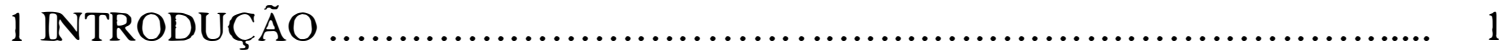

2 REVISÃO DE LITERATURA ..................................................................... 5

2.1 Aspectos produtivos em citricultura ....................................................... 5

2.2 Estudos de análise espacial e temporal da produção ....................................... 11

2.3 Resposta espectral das plantas, parâmetros de copa e produção ......................... 21

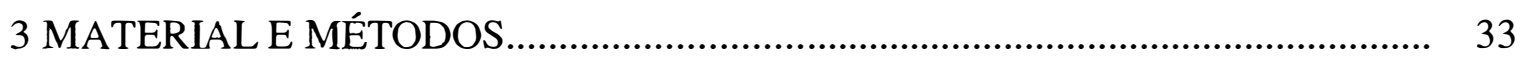

3.1 Área de estudo ................................................................................... 33

3.2 Balanço hídrico e armazenamento de água no solo ......................................... 34

3.3 Levantamento dos dados de produção ..................................................... 34

3.4 Georeferrenciamento das árvores ............................................................. 34

3.5 Captura e transformação das imagens aéreas .............................................. 35

3.6 Obtenção dos valores de NDVI, SAVI e nível de cinza nas faixas do vermelho e do infravermelho próximo das árvores .................................................. 38

3.7 Obtenção dos parâmetros de copa .............................................................. 38

3.8 Análise dos dados ............................................................................. 40

3.8.1 Análise espacial e temporal da produção ................................................. 40

3.8.2 Determinação dos coeficientes de correlação intraclasse para resposta espectral 45

3.8.3 Estudo das relações entre parâmetros de copa, resposta espectral e produção .... 46

4 RESULTADOS E DISCUSSÃO .............................................................. 47 
4.1 Análise espacial e temporal da produção ............................................................ 47

4.1.1 Descrição univariada ..................................................................................... 47

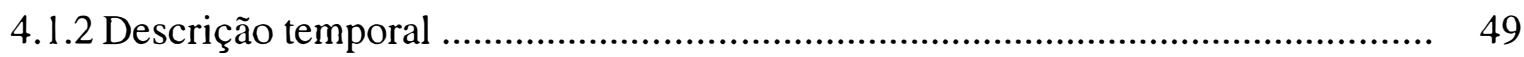

4.1.3 Descrição espacial ....................................................................................... 54

4.1.4 Descrição espaço-temporal ............................................................................ 66

4.2 Estudo das relações entre parâmetros de copa e produção ……………………...... 82

4.3 Estudo das relações entre resposta espectral e parâmetros de copa ........................ 85

4.4 Estudo das relações entre resposta espectral e produção ........................................... 91

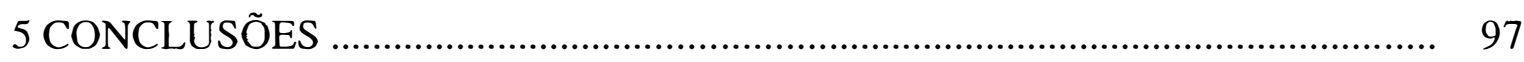

REFERÊNCIAS BIBLIOGRÁFICAS _.................................................................... 99 


\section{LISTA DE ABREVIATURAS E SIGLAS}

ARM Armazenamento de Água no Solo

CAD Capacidade de Água Disponível

CCD Charge Coupled Advice

CIR Color Infrared

DEF Deficiência Hídrica

DLLAI Drip Line Leaf Area Index

DN Digital Number

EXC Excedente Hídrico

GPS Global Positioning System

|h| Distância de Separação

IAF Índice de Área Foliar

IV Infravermelho Próximo

L Fator de Ajuste para Influência do Solo

LAI Leaf Area Index

NDVI Normalized Difference Vegetation Index

MPE Modified Partition Entropy

RGB Red Green Blue

SAVI Soil Adjusted Vegetation Index

S Separate Distance

UTM Universal Transversa de Mercator

V Vermelho

$\gamma(|\mathrm{h}|) \quad$ Semivariância em Função da Distância de Separação 


\title{
PADRÕES DE VARIABILIDADE ESPACIAL E TEMPORAL DA PRODUÇÃO EM UM POMAR JOVEM DE LARANJA HAMLIN
}

\author{
Autor: FRANCISCO JOSÉ DE OLIVEIRA PARISE \\ Orientador: Prof. Dr. CARLOS ALBERTO VETTORAZZI
}

\section{RESUMO}

Em um pomar jovem de laranja Hamlin, não irrigado, foi realizado um estudo que procurou investigar a potencialidade do levantamento dos padrões de variabilidade espacial e temporal da produção e da resposta espectral das árvores para o gerenciamento localizado da produção. A produção de 1471 árvores foi levantada em dois ciclos sucessivos, 2000/2001 e 2001/2002, e analisada por meio de técnicas geoestatísticas e análise de agrupamentos via lógica fuzzy. 52 árvores distribuídas ao longo de duas transeções foram selecionadas para o levantamento das variáveis área de projeção de copa, volume, altura, densidade foliar, DLLAI, área foliar e resposta espectral. Imagens multiespectrais de alta resolução espacial foram tomadas do pomar em três fases fenológicas distintas: durante a fase de repouso vegetativo, no início da fase de maturação dos frutos e logo após o florescimento do ciclo seguinte. Os índices de vegetação NDVI e SAVI e os níveis de cinza nas faixas do vermelho e do infravermelho próximo foram utilizados nas análises de regressão entre a resposta espectral e as variáveis. Os resultados mostraram que houve dependência espacial nos dois ciclos estudados, com maior dependência no ciclo em que as condições climáticas 
foram adversas. A dependência espacial tendeu a se manter no tempo, a despeito das grandes variações climáticas. Foi possível formar classes distintas de comportamento produtivo em função dos padrões de variabilidade espacial e temporal da produção. No entanto, as classes apresentaram baixa coerência espacial, o que dificulta o gerenciamento localizado da produção em nível de árvores individuais. A despeito disso, a resposta espectral esteve significativamente relacionada às classes formadas. Os parâmetros área de projeção de copa, volume, densidade foliar, DLLAI e área foliar não apresentaram relação significativa com a produção. Por outro lado, apresentaram relação significativa com a resposta espectral. Por sua vez, a resposta espectral apresentou relação significativa com a produção, especialmente, no ciclo em que as condições climáticas foram mais favoráveis. O índice de vegetação NDVI é o que melhor expressa as relações entre resposta espectral, parâmetros biofísicos e produção em pomares jovens de laranja Hamlin. A resposta espectral permitiu avaliar o potencial produtivo das árvores, entretanto, o levantamento de outros fatores, em particular daqueles relacionados ao solo, é recomendável para incrementar as relações. A tomada de imagens multiespectrais voltadas ao gerenciamento localizado da produção, tanto na época anterior, como posterior à fase de desenvolvimento vegetativo apresenta desempenho semelhante. 


\title{
PATTERNS OF SPATIAL AND TEMPORAL YIELD VARIABILITY IN A COMMERCIAL GROVE OF YOUNG HAMLIN TREES
}

\author{
Author: FRANCISCO JOSÉ DE OLIVEIRA PARISE \\ Adviser: Prof. Dr. CARLOS ALBERTO VETTORAZZI
}

\section{SUMMARY}

Yield data of 1471 young Hamlin trees in a commercial grove were collected in 2 seasons, 2000/2001 and 2001/2002, for identifying the patterns of spatial and temporal yield variability. Geostatistical tools and fuzzy clustering were used for the analyses. Also, the projected crown area coverage, volume, height, foliage density, DLLAI, total leaf area, and spectral response data of 52 trees distributed along 2 transects were collected for studying the relationships between crown parameters, spectral response, and yield. Multispectral digital images of the grove area were captured by a high resolution video camera in 3 distinct phenological stages: during winter dormancy, beginning of the fruit maturation and just after the flowering period of the next season. NDVI, SAVI, red and infrared raw DN data were used in regression analyses between spectral response and variables. The results showed there was spatial dependence between pairs of yield data, especially when the climatic conditions were poor. Crosssemivariogram showed the yield was consistently spatially dependent throughout the 2 seasons, despite the great climatic fluctuations. Fuzzy classification has identified general patterns of between-season variation within a field. But, these patterns correspond to regions poorly spatially coherent. Despite such behavior, spectral response 
of the trees was significantlyrelated to these regions. Regression analyses showed poor relations between yield and projected crown area coverage, volume, height, foliage density, DLLAI, and total leaf area of the trees. But, spectral response was significantly related to crown parameters and yield. NDVI was found to relate better with the variables. Despite the significant relations between yield and spectral response, particularly when the climatic conditions are favorable, it is suggested the regression analyses should be separate by soil type to improve the relations. Taken multispectral digital images before or after the vegetative growth period were similar performed. 


\section{INTRODUÇÃO}

Em citricultura, além da previsão de safra, conhecer antecipadamente o volume específico de produção em nível de talhão é primordial para fim de manejo. Em um mercado altamente competitivo, qualquer diferença na otimização da produção acaba sendo significativa. No entanto, os citricultores, em geral, ainda têm encontrado dificuldades em estimar o número de frutos por pé antes da colheita. Afinal, as dimensões espacial e temporal da produção são variáveis e os citricultores não têm uma idéia exata de como se dá a distribuição dessa variabilidade. Conseqüentemente, os métodos existentes de estimativa são inexatos ou onerosos, devido ao número elevado de frutos a serem contados.

A variabilidade espaço-temporal pode ocorrer em padrões, ou seja, a produção de grupos de árvores pode seguir um mesmo padrão de variabilidade em ciclos produtivos sucessivos, permitindo estabelecerem-se classes de comportamento produtivo. Por exemplo, um grupo de árvores sempre produzir acima das demais, a despeito do total de produção, ou responder às variações de clima e manejo semelhantemente nos diferentes ciclos.

Uma vez que o padrão de variabilidade está associado às variações dos fatores de produção, o estudo da variabilidade também daria um indicativo dos locais onde há maior ou menor limitação à produção. A partir da identificação desses locais, seria possível investigar, por meio de amostragem e correlação, quais fatores são restritivos e tomar-se medidas no sentido de contornar ou minimizar seus efeitos. 
Aos citricultores, esse tipo de informação viabilizaria uma utilização mais racional dos insumos, uma vez que se saberia de antemão quais fatores são restritivos, quanto o pomar pode produzir e, sobretudo, quais áreas produziriam mais, ou menos.

No entanto, para que isso se concretize, duas condições precisam ser satisfeitas. Primeiramente, grande parte da variabilidade deve ser intrínseca, de modo que as causas da variabilidade sejam permanentes ou, pelo menos, perdurem por vários ciclos. Assim, a formação das classes de comportamento produtivo seria possível e duraria por um certo período. Em segundo lugar, as principais causas devem ser identificáveis, para permitir uma intervenção mais racional no processo produtivo.

A despeito das baixas correlações encontradas entre produções em ciclos sucessivos aparentemente indicarem variabilidade não intrínseca, isso não corresponde necessariamente à realidade. Afinal, a manifestação dos diferentes efeitos restritivos à produção depende também de fatores que mudam de ciclo para ciclo, como o clima e o manejo. Por exemplo, a capacidade de armazenamento de água do solo é um fator intrínseco, cuja significância para a produção depende do clima. Assim como, no caso de culturas permanentes, o potencial genético para a produção das árvores também é um fator intrínseco, cuja significância também depende do clima.

Atualmente, métodos de classificação de dados utilizando a lógica fuzzy têm sido propostos. No caso de dados de produção coletados em ciclos sucessivos, sua principal vantagem é permitir identificar padrões de variabilidade entre ciclos que acompanham as flutuações de clima e manejo. De outra forma, como no caso da classificação baseada na continuidade temporal dos níveis produtivos, a identificação desses padrões seria perdida.

Ainda com relação aos estudos espaciais e temporais, técnicas geoestatísticas, ao indicarem o grau de dependência espacial entre pares de pontos separados por uma 
determinada distância, dão uma idéia se a distribuição dos dados está estruturada no espaço e se essa estrutura muda ou se mantém ao longo do tempo.

Em citricultura, comparativamente às culturas anuais, a variabilidade intrínseca às próprias plantas adquire uma dimensão importante, pois o número de plantas por área é bem menor e sua longevidade muito maior. Portanto, espera-se que parte da variabilidade de produção seja devida à variabilidade intrínseca às próprias plantas.

Um método para se estudar parâmetros relacionados à variabilidade intrínseca às próprias plantas seria recorrer às técnicas do sensoriamento remoto. Afinal, segundo a literatura, existe uma relação entre a resposta capturada pelos sensores e parâmetros biofisicos, por exemplo, quantidade de folhas e o vigor das plantas, nesse trabalho definido como quantidade de vegetação sadia. Além disso, a resposta espectral poderia ser utilizada para avaliar o potencial produtivo das plantas.

Uma das técnicas atualmente disponíveis ao levantamento de parâmetros biofísicos e potencial produtivo das plantas é a videografia aérea. Dentre suas vantagens, destaca-se sua capacidade elevada de recobrimento de área, conseqüentemente, de plantas.

Por meio da utilização das técnicas da videografia aérea, é possível capturar imagens multiespectrais já no formato digital, que representam a resposta espectral das plantas em diferentes faixas do espectro eletromagnético. Conforme o grau de resposta espectral, espera-se que as plantas tenham uma maior ou menor quantidade de folhas, conseqüentemente, maior ou menor potencial produtivo. A resposta espectral é calculada na forma de níveis de cinza em faixas individuais do espectro eletromagnético ou de índices de vegetação, que são razões entre a resposta espectral nas diferentes faixas. Geralmente, as faixas do vermelho e do infravermelho próximo e os índices de vegetação NDVI e SAVI são os mais utilizados. 
Dentre as variedades de laranja, a Hamlin enxertada sobre a citrumelo Swingle é uma variedade precoce, com menor tendência à alternância de produção e mais sensível à seca. A despeito de não estar entre as variedades mais plantadas no Brasil, apresenta características apropriadas ao tipo de estudo investigativo proposto neste trabalho. Além disso, em um pomar jovem, espera-se que a diferença entre as árvores seja maior, afinal as árvores ainda estão em formação, ou seja, não atingiram a maturidade fisiológica.

Assim, os objetivos deste trabalho são:

- Estudar a variabilidade espacial e temporal da produção por árvore, num pomar jovem de laranja Hamlin, em dois ciclos sucessivos;

- Verificar se é possível dividir o pomar em classes distintas de comportamento produtivo por meio da análise de agrupamentos via lógica fuzzy, com vistas ao gerenciamento localizado da produção;

- Verificar se o fator planta, representado por sua resposta espectral, está associado às classes de comportamento produtivo;

- Estudar as relações entre parâmetros de copa, resposta espectral e produção;

- Avaliar épocas de tomada de imagens multiespectrais, com vistas ao gerenciamento localizado da produção. 


\section{REVISÃO DE LITERATURA}

\subsection{Aspectos produtivos em citricultura}

A despeito de todos os avanços tecnológicos em citricultura, o clima ainda é o fator que maior influência exerce sobre a produção (Di Giorgi et al., 1991). Em um estudo realizado por Plessis (1983), em três localidades da África do Sul, o clima explicou de 59 \% a 88 \% das variações anuais na produção da laranjeira Baía. Sanikidze \& Mamulaishvili (1990) observaram que, em um ensaio de adubação com tangerineiras, as variações anuais na produção de árvores sob níveis nutricionais semelhantes foram atribuídas também às variações climáticas.

Com base nos resultados obtidos ao longo de vários anos de pesquisa, é possivel afirmar que a temperatura e a precipitação são os fatores climáticos mais importantes na produção citrícola. Ademais, as épocas em que o clima exerce influência mais marcante sobre a produção estão entre o pré-florescimento e a fase final da frutificação.

Para Camargo et al. (2001), a relação encontrada entre a produção e fatores hídricos, após uma análise de sensibilidade, foi maior nas fases de florescimento e início da frutificação, em pomares de laranja Valência. Já para Paulino \& Volpe (2001), as variações climáticas ocorridas no pré-florescimento, florescimento e frutificação da laranjeira Pêra determinaram a produção. 
Ben-Mechlia \& Carroll (1989), ao desenvolverem um modelo agrometeorológico para estimativa de produção das laranjeiras Baía e Valência, definiram os seguintes parâmetros e épocas para os cálculos: temperatura média no préflorescimento; temperatura média no final do florescimento; temperatura máxima durante a frutificação; demanda atmosférica; balanço hídrico; número de dias chuvosos durante o florescimento e número de dias com temperatura abaixo de zero. Martins (2000), por outro lado, optou pelos fatores hídricos e térmicos para análise, nas fases pré-florescimento, florescimento/início da frutificação e restante da frutificação, nas laranjeiras Valência e Hamlin. Ao passo que Tubelis \& Salibe (1989) definiram como parâmetro climático para estimativa da produção da laranjeira Hamlin, na região de Botucatu, no Estado de São Paulo, apenas a precipitação, especialmente, no mês de setembro, quando ocorre o florescimento.

Em Pindorama, também no Estado de São Paulo, Iaffe (1996) constatou que os meses de agosto e dezembro foram os períodos nos quais a disponibilidade hídrica teve maior influência no rendimento anual de frutos da laranjeira Hamlin. Em agosto, quando ocorre o florescimento, a correlação foi negativa e, em dezembro, quando ocorre a fixação dos frutos, a correlação foi positiva. Di Giorgi et al. (1991) também verificaram, para a laranjeira Hamlin, que as precipitações ocorridas em setembro apresentaram relação negativa com a produção, em concordância com Tubelis \& Salibe (1989). Di Giorgi et al. (1991) relataram, ainda, que as maiores safras foram acompanhadas de maior quantidade de chuva no período de frutificação e crescimento dos frutos (outubro a maio).

Para Martins (2000), em estudos realizados em Matão e Pindorama, ainda no Estado de São Paulo, a ocorrência de deficiência hídrica no período de pré-florescimento favorece a produção, ao passo que no florescimento e início da frutificação, ao contrário, ela deve ser nula. Já para Gallo et al. (1977), em Cordeirópolis, SP, deficiência hídrica nos meses antecedentes à colheita não compromete a produção da laranjeira Baianinha. 
Van Noort (1969), ao invés de lançar mão da precipitação como fator hídrico, recorreu à água de irrigação para determinar o potencial de produção da laranjeira Baía. $\mathrm{O}$ autor nada mais fez do que estabelecer funções de produção das plantas à quantidade de água de irrigação aplicada no pré e no pós-florescimento.

Também para Di Giorgi et al. (1991), assim como para Martins (2000), o fator hídrico, como parâmetro climático, tem influência marcante na produção. Entretanto, conforme os autores, a explicação da produtividade somente pelos fatores hídricos e térmicos apresenta limitações, afinal os processos de florescimento e frutificação não estão somente relacionados a esses fatores.

Segundo Martins (2000), o estado fitossanitário das plantas, com certeza, é outro fator também relacionado aos processos de florescimento e frutificação. Ainda um fator adicional de extrema importância para explicação da produtividade é o estado nutricional das plantas.

Para Coelho Filho (1998), em citricultura, a planta é outro fator que assume posição de destaque, tanto para explicar a produção, como para explicar a variabilidade de produção, afinal o ciclo das plantas citrícolas é longo e o efeito da variabilidade genética tende a ser maior. Conforme Brar et al. (1983), a variabilidade inerente às plantas, no caso de culturas frutíferas, é um componente importante da variabilidade, graças à heterogeneidade genética entre árvores originadas de mudas, causas fisiológicas e sanitárias etc. Batchelor \& Reed (1918) já haviam constatado esse aspecto ao afirmarem que as plantas citrícolas estão expostas às condições ambientais por um período de tempo mais prolongado e apresentam uma variabilidade intrínseca maior, graças ao menor número de plantas por área.

Ao lançarem as bases para a fundamentação teórica de um modelo de produção citrícola chamado CITROS (Bustan et al., 1999), Goldschmidt \& Monselise (1977) 
constataram que os três principais fatores determinantes da produção citrícola pareciam ser: o número de flores, a porcentagem final de fixação dos frutos e o potencial para o seu crescimento. Hoje, sabe-se que esses eventos fenológicos ocorrem em função do balanço nutricional, especialmente de carboidratos e compostos nitrogenados, e do controle hormonal.

No entanto, ainda não se sabe ao certo porque uma árvore de citros, em geral, produz um número elevado de flores e frutos jovens em relação ao número de frutos fixados. É possível que seja uma estratégia de sobrevivência da planta para assegurar um certo número de frutos fixados e garantir a continuação da espécie (Bustan \& Goldschmidt, 1998). Talvez seja por isso que haja muita dificuldade em estabelecer uma relação entre o número de flores e frutos jovens e a produção. Guardiola (1992) informou aos participantes de um congresso ocorrido no Brasil que, em estudos realizados com a laranja doce Navelina e a tangerina Satsuma, o número de frutos formados permaneceu quase constante ao longo de uma ampla faixa de florescimento.

Em contrapartida, pesquisadores japoneses (Ikeda et al., 1991; Ikeda, 1992 e Morinaga \& Ikeda, 1991), ao utilizarem índices de visibilidade de flores, obtidos pelo processamento de imagens capturadas por uma câmara de vídeo montada num balão posicionado a $10 \mathrm{~m}$ do solo ou numa plataforma ajustável, obtiveram bom grau de relação entre os índices de visibilidade de flores e o número de flores e a produção contada em campo. Também utilizaram índices de visibilidade de frutos maduros e concluíram que a visibilidade dos frutos também se mostrou útil para a estimativa da produção de frutos cítricos, uma vez que o número estimado de frutos maduros teve boa correlação com os valores observados em c ampo.

Blazquez et al. (1984), por outro lado, estabeleceram o potencial produtivo de um pomar-amostra na Flórida, E.U.A., em função do tamanho da copa e de suas condições fisiológicas avaliadas visualmente em fotografias aéreas infravermelhas. 
Afinal, quanto maior o tamanho da copa e a resposta nessa faixa do espectro eletromagnético, mais vigorosas serão as árvores e maior o potencial produtivo.

De acordo com Martins (2000), a inclusão da produção do ano anterior na estimativa da safra do ano seguinte é uma medida interessante na parametrização de modelos de previsão de safra, apesar da alternância bienal de produção em laranjeiras, segundo a autora, não ser um fenômeno muito marcante.

Ainda Mataa \& Tominaga (1998), ao estudar as inter-relações entre o desenvolvimento vegetativo e o reprodutivo em árvores jovens de tangerina Ponkan, durante seus dois primeiros ciclos produtivos, separando árvores maiores e menores e com diferentes capacidades produtivas, constataram que as árvores com maior capacidade produtiva no primeiro ciclo mantiveram essa maior capacidade no segundo ciclo, às custas de um menor desenvolvimento vegetativo. No entanto, apresentaram um menor aumento relativo de produção de um ciclo para o outro. Também, as árvores com maior desenvolvimento vegetativo mantiveram esse comportamento no ciclo seguinte.

No que concerne à produção, ainda foram realizadas pesquisas baseadas em outros índices biométricos. Assim, Parker \& Batchelor (1932), ao estudarem o comportamento produtivo das árvores de um pomar de laranja Baía com vistas ao planejamento de ensaios de adubação, já haviam verificado a tendência das árvores maiores produzirem mais. Assim como Tachibana \& Nakai (1989) e Mataa \& Tominaga (1998) verificaram que o índice de área foliar (IAF) em pomar de tangerina Wase Satsuma, no primeiro trabalho, e volume de copa, no segundo trabalho, foram determinantes para a maior ou menor produção das árvores. Parker \& Batchelor (1932), ainda, verificaram que a correlação entre o volume de copa e a produção foi maior que entre a área de seção transversal do tronco e a produção. Ademais, constataram correlações mais ou menos constantes no tempo entre aquelas variáveis e a produção, 
com exceção de um ano. Os autores concluíram que o tamanho da árvore seria um bom parâmetro para avaliar, no futuro, o efeito das diferentes doses de fertilizantes.

Também Brar \& Mann (1986) concluíram que o sucesso da experimentação com árvores de tangerina Kinnow depende, principalmente, da uniformidade das plantas quanto ao volume de copa. Já, Menon \& Tyagi (1971) verificaram que a altura e as extensões Norte-Sul e Leste-Oeste da árvore melhoraram a precisão de experimentos com árvores de tangerina (Citrus reticulata Blanco), por meio de uma análise de covariância, graças à correlação entre aquelas variáveis e a produção.

Ainda Brar et al. (1988) e Brar et al. (1990) constataram que a estimativa de produção de parcelas com 10 árvores de tangerina Kinnow baseada na probabilidade de seleção de árvores individuais proporcional à circunferência do tronco, tamanho da copa e altura das árvores apresentaram ganhos em eficiência 3,45 vezes, 1,44 vezes e 1,21 vezes superiores à probabilidade de seleção igual às 10 árvores. Shamasundaran et al. (1983) e Shamasundaram (1984) encontraram estreita relação entre as variáveis extensão Leste-Oeste da copa, raio de copa, índice de peso da copa (index of crown weight) e número de galhos por árvore de tangerina Coorg (Citrus reticulata Blanco) e a produção. No entanto, várias características morfológicas, entre elas, volume, altura, área de superfície de copa, circunferência do tronco e circunferência dos galhos não apresentaram relação significativa com a produção. Também Albrigo et al. (1975), ao avaliarem a aplicabilidade das medidas de superfície e volume de copa em árvores de laranja Valência para estimativa de produção em nível de talhão ou pomar individual ou parcela experimental, não encontraram relações significativas entre aquelas medidas e a produção em árvores individuais. Por outro lado, Ono et al. (1987), também ao avaliar o efeito de características morfológicas das plantas sobre a produção, concluíram que o volume de copa, IAF e a porcentagem do espaço do pomar utilizado pela árvore tiveram relação com a produção. 
Ainda com relação às pesquisas baseadas em outros índices biométricos, Dhillon et al. (1962) verificaram que as plantas mais vigorosas de lima doce (Citrus limettioides Tanaka) apresentaram uma proporção maior de inflorescências com folhas, que, segundo Amami (1974), estão relacionadas à produção. Ademais, conforme Dhillon et al. (1962), as inflorescências com folhas fixaram melhor os frutos quando comparadas com as sem folhas, particularmente, nas árvores mais vigorosas.

\subsection{Estudos de análise espacial e temporal da produção}

Para Blackmore (2003), estudos de análise espacial e temporal da produção têm sido desenvolvidos com o propósito de extrair dos conjuntos de dados suas características mais significativas e apresentá-los de tal forma que o produtor possa melhorar o processo de tomada de decisão dentro do gerenciamento. $\mathrm{O}$ autor ressaltou que esses estudos, apresentados na forma de mapas de produtividade, visam identificar no terreno zonas onde as plantas produzem semelhantemente ao longo dos anos. Segundo Blackmore (2003), os mapas de produtividade permitiriam ao gerente agrícola investigar ou mesmo manejar essas zonas de forma diferenciada.

No entanto, Lark \& Stafford (1997) argumentaram que, para serem úteis, os mapas de produtividade precisam satisfazer a duas condições: aquelas zonas de produtividade precisam estar associadas a características intrínsecas do terreno, por exemplo, textura do solo; e essas características precisam ser identificáveis, isto é, que as causas da variação ou mesmo os fatores determinantes da produção possam ser estabelecidos. Afinal, conforme os autores, um mapa de produtividade representa algo que já passou, ou seja, apresenta um caráter retrospectivo dos efeitos acumulados de muitos fatores variáveis no espaço.

De acordo com Blackmore (2003), os mapas de produtividade, por representarem uma situação passada, não poderiam ser utilizados para prever os padrões 
espaciais de produção no futuro. Em sua pesquisa, Blackmore (2003) constatou que a variabilidade espacial num ciclo de produção anulou a dos ciclos seguintes durante seis ciclos sucessivos de produção com culturas anuais.

Lark \& Stafford (1997) também encontraram coeficientes de correlação baixos entre três ciclos de produção sucessivos com culturas anuais. No entanto, segundo os autores, tal fato não implica necessariamente em baixa variação intrínseca da produtividade. Afinal, a manifestação dos diferentes efeitos limitantes à produção depende de fatores como o clima, a cultura e/ou variedade e práticas culturais, os quais podem mudar de um ciclo para outro. Lark \& Stafford (1997) citaram como exemplo a capacidade de armazenamento de água no solo, como uma característica intrínseca do solo, cuja importância para a produtividade depende do clima. Para os autores, portanto, é muito pouco provável que as causas da variação intrínseca da produtividade possam ser determinadas simplesmente pela identificação daquelas zonas que sempre produziram bem, mal ou na média, conclusão a que chegou Blackmore (2003), após a análise de seis ciclos sucessivos de dados de produção.

Aliás, Blackmore (2003), ao analisar seus dados, identificou três tipos de variabilidade da produção: variabilidade espacial, temporal e de previsão. A primeira, o autor determinou calculando a média de produção dos seis ciclos para cada ponto do terreno. A segunda, separada em dois tipos de variabilidade temporal, uma geral, pela diferença de produção entre um ano e outro para todos os pontos do terreno e uma particular, por meio da variância dos seis ciclos em relação à média de cada ciclo para cada ponto do terreno. E a terceira, pelo coeficiente de correlação entre a produção esperada e a real.

Como um método alternativo de análise espacial e temporal da produção, Lark \& Stafford (1997) propuseram agrupar aquelas zonas do terreno que apresentassem o mesmo comportamento produtivo em três ciclos sucessivos, lançando mão da lógica 
difusa, nebulosa ou imprecisa, ou simplesmente, lógica fuzzy. A grande diferença desse método para o de Blackmore (2003) é a de classificar os dados conforme o comportamento produtivo em cada ciclo e não de acordo com a média de produção em todos os ciclos. Para o próprio Blackmore (2003), o método de classificar as zonas de produtividade pela média possui a tendência de minimizar, com o passar do tempo, as diferenças de produção entre as zonas do terreno.

Blackmore (2003) procurou melhorar sua análise calculando a variância temporal em relação à média geral para cada ponto do terreno, com o intuito de dar uma idéia do grau de estabilidade temporal da produção. Após cruzar essa informação com aquela obtida pela simples média de produção dos seis ciclos produtivos, gerou um mapa com quatro zonas: duas altamente produtivas, uma estável e outra instável e duas com baixa produção, uma estável e outra instável.

Lark \& Stafford (1997), além de dividirem a área de estudo em classes de comportamento produtivo, procuraram verificar se essas classes, formadas pela análise de agrupamentos via lógica fuzzy, coincidiam com as classes de solo da área de estudo. Afinal, conforme os autores, espera-se que a produtividade numa zona do terreno seja limitada ou mesmo determinada por algum fator ou fatores relacionados. Caso tal prerrogativa seja válida, de acordo com Lark \& Stafford (1997), é provável que zonas do terreno onde fatores semelhantes limitam ou mesmo determinam a produtividade por vários anos respondam também de forma similar ao clima e às práticas culturais em diferentes ciclos.

Os resultados obtidos por Lark \& Stafford (1997) permitiram a esses autores concluir que o método proposto reduziu a considerável complexidade espaço-temporal dos dados de produção em poucos padrões gerais de variação entre ciclos. E que as classes formadas pela análise de agrupamentos via lógica fuzzy apresentaram coerência espacial e tenderam a coincidir com algumas das características intrínsecas das zonas a 
elas correspondentes, tais como o tipo de solo e a capacidade de armazenamento de água do solo.

O método de classificação baseado na análise de agrupamentos via lógica fuzzy consiste basicamente da distribuição contínua dos indivíduos em classes. Ou seja, um indivíduo não pertenceria mais a uma classe apenas, mas pertenceria em maior ou menor grau a várias classes. Por meio da análise de agrupamentos via lógica fuzzy calcula-se o valor de grau de pertinência (membership) de cada indivíduo a cada classe. Para tanto, é necessário pré-fixar o número de classes e o expoente de imprecisão (fuzzy exponent), que segundo McBratney \& Moore (1985) e Triantafilis et al. (2003), determina o grau de imprecisão da análise. Quanto maior esse grau, maior será a participação do indivíduo em cada classe, portanto mais confusa é a classificação. McBratney \& Moore (1985) propuseram um método para avaliar a análise e indicar o número de classes e o expoente de imprecisão mais adequados. Lançando mão da entropia de classificação normalizada, também conhecida como entropia de partição modificada (Modified Partition Entropy, $\mathrm{MPE}$ ), além de outro índice de desempenho, os autores conseguiram indicar o número de classes mais adequado para uma série de dados de clima. Conforme McBratney \& Moore (1985), o número de classes mais adequado corresponde ao menor valor da entropia de partição modificada. Já, o valor mais adequado de expoente de imprecisão corresponde ao valor máximo da curva formada entre o expoente de imprecisão e a derivada da função objetiva em relação ao expoente de imprecisão multiplicada pela raiz do número de classes. De acordo com McBratney \& Moore (1985), a função objetiva nada mais é do que um tipo de soma de quadrados dos resíduos. Outro índice de validação também utilizado para indicar o número de classes mais adequado é a distância de separação (Separate Distance, S). Quanto menor a distância de separação, mais adequado é o número de classes sugerido.

Ainda com relação aos estudos de análise espacial e temporal da produção, Isaaks \& Srivastava (1989) apresentam uma metodologia bastante interessante para 
abordar temas semelhantes. A partir de uma análise exploratória de uma série de dadosexemplo, esses autores vão refinando a análise até, havendo continuidade espacial entre os dados, possibilitar o mapeamento das variáveis. A análise exploratória consta de uma descrição univariada, onde as variáveis são observadas separadamente (uma a uma), e uma bivariada, onde as variáveis são estudadas duas a duas. A seguir, as variáveis são analisadas no espaço (descrição espacial) e mapeadas.

Quanto à forma de representação dos dados, há basicamente, segundo Burrough \& McDonnell (2000), duas formas: como entidades no espaço ou como uma superficie contínua. Como entidades no espaço, os dados são representados, por exemplo, por pontos, linhas ou polígonos. Como uma superfície contínua, eles são representados, por exemplo, por linhas de contorno ou curvas de nível, que evidenciam a variação suave e contínua do fenômeno estudado ao longo do espaço.

Blackmore (2003) afirmou que, embora a representação dos dados de produção como entidades no espaço, ou melhor, na forma de pontos, seja acurada, ela considera os dados independentes entre si no espaço, o que, conforme o autor, não condiz com a realidade, afinal a produtividade, no caso de culturas anuais, é espacialmente dependente. Ademais, a malha de dados é densa e muito variável, o que dificulta sua interpretação.

De acordo com Blackmore (2003), é recomendável, portanto, que se aplique algum tipo de técnica estatística para diminuir essa variabilidade exagerada dos dados de produção. Uma possibilidade é, segundo Burrough (1989), simplesmente classificar os dados conforme, por exemplo, sua freqüência ou seu desvio em relação à média ou mesmo a distância entre si calculada por uma análise de agrupamentos. Para Lark (1998), a classificação é vantajosa no sentido de permitir obter generalizações significativas de conjuntos de dados extensos ao identificar entre eles alguns poucos 
padrões básicos. Outra possibilidade é lançar mão de técnicas que produzam uma superfície contínua, ou seja, técnicas de interpolação.

Segundo Blackmore (2003), interpolação é o processo de estimativa do valor de um ponto no terreno a partir dos valores dos pontos vizinhos. Há várias técnicas de interpolação, mas o método da krigagem e o do inverso da distância são os mais utilizados em mapeamentos da produtividade. Conforme Blackmore (2003), o método da krigagem é uma ferramenta estatística mais poderosa, uma vez que produz estimativas sem tendência e com variância mínima. No entanto, exige o desenvolvimento de um modelo de dependência espacial, o semivariograma. O método do inverso da distância é uma técnica mais simples e define as relações espaciais como uma lei do inverso do quadrado.

O semivariograma, de acordo com Gonçalves (1997), é o gráfico que representa os valores de semivariância entre todos os pares de pontos de um terreno separados pela mesma distância h. Nesse caso, a semivariância é calculada como:

$$
\gamma(\mathrm{h})=\frac{1}{2 \mathrm{~N}(\mathrm{~h})} \sum_{\mathrm{i}=1}^{\mathrm{N}(\mathrm{h})}\left[\mathrm{Z}\left(\mathrm{s}_{\mathrm{i}}\right)-\mathrm{Z}\left(\mathrm{s}_{\mathrm{i}}+\mathrm{h}\right)\right]^{2}
$$

sendo: $\mathrm{N}(\mathrm{h})$ = o número de pares de pontos defasados pela distância $h$;

$\mathrm{Z}\left(\mathrm{s}_{\mathrm{i}}\right)=\mathrm{o}$ valor da variável $\mathrm{Z}$ na posição $\mathrm{s}_{\mathrm{i}}$;

$\mathrm{Z}\left(\mathrm{s}_{\mathrm{i}}+\mathrm{h}\right)=\mathrm{o}$ valor da variável $\mathrm{Z}$ na posição $\mathrm{s}_{\mathrm{i}}+\mathrm{h}$.

O esquema mostrado na Figura 1 expressa o comportamento típico de um semivariograma experimental de uma propriedade que apresenta dependência espacial. Pontos próximos entre si são mais semelhantes que pontos mais afastados, ou seja, à medida que $\mathrm{h}$ cresce, se há dependência espacial, os pontos estarão cada vez mais dispersos, crescendo a semivariância, até um certo limite de valor de h. 


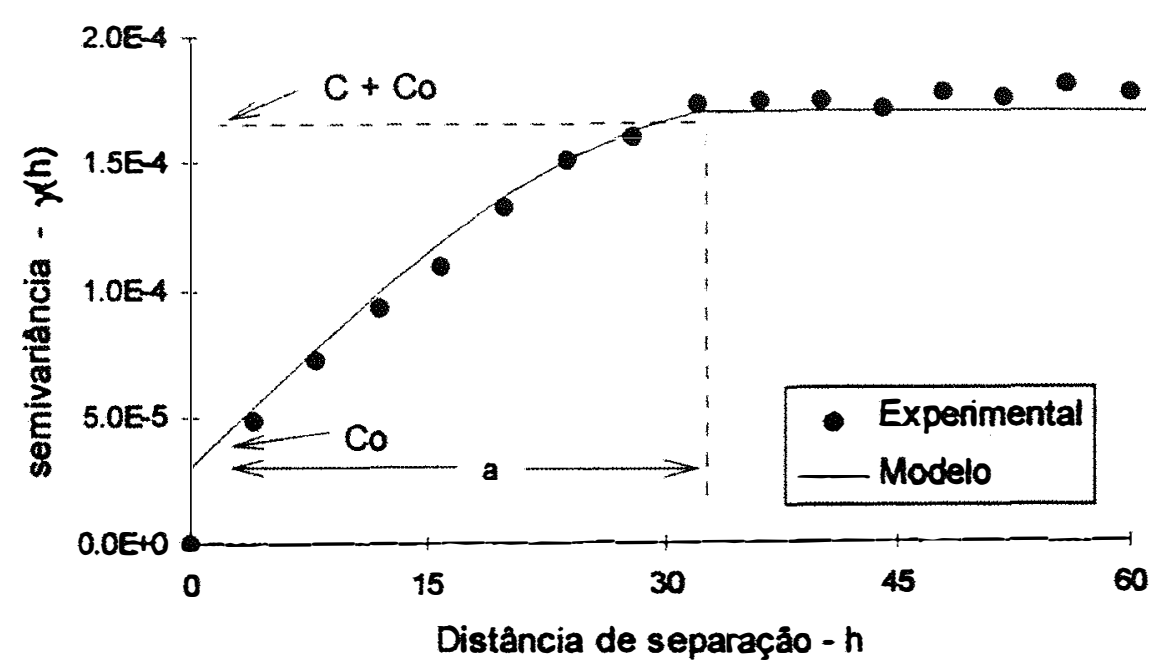

Figura 1 - Semivariograma experimental e modelo matemático ajustado Fonte: Gonçalves (1997)

O semivariograma começa com um baixo valor, denominado efeito pepita $\left(\mathrm{C}_{0}\right)$ e cresce à medida que $\mathrm{h}$ cresce, até uma distância $\mathrm{a}$, denominada alcance, que determina a distância até a qual a propriedade se apresenta espacialmente dependente. A partir dessa distância, os dados podem ser considerados independentes. Para distâncias maiores que o alcance, o semivariograma tende a se estabilizar em torno de um valor denominado patamar $\left(C+C_{0}\right)$, onde $C$ é o componente estrutural. Cabe mencionar que, além do semivariograma experimental e modelo matemático ajustado auxiliarem no processo de interpolação via krigagem, segundo Blackmore (2003), o semivariograma experimental também é utilizado como um instrumento de análise estatística de fenômenos espaciais.

No que concerne especificamente à citricultura, ainda não há estudos de análise espacial e temporal da produção voltados ao mapeamento. No entanto, Batchelor \& Reed (1918) e Parker \& Batchelor (1932) desenvolveram estudos pioneiros, onde procuraram investigar a influência das variabilidades espacial e temporal da produção sobre a acurácia e eficácia de experimentos futuros com árvores de citros. 
Batchelor \& Reed (1918) verificaram coeficientes de variação de 39,55\% e 29,72 \% para as produções de duas variedades de laranja Baía (Arlington e Antelope Heights), 39,72 \% para laranja Valência e 30,06 \% para limão Eureca (Eureka lemon). Para os autores, as causas prováveis dessa variação eram fertilidade do solo e vigor do porta-enxerto, que estariam, possivelmente, além da capacidade de discriminação por parte de um pesquisador cuidadoso, de acordo com os autores.

Já naquela época, Batchelor \& Reed (1918) haviam percebido que a alta variabilidade espacial do solo tendia a tornar árvores próximas no espaço próximas também na capacidade produtiva. Ao passo que, ainda segundo Batchelor \& Reed (1918), a baixa variabilidade temporal, em nível de pomar, não permitia concluir que a produção das árvores de uma mesma região do pomar num determinado ano se correlacionasse com os demais.

Posteriormente, Parker \& Batchelor (1932) observaram o comportamento produtivo das árvores de um pomar de laranja Baía durante seus primeiros sete ciclos de produção (1921 a 1927). O pomar foi plantado em 1917 aleatoriamente com mudas cuidadosamente selecionadas e bem misturadas para assegurar uniformidade. O sistema de irrigação foi disposto numa forma tal a poder irrigar o pomar separadamente, conforme as condições de umidade do solo de cada região. As demais práticas culturais foram executadas da maneira mais uniforme possível para assegurar às plantas as mesmas condições de crescimento e produção.

Parker \& Batchelor (1932) verificaram que a distribuição de freqüências das produções das árvores em todos os anos aproximou-se da distribuição normal, com exceção do primeiro ciclo produtivo (1921), quando nem todas as árvores haviam entrado na fase produtiva. Nesse ano (1921), também, o coeficiente de variação foi bem superior aos demais, 64,35\% contra 25,4\% em média. Em geral, houve a tendência dos coeficientes de variação diminuírem ao longo do tempo, com exceção do ano de 1926, 
quando as condições climáticas foram adversas e prejudicaram mais algumas regiões do que outras.

Ademais, conforme os mesmos autores, houve a tendência de grupos de oito árvores, dispostas em seqüência nas linhas de plantio ao longo do pomar, apresentarem a mesma produção relativa à média da população em todos os anos, com exceção de 1921 . Ou seja, os graus de correlação espacial entre as oito árvores e entre grupos adjacentes e temporal entre os diferentes anos dos mesmos grupos foram consideráveis. Tal constatação permitiu a Parker \& Batchelor (1932) estabelecer um índice de produtividade para cada grupo de oito árvores e, assim, dividir o pomar em parcelas mais e menos produtivas visando ao delineamento experimental para ensaios de adubação.

Com o mesmo objetivo, Clark Powell (1932) selecionou pomares comerciais na África do Sul que apresentassem uniformidade quanto às árvores e aos solos e que possuíssem o registro de produção dos anos anteriores ao início do experimento. De acordo com o autor, foi possível estabelecer o delineamento experimental com cinco parcelas de cinco ou 10 árvores para cada tratamento, dependendo do tamanho do pomar, uma vez que houve uma alta correlação entre um ano e os seguintes na produção de uma mesma árvore, sem tendências de alternância de produção, ou seja, as árvores das parcelas mantiveram sua capacidade relativa de produção constante no período anterior ao início do experimento. $\mathrm{O}$ autor, ainda, constatou que esse comportamento produtivo das árvores foi válido tanto para árvores jovens (até sete anos) como para as mais adultas (até 12 anos).

Segundo Clark Powell (1932), as prováveis causas de variabilidade na produção entre as parcelas em um dos pomares foram: a) variação na textura do solo e nas relações hídricas; b) variações na fertilidade do solo e c) influências do porta-enxerto. 
Por outro lado, pesquisadores indianos verificaram uma alta variabilidade entre árvores de citros, entre elas aquela relacionada à produção. Assim, Shanmugasundaram \& Ramachander (1983) e Shamasundaran \& Ramachander (1983), ao desenvolverem um estudo sobre o tamanho ótimo de amostragem, objetivando a previsão de safra citrícola, acompanharam a produção durante quatro anos e verificaram que, em função da grande variabilidade de produção entre as árvores, o tamanho ótimo também foi bastante variável entre os anos. Recomendaram, portanto, que pelo menos $30 \%$ da população de árvores fosse amostrada para uma estimativa de produção satisfatória. Ao passo que Brar \& Mann (1986) não encontraram correlação entre árvores vizinhas e atribuíram essa variação árvore a árvore à alta variabilidade do solo.

Com relação aos estudos de análise exclusivamente espacial da produção voltados ao mapeamento, Farias et al. (2003) encontraram dependência espacial em pomares adultos de laranja Natal. Foram avaliados dois pomares: um irrigado e outro não. O pomar irrigado apresentou maior variabilidade espacial e maior semivariância entre pares de árvores mais próximas. Ao passo que o pomar não irrigado apresentou maior alcance da dependência espacial. Ainda, conforme os autores, os mapas de produtividade mostraram que outros fatores, como o tipo de solo, fertilidade, pragas, etc, também contribuíram para a maior variabilidade espacial do pomar irrigado. Afinal, se fosse somente o fator irrigação, o mapa apresentar-se-ia mais homogêneo quanto à produtividade.

Whitney et al. (1998), Whitney et al. (1999) e Whitney et al. (2000), objetivando o gerenciamento localizado da produção em pomares citrícolas, elaboraram mapas de produtividade no Estado da Flórida, E.U.A. Os mapas de produtividade apresentaram, em sua maioria, considerável variabilidade. Os autores atribuíram grande parte dessa variação da produtividade à variabilidade do solo e Whitney et al. (2000) concluíram que ainda não existia uma solução óbvia para lidar com essa variabilidade em nível localizado. Whitney et al. (1999) ainda concluíram que esses primeiros mapas 
de produtividade obtidos mostraram que a variação da produtividade tende a estar correlacionada ao tamanho de copa das árvores.

\subsection{Resposta espectral das plantas, parâmetros de copa e produção}

Resposta espectral é, nesse caso, aquela das plantas à energia radiante proveniente do Sol, seja, conforme Vettorazzi (1992), na forma de reflectância da luz solar, como na forma de emitância da radiação termal.

Quando a resposta espectral das plantas atinge um sensor do tipo CCD (Charge Coupled Device), que é constituído por milhares de pequenos sensores, os fótons a ela associados batem na superfície de cada um daqueles pequenos sensores e são convertidos numa carga proporcional à intensidade da radiação. A carga registrada em cada pequeno sensor, então, é transformada num valor numérico digital.

Freqüentemente, esse valor numérico digital é conhecido como número digital, valor de intensidade de brilho, contagem digital, ou ainda nível de cinza, e recebe essas designações para deixar claro que ele não é um registro da intensidade de radiação real (radiância) das diferentes cenas. Ao discorrer sobre a necessidade de correção radiométrica das cenas, que nada mais é do que a transformação dos valores de nível de cinza em valores de radiância, Campbell (1996) indica que a utilização do nível de cinza é suficiente para se comparar visualmente duas ou mais diferentes cenas ou mesmo para se examinar intensidades relativas de brilho entre alvos numa mesma cena ou em cenas diferentes.

Segundo Campbell (1996), as imagens digitais apresentam um arranjo de números digitais que podem ser adicionados, subtraídos, multiplicados, divididos e, em geral, sujeitos às manipulações estatísticas que não seriam possíveis caso uma imagem fosse apresentada somente como uma fotografia convencional, no formato analógico. 
Assim, a representação digital aumenta consideravelmente a habilidade para examinar, analisar e apresentar dados obtidos por sensores remotos.

Com o advento da videografia aérea, que pode ser definida como o conjunto de técnicas utilizadas para o registro de imagens aéreas capturadas por câmaras de vídeo, o registro digital da resposta espectral das plantas na forma de imageamento tornou-se uma atividade menos complexa, principalmente em função dos dados já estarem no formato digital (Vettorazzi et al., 2000). Além do mais, o equipamento é portátil, versátil e simples de operar. Apresenta ainda como vantagens: um custo operacional menor que os de sistemas fotográficos convencionais; uma elevada velocidade de captura dos quadros; sua pronta compatibilidade com sistemas como o GPS (Global Positioning System Sistema de Posicionamento Global); sistemas de informações geográficas e sistemas de processamento digital das imagens. Além disso, permite observar em um monitor a imagem em tempo real, simultaneamente à aquisição. Dowman (1996) acrescenta que uma grande diferença entre os novos sistemas de aquisição e manipulação das imagens e os sistemas fotográficos convencionais reside na independência dos novos sistemas de qualquer tipo de equipamento óptico-mecânico para visualização e análise das imagens. Campbell (1996) considera os novos sistemas mais confiáveis, pois ao responderem linearmente à intensidade de brilho, produzem imagens que têm uma relação mais consistente com a intensidade de brilho da cena, ao contrário dos sistemas fotográficos convencionais.

Uma vez registrada, a resposta espectral das plantas pode nos dar uma idéia sobre vários aspectos de culturas agrícolas e florestais, entre eles, aqueles associados à quantidade de folhas e produção. Afinal, as plantas respondem à radiação eletromagnética conforme sua configuração bioquímica e estrutural.

Em citricultura, conforme Covre (1989), a resposta espectral das plantas é o resultado de uma combinação de características de alvos agrícolas, entre elas a 
disposição das plantas em fileiras, e florestais como o porte arbóreo. Além disso, segundo Formaggio (1989), dos vários componentes das plantas responsáveis por sua resposta espectral, as folhas são os elementos refletores dominantes.

Para Myers (1983), a resposta espectral das plantas nas faixas do vermelho e do infravermelho próximo do espectro eletromagnético é a mais indicada para a estimativa de biomassa foliar verde e outros parâmetros biofísicos relacionados.

Myers (1983) explica que, na faixa do vermelho $(630 \mathrm{~nm}$ a $700 \mathrm{~nm})$, as folhas das plantas absorvem a maior parte da radiação incidente, graças à presença de pigmentos, especialmente clorofila. Já na faixa do infravermelho próximo (750 nm a $1000 \mathrm{~nm}$ ), a reflectância e a transmitância predominam, graças à estrutura interna das folhas. Segundo Myers (1983), nessas faixas, o contraste entre a vegetação e o solo imediatamente abaixo é maior, permitindo uma melhor discriminação da vegetação verde. Afinal, quando uma planta é imageada, a resposta espectral do solo também é capturada pelo sensor, cuja intensidade e tipo, conforme Guyot (1990), dependem do volume de folhas das plantas e das características químicas, físicas e biológicas do solo. Em geral, conforme Formaggio (1989), a resposta espectral das plantas tende a diminuir nas faixas do vermelho e do infravermelho próximo graças à contribuição do solo.

Ainda com relação à resposta espectral das plantas nas faixas do vermelho e do infravermelho próximo, Guyot (1990) afirmou que, na faixa do vermelho, por serem baixos, os níveis de reflectância logo atingem níveis de saturação ao se sobreporem várias camadas de folhas. Na faixa do infravermelho próximo, ao contrário, conforme Formaggio (1989), os níveis de reflectância aumentam ao se sobreporem várias camadas de folhas até se atingir um valor estável máximo.

A Figura 2 ilustra tal fenômeno. Nela, estão representadas as variações de reflectância nas faixas do vermelho e do infravermelho próximo em função do IAF. Ao 
se observar a Figura 2, é possível notar que, na faixa do vermelho, o nível de saturação é alcançado em IAF ao redor de 3, ao passo que, na faixa do infravermelho próximo, ao redor de 5 ou 6 . Entretanto, segundo Guyot (1990), valores mais altos de IAF podem ser atingidos caso as folhas apresentem uma configuração geométrica mais ereta.

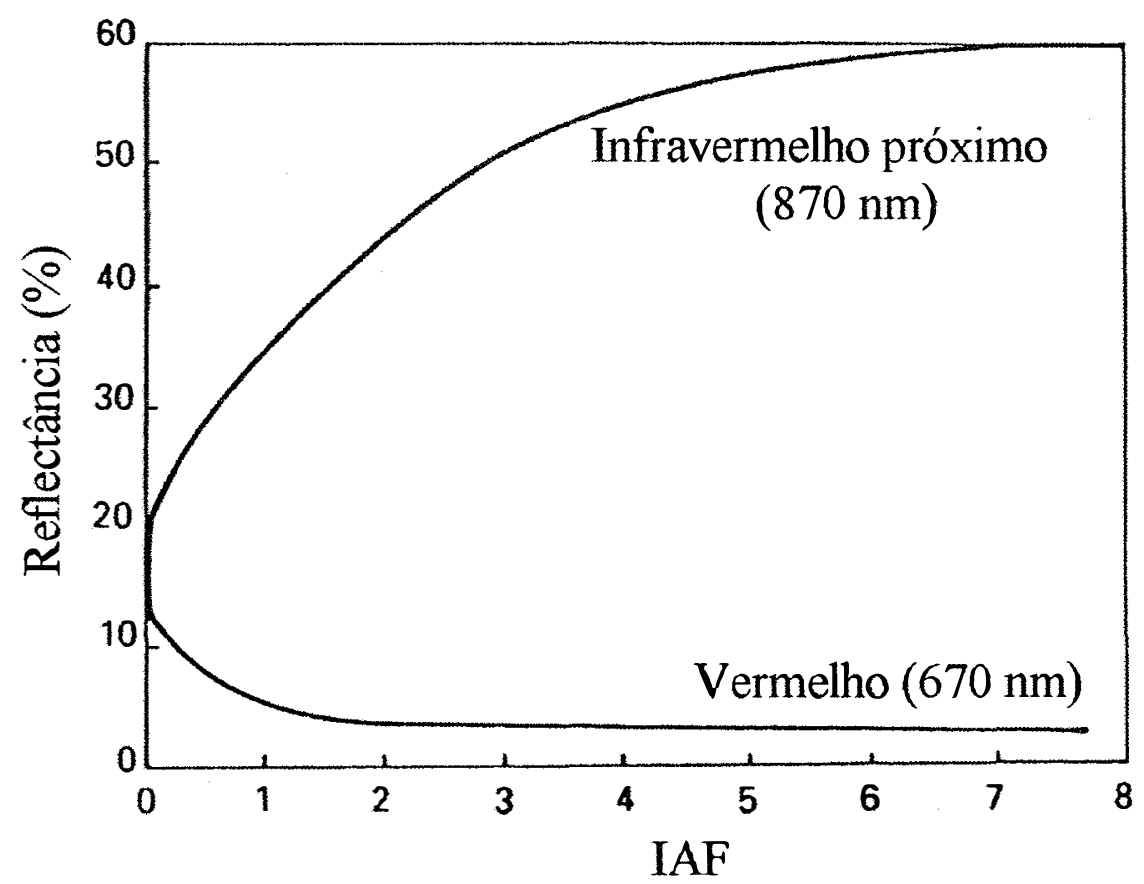

Figura 2 - Variação da reflectância de um dossel vegetativo em função do IAF Fonte: Adaptado Guyot (1990)

Por sinal, conforme Guyot (1990), um dos fatores mais importantes à resposta espectral das plantas é a estrutura geométrica ou, simplesmente, a arquitetura das plantas. Afinal, segundo Peterson \& Running (1989), a orientação geométrica das folhas, por exemplo, de árvores, pode assumir todas as distribuições possíveis. A despeito das folhas de árvores estarem geralmente dispostas em feixes e camadas, sua distribuição variável pode alterar sua resposta espectral e dificultar a estimativa de parâmetros biofísicos. 
De acordo com Guyot (1990), a resposta espectral das plantas nas faixas do vermelho e do infravermelho próximo pode variar também em função de deficiências nutricionais e do ataque de pragas e doenças. Com relação às deficiências nutricionais, a clorose (deficiência de ferro) interfere principalmente na faixa do vermelho, enquanto que a deficiência de nitrogênio aumenta a reflectância na faixa do vermelho e diminui na do infravermelho próximo. No que concerne ao ataque de pragas e doenças, seu impacto dependerá do tipo de dano causado às plantas, podendo aumentar ou diminuir a reflectância nas faixas do vermelho e do infravermelho próximo.

Quanto ao conteúdo de água, Guyot (1990) informa que, em condições naturais, as plantas precisam sofrer um estresse hídrico extremamente severo para alterar sua resposta nas faixas do vermelho e do infravermelho próximo.

Ainda conforme Guyot (1990), a resposta espectral das plantas sofre influência de outros componentes das plantas que não as folhas. No caso de árvores, a casca do tronco e dos galhos aumenta a reflectância na faixa do vermelho e diminui na do infravermelho próximo. Segundo Formaggio (1989), também as sombras provocadas principalmente pelas folhas exercem influência sobre a resposta espectral das plantas, quando essas são pensadas em termos de dossel. As sombras, cuja quantidade depende do ângulo solar e da distribuição e orientações das folhas, geralmente, diminuem a reflectância, tanto na faixa do vermelho, como na do infravermelho próximo.

Com o propósito de minimizar a contribuição desses outros elementos que não folhas, dentre os principais estão, de acordo com Huete (1989), o solo, a irradiância solar, o ângulo solar, a vegetação senescente e a atmosfera, foram desenvolvidos índices de vegetação, que, conforme Formaggio (1989), são a razão, diferenciação ou outro tipo de combinação ou transformação de dados espectrais para produzir um único valor. 
Geralmente, segundo Huete (1989), são utilizados os dados espectrais das faixas do vermelho e do infravermelho próximo, graças à relação inversa entre a reflectância da vegetação nessas duas faixas, ou seja, baixa reflectância na faixa do vermelho e alta na do infravermelho próximo.

Para Campbell (1996), os índices de vegetação são especialmente efetivos, pois resumem concisamente num único valor o contraste entre as reflectâncias naquelas duas faixas. Afinal, quanto maior o contraste, maior o índice e mais vegetação sadia está presente.

A forma mais simples de índice de vegetação é uma razão simples entre os valores digitais das faixas do vermelho e do infravermelho próximo, isto é, IV/V. No entanto, de acordo com Campbell (1996), o Índice de Vegetação da Diferença Normalizada, IV-V/IV+V, ou mais conhecido como NDVI (Normalized Difference Vegetation Index), que, a princípio, suporta o mesmo tipo de informação que a razão simples IV/V, tem apresentado melhores resultados do ponto de vista estatístico.

De acordo com Xavier (2002), em áreas onde há considerável variação de brilho devida a diferenças de umidade, variações de rugosidade, sombra ou diferentes teores de matéria orgânica no solo, podem ocorrer mudanças no NDVI. Com o intuito de minimizar a influência desses fatores, Huete (1988), citado por Xavier (2002), propôs uma modificação do NDVI, o Soil Adjusted Vegetation Index (SAVI), ou seja, Índice de Vegetação Ajustado para Influência do Solo, $(1+\mathrm{L}) *(\mathrm{IV}-\mathrm{V}) /(\mathrm{IV}+\mathrm{V}+\mathrm{L})$, sendo L o fator de ajuste para influência do solo. Segundo Xavier (2002), L é uma constante que varia com a quantidade de vegetação, todavia, $\mathrm{L}=0,5$ seria um valor ótimo para um grande intervalo de condições da vegetação. 
Ainda, de acordo com Xavier (2002), os índices de vegetação são utilizados para avaliar variações temporais e espaciais de dados biofĩsicos, como o IAF, de maneira rápida e com nível aceitável de exatidão.

Xavier (2002) também informa que o comportamento geral dos índices de vegetação com o IAF é de saturar para maiores valores de IAF. Por exemplo, a saturação dos índices de vegetação em culturas agrícolas e florestais ocorreria, aproximadamente, em IAF de 2,50 e de 5,00, respectivamente. Além disso, os índices de vegetação, conforme Xavier (2002), são afetados, além do IAF, por outros fatores, entre eles, a estrutura do dossel como um todo; geometria sol-sensor-alvo; substrato e atmosfera.

Em seu estudo, Xavier (2002) procurou avaliar as relações entre IAF de várias coberturas vegetais e índices de vegetação, além das relações entre IAF e a reflectância de superfície das faixas do vermelho e do infravermelho próximo calculada a partir de imagens do satélite Landsat-7, que possui resolução espacial de $30 \mathrm{~m}$. As coberturas vegetais estudadas foram cana-de-acúcar, milho, pastagem, eucalipto e floresta ripária. $\mathrm{O}$ autor não encontrou relação significativa entre IAF de todas as coberturas juntas e a reflectância de superfície da faixa do infravermelho próximo, mas encontrou $\mathrm{r}^{2}$ de 0,64 , $0,70,0,72$ e 0,56 para a relação entre IAF e a reflectância de superfície da faixa do vermelho, razão simples, NDVI e SAVI, respectivamente. Ainda, vale comentar que a função matemática que melhor expressou a relação entre IAF e resposta espectral foi a potencial.

Colombo et al. (2003) também avaliaram a relação entre IAF e índices de vegetação calculados a partir de imagens do satélite Ikonos, que possui resolução espacial de $1 \mathrm{~m}$. As coberturas vegetais estudadas foram milho, soja, uva, um tipo de árvore utilizada como madeira e floresta. Colombo et al. (2003) não encontraram relação significativa entre IAF de todas as coberturas juntas e os índices de vegetação. Entretanto, ao separarem as análises de regressão por tipo de cobertura, encontraram 
relação significativa entre índices de vegetação e IAF de cada cobertura com exceção da floresta. Colombo et al. (2003) atribuíram as baixas relações entre IAF de floresta e índices de vegetação à alta heterogeneidade interna da floresta.

Conforme Wickland (1989), os índices de vegetação são indicadores do vigor e crescimento relativo da vegetação verde. Segundo a autora, índices espectrais ou variáveis estimadas a partir de dados espectrais (por exemplo, IAF) associados a dados meteorológicos e de solos têm sido utilizados para o levantamento do crescimento e produtividade de culturas.

De acordo com Ippoliti-Ramilo et al. (1999), as correlações significativas entre a resposta espectral das culturas e os parâmetros relacionados ao rendimento das mesmas têm estimulado o uso dos dados espectrais em modelos de rendimento. Dentre os trabalhos realizados no Brasil, Ippoliti-Ramilo et al. (1999) citaram aqueles com canade-açúcar, trigo e soja. Cabe destacar que, nos três estudos, foi utilizada a relação entre a resposta espectral das plantas nas faixas do vermelho e do infravermelho próximo para estimar a produção.

Com relação à cultura do citros, o potencial produtivo foi determinado, na maior parte dos estudos, em função das condições das plantas por meio de sua resposta espectral na banda do infravermelho. Em geral, foram dadas notas às árvores quanto as suas condições num processo visual. Assim, Blazquez et al. (1984) procederam para estimar a produção e a renda bruta de pomares-amostra na Flórida, E.U.A. Após dividirem as árvores em subcategorias de potencial produtivo, em função da área de projeção das árvores e do grau de vigor e em função de árvores produtivas normais, os autores estimaram a produção de cada subcategoria com base numa série histórica de produção. 
Já, Whitney et al. (1999) e Whitney et al. (2000), ao relacionarem por meio de análise de regressão a produtividade de um pomar citrícola em ton.ha ${ }^{-1}$ com a porcentagem de cobertura do solo pelas árvores estimada a partir de fotografias aéreas, demonstraram que o tamanho de copa das árvores estava relacionado à produtividade ( $\mathrm{r}$ $=0,45$; valor de $\mathrm{p}=0,0001)$. Whitney et al. (1998) já haviam constatado que havia correlação entre a produtividade e a largura ou tamanho de copa.

Blazquez et al. (1978) e Blazquez et al. (1979) já haviam constatado a superioridade do método de levantar as condições gerais das árvores com auxílio de fotografias aéreas infravermelhas. Posteriormente, Edwards \& Blazquez (1985) desenvolveram um método para classificar as árvores quanto ao grau de estresse - ou também potencial produtivo - utilizando um densitômetro para medir a densidade de filmes infravermelhos. O densitômetro separa a resposta espectral das árvores em diferentes bandas e apresenta os resultados em forma digital. Essa informação digital auxilia o processo de fotointerpretação e classificação das árvores.

Mais tarde, Blazquez (1988b) lançaram mão dos recursos computacionais para aprimorarem o método de avaliação de pomares cítricos. Naquele momento, a deteç̧ão de mudanças nos pomares era facilitada pela visualização simultânea de dois monitores.

Em Blazquez (1988a) e Blazquez (1989), comparações entre graduação visual e densitométrica de árvores quanto ao nível de estresse foram feitas. Os resultados sugeriram que as medidas densitométricas foram semelhantes ou melhores que a graduação visual e, portanto, poderiam ser utilizadas num sistema automático para contar e separar árvores estressadas das não estressadas.

Também em Blazquez (1991), comparações foram feitas entre a graduação visual arbitrária de árvores e a utilização de curvas espectrais geradas por um densitômetro de varredura. As curvas espectrais obtidas de árvores não estressadas e 
estressadas apresentaram um pico entre $500 \mathrm{~nm}$ e $520 \mathrm{~nm}$ e outro entre $600 \mathrm{~nm}$ e 620 $\mathrm{nm}$. As razões entre esses picos na forma integral (corresponde à área medida sob a área da curva) e de transmitância separaram os graus visuais em apenas 3 grupos, tornando as medidas densitométricas mais realistas.

Já em Blazquez (1993), foram feitas comparações entre duas séries de fotografias do mesmo pomar, utilizando-se um densitômetro de varredura e interpretação visual. A despeito das variações no balanço e saturação de cor entre as duas séries de fotografias, a utilização do densitômetro de varredura mostrou-se uma boa técnica para classificar árvores quanto ao nível de estresse em diferentes épocas.

Conforme Blazquez et al. (1998), a utilização seqüencial de fotografias ou imagens aéreas na faixa do visível ou do infravermelho próximo permitiria rapidamente identificar quaisquer mudanças ocorridas no pomar. Conseqüentemente, refinaria o processo de estimativa de produção e auxiliaria grandemente o gerenciamento e as tomadas de decisão.

Craig et al. (2000) também avaliaram o nível de estresse de árvores citrícolas por meio da utilização de fotografias aéreas nas faixas do vermelho e do infravermelho próximo. Elegeram os parâmetros volume e altura de copa para sua avaliação. Afinal, segundo os autores, o tamanho da árvore pode ser um indicador de nível de estresse. A partir dos dados de resposta espectral extraídos das fotografias, calcularam o NDVI e verificaram o grau de relação entre NDVI e parâmetros de copa por meio de análises de regressão. Encontraram relação significativa entre NDVI e volume, embora a relação não tenha sido uma simples relação linear $\left(r^{2}=0,339\right)$. Já, a relação entre NDVI e altura apresentou um coeficiente de determinação $\left(r^{2}\right)$ de 0,487 , ou seja, quase metade da variação na altura foi explicada pela variação no NDVI. 
De acordo com Craig et al. (2000), o volume de copa é normalmente considerado melhor indicador do potencial produtivo das árvores citrícolas do que altura. No entanto, em seu estudo, um único pixel de $0,9 \mathrm{~m}$ foi utilizado para representar cada árvore. Segundo os autores, um único pixel quadrado de $0,9 \mathrm{~m}$ não captura realmente a informação necessária para estimar a largura da copa, afinal, além de $0,81 \mathrm{~m}^{2}$, a estimativa não é possível. Sugerem, então, a utilização de imagens com maior resolução espacial para possibilitar uma estimativa mais efetiva da largura de copa. Conforme Craig et al. (2000), a largura de copa poderia ser estimada utilizando um algoritmo que identificasse a extensão horizontal da copa a partir de um ponto no centro dela. A largura da copa combinada com a altura daria a estimativa do volume. Afinal, segundo Craig et al. (2000), a área de projeção da copa por si só não é uma boa indicadora do volume.

Outra proposta metodológica que recorre à utilização de fotografias aéreas nas faixas do vermelho e do infravermelho próximo para estimar a produção em pomares citrícolas foi elaborada por Weepener et al. (2000), na África do Sul. A proposta parte da hipótese de que o comportamento espectral das plantas pode ser utilizado para esse propósito. Imagens aéreas multiespectrais de alta resolução espacial (de $0,75 \mathrm{~m}$ a $1 \mathrm{~m}$ ), capturadas a uma altura média de 2.000 m por uma câmara de vídeo digital montada numa aeronave, seriam processadas originando duas máscaras: uma contendo somente as árvores e a outra, o solo. Cada uma das imagens seria separada em três classes de resposta espectral e, posteriormente, recombinadas, formando nove classes. O mapa final, então, seria usado para selecionar as árvores, dentro de cada classe, que seriam amostradas e a produção extrapolada para o restante das árvores de cada classe.

Segundo Weepener et al. (2000), o imageamento multiespectral de alta resolução voltado à estimativa (e previsão) de produção em pomares de citros pode ser uma boa alternativa aos métodos operacionais ainda em desenvolvimento. Afinal, a disponibilidade de imagens pode auxiliar a levantar as condições fisiológicas gerais dos pomares e a extrapolar as estimativas de produção a partir de amostras. Do ponto de 
vista prático, o imageamento é utilizado para identificar áreas homogêneas quanto às condições fisiológicas, de onde serão selecionadas as árvores a serem amostradas em campo quanto ao potencial de produção e seus respectivos valores extrapolados às outras árvores com características semelhantes.

A proposta de Weepener et al. (2000) leva em conta que a resposta espectral pode explicar melhor a produção, caso seja utilizado um índice de vegetação que relacione as faixas do vermelho e do infravermelho próximo. Eles sugeriram uma modificação do NDVI. 


\section{MATERIAL E MÉTODOS}

\section{1 Área de estudo}

A área de estudo foi selecionada em função: de seu tamanho (com número de pés de laranja que fosse simultaneamente representativo e adequado ao tipo de levantamento adotado); que desse indicativo de haver variabilidade espacial; que as árvores fossem precoces (para evitar a interferência de sobreposição de frutos de safras diferentes e a permanência dos frutos por longo tempo no pé); não apresentassem forte alternância de produção e suas copas ainda fossem individualizadas, para permitir a fácil discriminação e medição em fotografias aéreas. Os dados de produção foram levantados em um pomar comercial de laranja doce (Citrus sinensis L. Osbeck) da variedade

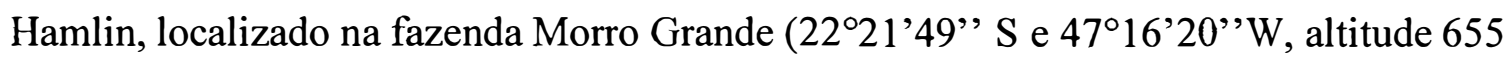
$\mathrm{m}$ aproximadamente), município de Araras, Estado de São Paulo. As árvores enxertadas sobre citrumelo Swingle (Citrus paradisi $\mathrm{x}$ Poncirus trifoliata) foram plantadas em julho de 1996, com espaçamento $8,5 \mathrm{~m}$ x 4,5 m, totalizando 1471 árvores, distribuídas em 35 linhas. Suas linhas estavam orientadas na direção N-S. O solo foi classificado por Oliveira et al. (1982) e pela Empresa Brasileira de Pesquisa Agropecuária (1999) como Latossolo Vermelho Distrófico Típico e o clima, segundo o sistema de Köppen, foi classificado por Oliveira et al. (1982) como tipo CWa, ou seja, clima mesotérmico de inverno seco. Tratando-se de um pomar comercial, ele foi bem conduzido, apesar de não ter sido irrigado. Recebia três aplicações de fertilizantes ao ano, coincidindo com as épocas de maior crescimento vegetativo da cultura e era submetido a rígido monitoramento e controle de pragas e doenças. O pomar era gramado nas entrelinhas, sendo que nas linhas de plantio efetuava-se o controle das plantas daninhas. Em sua 
borda, na face $\mathrm{N}$, existia um quebra-vento formado por grevilhas que sombreavam as árvores mais próximas. Além disso, o terreno apresentava leve declividade na direção $\mathrm{S}$, onde no seu limite se localizava uma baixada úmida.

\subsection{Balanço hídrico e armazenamento de água no solo}

O balanço hídrico e o armazenamento de água no solo (ARM) foram calculados a partir de dados coletados em local próximo à área de estudo por meio da utilização do programa Bhnorm, elaborado em planilha eletrônica por Rolim et al. (1998). Como capacidade de água disponível (CAD) utilizou-se o valor de $100 \mathrm{~mm}$.

\subsection{Levantamento dos dados de produção}

Para facilitar o levantamento dos dados, inicialmente, as árvores foram identificadas alternadamente (uma sim, uma não) por meio de etiquetas metálicas, informando o número da árvore e da linha. Acompanhou-se a colheita manual, quando os sacos-caixa (aproximadamente $27,5 \mathrm{~kg}$ de frutos) eram colocados na entrelinha. Excepcionalmente nas duas colheitas monitoradas no presente estudo, em junho de 2001 e junho de 2002, esses sacos foram posicionados na lateral de cada uma das árvores para que fossem contabilizados.

\subsection{Georeferrenciamento das árvores}

Foram demarcados 10 pontos de controle, distribuídos ao longo do terreno, dos quais foram determinadas as coordenadas geográficas por meio da utilização de um receptor GPS da marca Trimble (sub-métrico). Em cada ponto, cuja localização normalmente foi escolhida entre as linhas de plantio, o receptor coletou dados por 5 minutos. Foi tomado o cuidado de erguer-se a antena de recepção para evitar uma maior interferência das copas das árvores que apresentavam, na época, uma altura média aproximada de 2 metros. Posteriormente, os dados armazenados no aparelho foram 
transferidos para um programa de computador, onde foram corrigidos de acordo com os dados de uma estação base localizada no campus da Escola Superior de Agricultura "Luiz de Queiroz", da Universidade de São Paulo, em Piracicaba.

Após a transformação de suas coordenadas para o sistema de projeção UTM, esses pontos foram demarcados com placas brancas e pretas. A seguir, foram capturadas imagens aéreas do pomar por meio de uma câmara de vídeo multiespectral digital de alta resolução. Essas imagens aéreas foram corrigidas geometricamente por meio da utilização dos pontos de controle, no software Idrisi v.32.11 (Clark University, 2000); conseqüentemente, foi possível determinar as coordenadas de todas as árvores. Ainda, por meio da utilização do Idrisi foi digitalizado um ponto sobre cada uma das árvores, nas imagens, estabelecendo um arquivo de pontos com as coordenadas das árvores. Posteriormente, esse arquivo foi transformado em um arquivo compatível com o programa computacional Surfer v. 6.01 (Golden Software Inc., 1995).

Cabe informar que, ao se criar o arquivo de pontos das árvores georeferrenciadas, também os dados de produção foram inseridos no arquivo. No ano de 2002, os dados de produção não foram inseridos da mesma forma. Uma vez que já se conheciam as coordenadas das árvores, simplesmente o arquivo de 2002 foi alimentado com os dados de produção dentro do próprio Surfer.

\subsection{Captura e transformação das imagens aéreas}

Com o intuito de se estudar as relações entre a resposta espectral, os parâmetros biofísicos das árvores e a produção, imagens aéreas do pomar foram capturadas por meio da utilização de uma câmara de vídeo digital, cujas vantagens foram ressaltadas por Dowman (1996), Campbell (1996) e Vettorazzi et al. (2000). A câmara utilizada foi do tipo 3 CCD RGB/CIR de alta resolução (1392 x 1040 pixels). Ou seja, uma câmara que operava com 3 sensores do tipo CCD e 4 filtros passa-banda. Tratava-se de uma câmara da empresa Duncan Technologies, Inc. (1999a), modelo MS 
3100, com lente de $17 \mathrm{~mm}$. Os sensores apresentavam sensibilidade espectral entre 400 $\mathrm{nm}$ a $1000 \mathrm{~nm}$ e os filtros operavam nas seguintes faixas: azul, centro da faixa $460 \mathrm{~nm}$ (intervalo de $45 \mathrm{~nm}$ ); verde, centro da faixa $540 \mathrm{~nm}$ (intervalo de $40 \mathrm{~nm}$ ); vermelho, centro da faixa $660 \mathrm{~nm}$ (intervalo de $40 \mathrm{~nm}$ ); infravermelho próximo, centro da faixa $800 \mathrm{~nm}$ (intervalo de $65 \mathrm{~nm}$ ). O avião utilizado foi do tipo monomotor, modelo Cessna 180 e os vôos apresentaram uma altura média de $1145 \mathrm{~m}$ sobre o solo.

Foram realizados três vôos: durante a fase de repouso vegetativo da cultura (agosto de 2001, vôo 1), no início da maturação de frutos (abril de 2002, vôo 2) e logo após o florescimento do ciclo seguinte (setembro de 2002, vôo 3). O primeiro pode ser considerado como um vôo teste, porque não havia a certeza de que configuração da câmara era a mais indicada para cumprir o objetivo proposto. A configuração de ganho nas faixas do vermelho e do infravermelho próximo, offset e tempo de exposição nas mesmas faixas foram as seguintes: $32,1 \mathrm{~dB}$ e $32,1 \mathrm{~dB} ; 0 \mathrm{DN}$ e $0 \mathrm{DN} ; 0,125 \mathrm{msec}$ e 130,75 msec. Cabe esclarecer que a configuração da câmara foi realizada por meio de um programa desenvolvido pela própria Duncan Technologies, Inc. (1999b). As imagens apresentaram uma resolução radiométrica de 8 bits (256 níveis de cinza).

Essas primeiras imagens obtidas, em função de valores elevados de tempo de exposição e ganho, apresentaram saturação dos níveis de cinza. Além disso, não foram corrigidas radiometricamente. Mas, a despeito dessas limitações e da limitação do pomar ser representado por duas imagens ( $a$ e b) ao invés de uma, os dados extraídos dessas imagens pareceram não comprometer as análises, conseqüentemente, foram incluídos na pesquisa. Campbell (1996), ao discorrer sobre a necessidade de correção radiométrica das cenas, afirmou que a utilização do nível de cinza é suficiente para se comparar cenas diferentes.Vale comentar ainda que essas imagens eram de fundamental importância, afinal representavam uma fase fenológica das árvores anterior à fase de desenvolvimento vegetativo, fase em que as plantas jovens adquirem massa foliar expressiva. 
Antes do segundo vôo, a câmara foi devidamente calibrada, com a seguinte configuração: $11 \mathrm{~dB}$ e $11 \mathrm{~dB}, 0 \mathrm{DN}$ e $0 \mathrm{DN}, 3 \mathrm{msec}$ e $3 \mathrm{msec}$, respectivamente para ganho, offset e tempo de exposição nas faixas do vermelho e do infravermelho próximo.

O objetivo de se realizar esse segundo vôo foi avaliar a relação entre resposta espectral e os diferentes parâmetros biofísicos após a fase de desenvolvimento vegetativo das árvores.

Já, o terceiro vôo apresentou a seguinte configuração: $12 \mathrm{~dB}$ e $15 \mathrm{~dB}, 0 \mathrm{dN}$ e 0 $\mathrm{dN}$ e $4 \mathrm{msec}$ e $4 \mathrm{msec}$. Cabe informar que, nesse vôo, foi possível visualizar o histograma da resposta espectral de cada faixa em tempo real no próprio programa de configuração da câmara, facilitando o processo de configuração. Daí, a mudança de configuração em relação ao segundo vôo.

Esse vôo foi feito com o intuito de se comparar as respostas espectrais das árvores em fases fenológicas semelhantes em 2002 e 2001.

Posteriormente, as imagens foram transformadas em imagens NDVI e SAVI, no software Idrisi. Adotou-se como fator de ajuste do solo para a transformação em imagens SAVI o valor de 0,5 .

É pertinente esclarecer que, no estudo específico da relação entre resposta espectral e produção visando sua estimativa, partiu-se da hipótese que árvores mais vigorosas, com mais vegetação sadia, produziriam mais, conforme Dhillon et al. (1962) e Amami (1974), e teriam maior resposta espectral (Blazquez et al., 1984; Blazquez et al., 1978; Blazquez et al., 1979; Edwards \& Blazquez, 1985; Blazquez, 1988a; Blazquez, 1988b; Blazquez, 1989; Blazquez, 1991; Blazquez, 1993; Blazquez et al., 1998).

Cabe comentar ainda que voar também durante o florescimento seria uma opção plausível, pois, segundo Goldschmidt \& Monselise (1977) e Bustan et al. (1999), o número de flores é um dos principais fatores determinantes da produção citrícola. No 
entanto, seria necessário um número maior de faixas do espectro eletromagnético para se poder estimar cada um dos componentes que contribuem à resposta espectral das árvores. Além disso, existe uma grande dificuldade em relacionar o número de flores e a produção, conforme Guardiola (1992) e Bustan \& Goldschmidt (1998), a despeito dos resultados obtidos por Ikeda et al. (1991), Morinaga \& Ikeda (1991) e Ikeda (1992).

\subsection{Obtenção dos valores de NDVI, SAVI e nível de cinza nas faixas do vermelho e do infravermelho próximo das árvores}

Inicialmente, foram selecionadas 52 árvores distribuídas ao longo de duas transeções cruzadas no pomar. Para cada árvore, foram criadas imagens, ou seja, janelas das imagens NDVI, SAVI e nível de cinza nas faixas do vermelho e do infravermelho próximo originais por meio da utilização da função window do software Idrisi. A seguir, foram obtidos arquivos com os valores de NDVI, SAVI e nível de cinza nas faixas do vermelho e do infravermelho próximo de todos os pixels contidos em cada janela por meio da utilização da função histo (image histogram). Cada arquivo foi exportado para uma planilha eletrônica, onde foi calculado o somatório dos valores de NDVI, SAVI e de nível de cinza nas faixas do vermelho e do infravermelho próximo. Cabe mencionar que os limites para separar a copa da árvore do resto dentro de cada arquivo foram definidos com base na visualização dos padrões de cor e valores associados dos pixels dentro de cada janela. Ainda foi calculada a média dos 10 maiores valores de nível de cinza, no caso da faixa do infravermelho próximo, e de índice, no caso do NDVI e SAVI, e dos 10 menores valores de nível de cinza, no caso da faixa do vermelho.

\subsection{Obtenção dos parâmetros de copa}

Com o intuito de contribuir ao estudo das relações entre resposta espectral e produção, parâmetros de copa das 52 árvores foram medidos e calculados. Afinal, era de se esperar que árvores com maior tamanho e área foliar tivessem também maior potencial de produção (Parker \& Batchelor, 1932; Menon \& Tyagi, 1971; Brar \& Mann, 
1986; Ono et al., 1987; Brar et al., 1988; Tachibana \& Nakai, 1989; Brar et al.; 1990 e Mataa \& Tominaga, 1998) e resposta espectral (Myers, 1983; Blazquez et al., 1984; Formaggio, 1989; Wickland, 1989; Guyot, 1990; Craig et al., 2000; Weepener et al., 2000; Xavier, 2002; Colombo et al., 2003).

Assim, as 52 árvores foram fotografadas e medidas com o aparelho LAI-2000 (LI-COR, 1992a), medidor de IAF, em setembro de 2001 e outubro de 2002. Conforme Xavier (2002), o LAI-2000, no cálculo da estrutura do dossel, faz uso da fração de abertura. A fração de abertura de um dossel é a fração de visão do céu em algumas direções abaixo do dossel. Medições da fração de abertura para uma certa gama de ângulos fornecem informação estrutural, como IAF e ângulo foliar.

Na prática, segundo Xavier (2000), a fração de abertura em 5 ângulos zenitais pode ser medida realizando uma medição de referência externa ao dossel e uma ou mais leituras abaixo do dossel. A razão entre as leituras obtidas abaixo do dossel e as obtidas fora do dossel é usada para se obter uma estimativa da fração de abertura nos 5 ângulos. Cabe ressaltar que as leituras obtidas abaixo e fora do dossel precisam estar sob as mesmas condições de luminosidade.

As leituras com o aparelho LAI-2000 foram realizadas sempre quando a luminosidade era difusa. Uma leitura de referência acima das árvores e outra no interior das mesmas foram feitas para cada lado da árvore, um lado face leste, outro lado face oeste. Foi utilizado o anel de obstrução à entrada de luz de $45^{\circ}$ para evitar a interferência do operador do aparelho e das árvores vizinhas nas leituras. $\mathrm{O}$ aparelho era localizado o mais próximo possível do tronco a uma altura do chão correspondente ao nível em que se iniciava a estrutura da copa das árvores.

Posteriormente, por meio da utilização de um programa computacional chamado C2000 (LI-COR, 1992b) que acompanhava o equipamento LAI-2000, foram corrigidas as distâncias entre a posição do aparelho na árvore e suas margens. Esse 
programa demandava a entrada de coordenadas $\mathrm{x}, \mathrm{y}$ do contorno da copa para recalcular as distâncias e o IAF. Portanto, cada árvore foi fotografada em dois lados opostos a $45^{\circ}$ da linha de plantio para se capturar a maior variabilidade possível do formato da copa.

É pertinente informar que foi utilizada uma trena como referência para corrigir a escala das fotografias. As fotografias foram importadas para o programa computacional AutoCad2000 (Autodesk Inc., 1999) por meio da utilização da função raster image. A seguir, o fator de escala foi determinado dividindo-se a medida real da trena pela obtida por meio da utilização da função distance do programa. Por meio da utilização da função scale, as fotografias foram corrigidas quanto à escala. A seguir, as fotografias foram georeferrenciadas. Cabe mencionar que as coordenadas 0,0 foram posicionadas no tronco da árvore por meio da utilização da função move do programa. A seguir, no próprio AutoCad2000 foram tomadas as coordenadas x,y do contorno da copa. Cabe esclarecer que as coordenadas das árvores foram tomadas em 4 quadrantes. Também foram tomadas as coordenadas em 2 quadrantes a partir das imagens capturadas em 2001 para avaliar a influência da variabilidade do formato da copa nos resultados das relações.

O programa C2000 calculava ainda o volume, a área de projeção da copa e o DLLAI (Drip Line Leaf Area Index), que nada mais é do que o IAF multiplicado pelo volume e dividido pela área de projeção da copa. O IAF calculado pelo programa é expresso em unidades de $\mathrm{m}^{2} \cdot \mathrm{m}^{-3}$, portanto é uma densidade foliar. A área foliar total em $\mathrm{m}^{2}$ foi obtida multiplicando-se a densidade foliar pelo volume da copa.

\subsection{Análise dos dados}

\subsubsection{Análise espacial e temporal da produção}

Inicialmente, com base em Isaaks \& Srivastava (1989), realizou-se uma análise exploratória dos dados por meio da utilização do programa computacional Statistica for Windows v. 4.3 (Statsoft Inc., 1993) para se verificar a distribuição dos dados e a 
existência de dados discrepantes. A análise exploratória dos dados foi chamada de descrição univariada. Por meio da utilização de uma planilha eletrônica, procurou-se verificar a relação entre os dados de produção em 2001 e 2002, análise essa chamada de descrição temporal.

Ainda, na descrição temporal, foi realizada uma análise de estabilidade temporal com o intuito de identificar árvores que mantiveram seu nível produtivo de 2001 para 2002. Conforme Vachaud et al. (1985), uma análise de estabilidade temporal nada mais é do que subtrair e dividir o valor de cada amostra pela média da população para cada evento e obter, a seguir, a média de todos os eventos. Essa é a diferença média relativa de cada observação. Ainda, calcula-se o desvio padrão médio da diferença relativa de todos os eventos, que possibilita identificar no terreno aqueles pontos que apresentam a maior ou menor estabilidade temporal.

Já na descrição espacial, os dados de produção em 2001 e 2002 georeferrenciados foram distribuídos espacialmente na forma de pontos por meio da função post do programa Surfer. Tal representação permitiu verificar a presença de tendências espaciais.

Posteriormente, foram estabelecidos os semivariogramas por meio da utilização do conjunto de programas Variowin v. 2.21 (Pannatier, 1996). Quando os semivariogramas indicaram tendência nos dados, aplicou-se o método de retirada de tendências proposto por Hamlett et al. (1986), chamado de refinamento pela mediana. Ou seja, o valor de produção de cada ponto amostral foi subtraído da mediana da linha à qual o ponto amostral pertencia. A seguir, o valor residual de cada ponto amostral foi subtraído do valor da mediana da coluna à qual o ponto amostral pertencia e, assim, foi determinado o valor de resíduo final. Os novos semivariogramas foram obtidos a partir desses novos valores. 
Quanto à classificação dos dados ou análise de agrupamentos visando o mapeamento da produção, duas abordagens foram adotadas. A da classificação dos dados via lógica fuzzy e a da classificação dos dados arbitrária. Vale comentar que, segundo Burrough (1989) e Lark (1998), a classificação é vantajosa no sentido de permitir obter generalizações significativas de conjuntos de dados extensos. Para classificar os dados via lógica fuzzy, utilizou-se o programa computacional FuzMe v. 3.5 (Minasny \& McBratney, 2002). Foi condição necessária para processar os dados préfixar um número de classes e um expoente de imprecisão, de tal forma que na apresentação dos resultados fosse possível avaliar o desempenho da classificação. Várias combinações de números de classes e expoentes de imprecisão foram testadas e a que produziu valores mais baixos de MPE (Modified Partition Entropy) e S (Separate Distance) e mais altos da curva formada entre os expoentes de imprecisão e a derivada da função objetiva em relação ao expoente de imprecisão multiplicada pela raiz do número de classes, conforme McBratney \& Moore (1985) e Triantafilis et al. (2003), foi selecionada. Cabe esclarecer que o programa FuzMe disponibiliza os dados de MPE, S e da derivada da função objetiva em relação ao expoente de imprecisão. Uma vez disponibilizados, os dados da derivada da função objetiva em relação ao expoente de imprecisão foram exportados para uma planilha eletrônica, onde foram elaborados os gráficos das relações entre os expoentes de imprecisão e a derivada da função objetiva em relação ao expoente de imprecisão multiplicada pela raiz do número de classes. Os valores mais adequados de número de classes de produção em 2001 e de expoente de imprecisão para os dados de 2001 foram, respectivamente, 4 classes e 2,03 e, para os dados de produção em 2002, 5 classes e 1,9.

Após a seleção do número de classes e do valor do expoente de imprecisão, foi possível especificar, finalmente, a que classe de produção cada árvore pertencia. É interessante lembrar que, na classificação ou análise de agrupamentos via lógica fuzzy, cada indivíduo pertence em maior ou menor grau a uma determinada classe. Esse grau de maior ou menor participação de um indivíduo a uma determinada classe é chamado 
de grau de pertinência. $O$ grau de pertinência varia continuamente de 0 até 1 . Quanto mais próximo de 1, mais um determinado indivíduo pertence a uma determinada classe.

De posse desse tipo de informação, ou seja, a que classe cada árvore pertencia, os mapas de classes de produção em 2001 e 2002 puderam ser gerados por meio de interpolação dos valores de classe de cada árvore pelo programa Surfer. Cabe comentar que a classe à qual cada árvore pertencia foi selecionada em função do maior valor de grau de pertinência à mesma.

Quanto à classificação do tipo arbitrária, a produção foi analisada de forma relativa. Ou seja, o valor de produção original de cada árvore foi dividido pela média geral. A seguir, os dados de produção relativa foram interpolados via krigagem por meio da utilização do programa Surfer e separados em classes arbitrárias. Cabe comentar que os dados de produção relativa foram interpolados adotando-se como tamanho de célula o próprio espaçamento entre elas e não o sugerido pela análise dos semivariogramas experimentais. Afinal, tinha-se o valor de produção de todas as árvores do pomar e não se precisava estimar nada.

No que diz respeito à descrição espaço-temporal, os dados de produção em 2001 e 2002 foram analisados conjuntamente. Os semivariogramas padronizados foram obtidos exportando-se os valores de semivariância calculados pelo conjunto de programas Variowin para uma planilha eletrônica, onde os gráficos foram elaborados. Ao passo que os semivariogramas cruzados foram determinados por meio da utilização do conjunto de programas Variowin.

Quanto à classificação ou análise de agrupamentos dos dados de produção via lógica fuzzy visando o mapeamento espaço-temporal, procedeu-se da mesma forma descrita anteriormente, com a exceção de que os graus de pertinência foram calculados a partir do conjunto de dados de produção de 2001 e 2002. Vale informar que, nesse caso, a classificação foi realizada com dados de produção relativa, cuja distribuição 
apresentava média zero e variância um. O número de classes e o valor de expoente de imprecisão selecionados foram, respectivamente, 10 classes e 1,66.

Nesse processo de formação das classes de comportamento produtivo via análise conjunta dos dados de produção de 2001 e 2002, foi adotado como critério para incluir uma árvore numa determinada classe o valor de grau de pertinência 0,5 . Ou seja, uma árvore para ser incluída numa determinada classe precisava ter um valor de grau de pertinência de pelo menos 0,5 . Esse valor foi adotado objetivando incluir o maior número possível de árvores na classificação, sem comprometer a formação das classes.

Com o intuito de se conhecer a distribuição espacial de cada classe de produção, utilizou-se a opção krigagem do programa Surfer para interpolar os valores de grau de pertinência a cada classe. Desse modo, obteve-se um mapa de grau de pertinência para cada classe de produção. Vale mencionar que cada mapa de grau de pertinência representava apenas duas regiões, uma cujas árvores apresentavam grau de pertinência maior que 0,5 e outra menor.

Ainda quanto à classificação visando o mapeamento espaço-temporal, aplicou-se metodologia semelhante à proposta por Blackmore (2003) aos dados de produção do presente estudo. Ou seja, calculou-se a média de produção entre 2001 e 2002 e sua variância temporal para cada árvore. A variância temporal foi calculada como:

$$
\sigma_{i}^{2}=\frac{\sum_{i=1}^{\mathrm{t}=\mathrm{v}}\left(\mathrm{Y}_{\mathrm{t}, \mathrm{i}}-\overline{\mathrm{Y}_{\mathrm{i}}}\right)^{2}}{\mathrm{u}}
$$

sendo: $\sigma_{i}^{2}=$ variância temporal para cada árvore;

$\mathrm{t}=\mathrm{ano}$

$\mathrm{v}=$ último ano avaliado;

$\mathrm{Y}_{\mathrm{t}, \mathrm{i}}=$ produção em cada ano;

$\overline{Y_{t}}=$ média geral de produção de todas as árvores em cada ano; 
$\mathrm{u}=$ número de anos.

A seguir, os dados de média e variância temporal foram interpolados via krigagem por meio da utilização do programa Surfer. Dois mapas foram gerados, um de média e outro de variância temporal. Cada mapa foi representado por 2 classes; no caso do mapa de média, uma classe de produção acima da média e a outra abaixo e, no caso do mapa de variância temporal, uma acima de um limite arbitrário de variância temporal e a outra abaixo. O limite para separação das classes de variância temporal correspondeu à mediana da distribuição dos dados de variância temporal. Posteriormente, os dois mapas foram sobrepostos no próprio Surfer, analisados visualmente e comparados aos mapas formados pela análise de agrupamentos via lógica fuzzy.

\subsubsection{Determinação dos coeficientes de correlação intraclasse para resposta espectral}

Inicialmente, as 52 árvores-amostra foram identificadas quanto à classificação obtida por meio da análise de agrupamentos conjunta via lógica fuzzy. Ou seja, cada uma das 52 árvores foi identificada por uma classe entre as 10 classes de comportamento produtivo. A seguir, as árvores foram distribuídas pelas 10 classes, cada árvore com seus valores de resposta espectral. Cabe informar que o número de árvores distribuído a cada classe foi diferente.

Para se determinar os coeficientes de correlação intraclasse para resposta espectral, foi realizada primeiramente uma análise de variância com dados não balanceados por meio da utilização de uma planilha eletrônica. A seguir, os coeficientes de correlação intraclasse foram calculados, conforme Ching (1995), pela seguinte fórmula:

$$
\hat{\rho}_{\mathrm{A}}=\frac{(\mathrm{QMA}-\mathrm{QMR})}{\mathrm{QMA}+\left(\mathrm{n}_{0}-1\right) \mathrm{QMR}}
$$


sendo: $\rho_{\mathrm{A}}=$ coeficiente de correlação intraclasse;

QMA = quadrado médio entre classes;

QMR = quadrado médio dos resíduos ou dentro das classes;

$\mathrm{n}_{0}=\frac{\left[\mathrm{N}-\frac{\sum_{\mathrm{i}=1}^{\mathrm{k}} \mathrm{n}_{\mathrm{i}}^{2}}{\mathrm{~N}}\right]}{(\mathrm{k}-1)}$

sendo: $\mathrm{n}_{0}=$ número de observações por classes com dados não balanceados;

$\mathrm{N}=$ número total de observações;

$\mathrm{k}=$ número de classes;

$\mathrm{n}_{\mathrm{i}}=$ número de observações por classe.

\subsubsection{Estudo das relações entre parâmetros de copa, resposta espectral e produção}

As relações entre parâmetros de copa e produção, entre resposta espectral e parâmetros de copa e entre resposta espectral e produção foram determinadas por meio da utilização de uma planilha eletrônica. Para a análise de variância das regressões, os dados foram transformados para logaritmo neperiano (ln), quando as funções eram potencial, exponencial ou logarítmica. No caso da função potencial, tanto a variável dependente como a independente foram transformadas. No caso da função exponencial, somente a variável independente foi transformada. Já no caso da função logarítmica, somente a variável dependente foi transformada. 


\section{RESULTADOS E DISCUSSÃO}

\subsection{Análise espacial e temporal da produção}

\subsubsection{Descrição univariada}

Como é possível verificar na Figura 3, a distribuição dos dados de produção por árvore, tanto em 2001 como em 2002, tendeu à normalidade. Em Parker \& Batchelor (1932), as distribuições seguiram a mesma tendência em 6 anos sucessivos. Batchelor \& Reed (1918) também encontraram distribuição normal para um pomar de laranja Bahia.

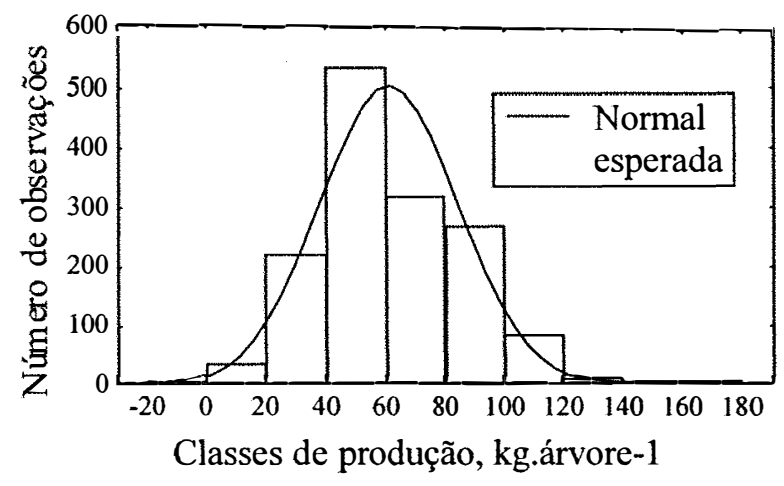

(a)

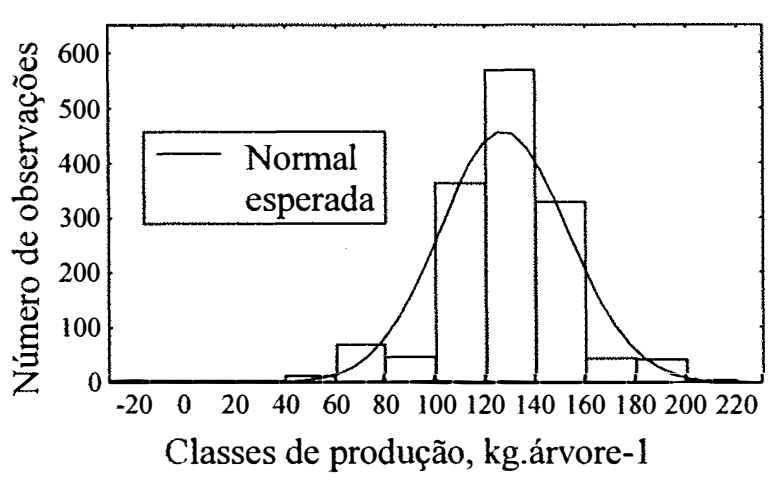

(b)

Figura 3 - Distribuição dos dados de produção em 2001 (a) e 2002 (b)

Pela Tabela 1, ainda se observa que o coeficiente de curtose e o coeficiente de assimetria ficaram próximos a zero, mostrando que as distribuições dos dados nos dois anos foram aproximadamente normais. Os valores mais afastados de zero em 2002 sinalizaram uma distribuição menos normal nesse ano, graças à presença de valores de 
produção bem distantes da média e próximos à produção zero, que podem ser visualizados na Figura 4. Já em 2001, não houve dados tão discrepantes em relação à média e o gráfico do tipo probabilidade normal da Figura 5 mostra pontos mais próximos da reta, a qual representa uma distribuição perfeitamente normal.

Tabela 1. Resumo estatístico da produção em 2001 e em 2002

\begin{tabular}{|c|c|c|}
\hline Resumo estatístico & Produção em 2001 & Produção em 2002 \\
\hline Média (kg.árvore ${ }^{-1}$ ) & 61,06 & 127,22 \\
\hline Erro padrão (kg.árvore ${ }^{-1}$ ) & 0,61 & 0,67 \\
\hline Mediana (kg.árvore ${ }^{-1}$ ) & 53,87 & 130,12 \\
\hline Modo (kg.árvore ${ }^{-1}$ ) & 53,87 & 130,12 \\
\hline Desvio padrão (kg.árvore $\left.{ }^{-1}\right)$ & 23,26 & 25,66 \\
\hline Variância da amostra $\left(\mathrm{kg}^{2}\right.$.árvore $\left.{ }^{-2}\right)$ & 541,05 & 658,53 \\
\hline Coeficiente de variação & 0,38 & 0,20 \\
\hline Curtose & $-0,02$ & 1,13 \\
\hline Assimetria & 0,09 & $-0,28$ \\
\hline Amplitude (kg.árvore ${ }^{-1}$ ) & 161,62 & 208,19 \\
\hline Mínimo (kg.árvore ${ }^{-1}$ ) & 0 & 0 \\
\hline Máximo (kg.árvore ${ }^{-1}$ ) & 161,62 & 208,19 \\
\hline Produção total (kg) & 89814,40 & 187147,20 \\
\hline Contagem & 1471 & 1471 \\
\hline
\end{tabular}

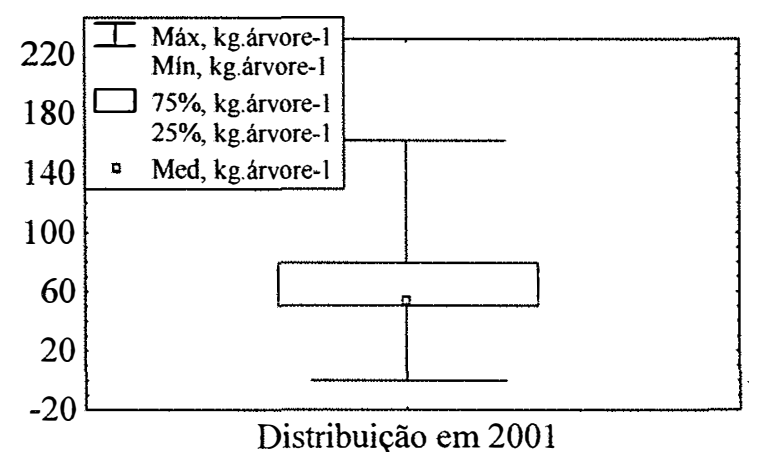

(a)

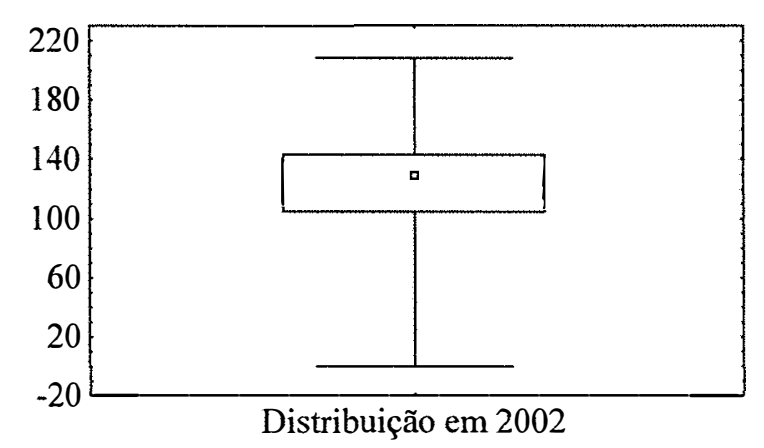

(b)

Figura 4 - Gráficos do tipo box plot da distribuição em 2001 (a) e em 2002 (b) 


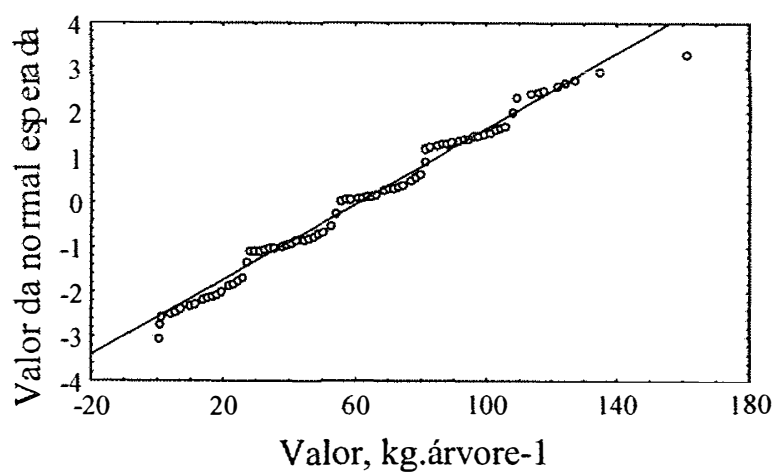

(a)

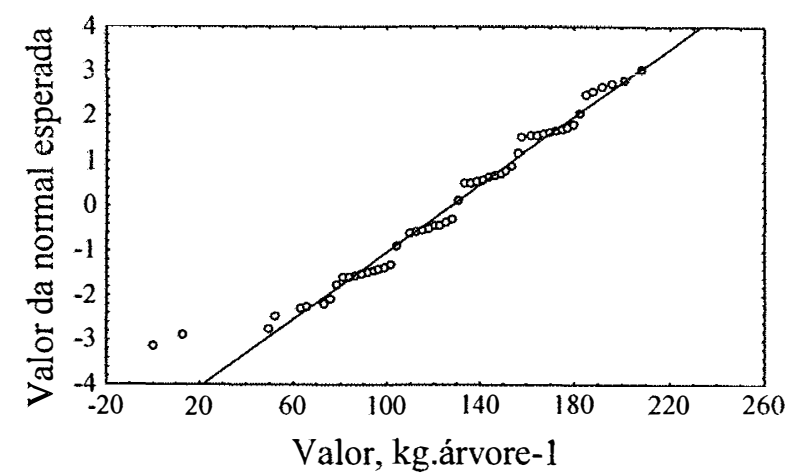

(b)

Figura 5 - Gráficos do tipo probabilidade normal da distribuição em 2001 (a) e em 2002 (b)

Porém, o gráfico do tipo probabilidade normal da distribuição em 2002 também mostra tendência à normalidade. Ou seja, os dados de produção, tanto em 2001 como em 2002, apresentaram um padrão de distribuição que propiciou análises posteriores.

Ainda no que tange à análise exploratória dos dados e com base nos gráficos do tipo box plot representados na Figura 4, percebe-se que a amplitude entre os valores mínimos e máximos de produção apresentou uma dimensão equilibrada em relação à distribuição dos dados. No entanto, em 2002, os valores mínimos (produção zero) se afastaram da média, candidatando-os a dados discrepantes. Essas árvores não produziram nada nos dois anos ou no segundo ano, então, ou estavam mortas ou seriamente prejudicadas. Portanto, foram descartadas das análises posteriores.

\subsubsection{Descrição temporal}

Ao se comparar as médias de produção em 2001 e em 2002 (Tabela 1), verifica-se que a de 2002 foi $115,67 \%$ maior. Muito embora tal resultado fosse esperado, 
afinal o pomar ainda não havia atingido a maturidade, parece que isso se deveu muito mais às condições climáticas (Figuras 6 e 7), que também favoreceram uma maior produção em 2002. Gallo et al. (1977), Plessis (1983), Ben-Mechlia \& Carroll (1989), Tubelis \& Salibe (1989), Sanikidze \& Mamulaishvili (1990), Di Giorgi et al. (1991), Iaffe (1996), Martins(2000), Camargo et al. (2001) e Paulino \& Volpe (2001) ressaltaram a importância das condições climáticas para a produção citrícola. Pelo exame das Figuras 6 e 7, é possível constatar que a deficiência hídrica em 2001, na época do pré-florescimento, foi mais prolongada, favorecendo a produção em 2002. Para Martins (2000), deficiência hídrica presente nesse período também favoreceu a produção. Ainda em 2001, as condições climáticas na época do florescimento/início da frutificação foram também mais favoráveis, ou seja, menos e mais precipitação nessas respectivas épocas. Iaffe (1996), Di Giorgi et al. (1991) e Martins (2000) encontraram correlação negativa entre precipitação e produção na época do florescimento e positiva no início da frutificação. Tubelis \& Salibe (1989) também encontraram correlação negativa na época do florescimento. Para Paulino \& Volpe (2001), as variações climáticas ocorridas no pré-florescimento, florescimento e frutificação determinam a produção. Assim como para Van Noort (1969), a água de irrigação aplicada no pré e pós-florescimento determinou a produção em laranjeira Bahianinha.

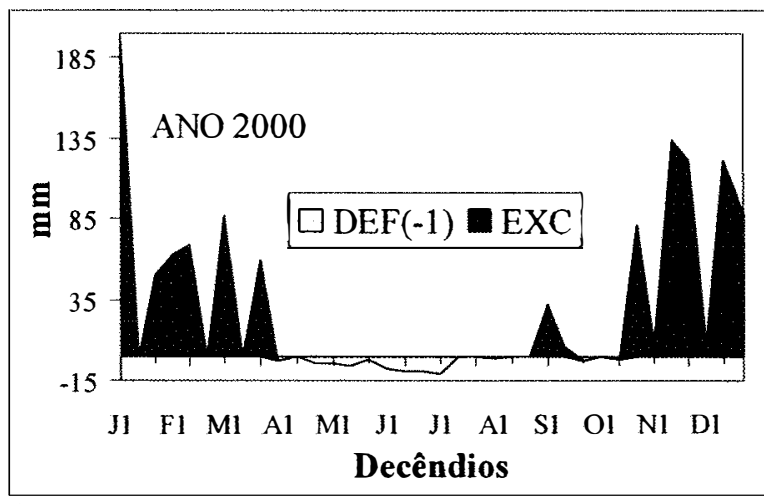

(a)

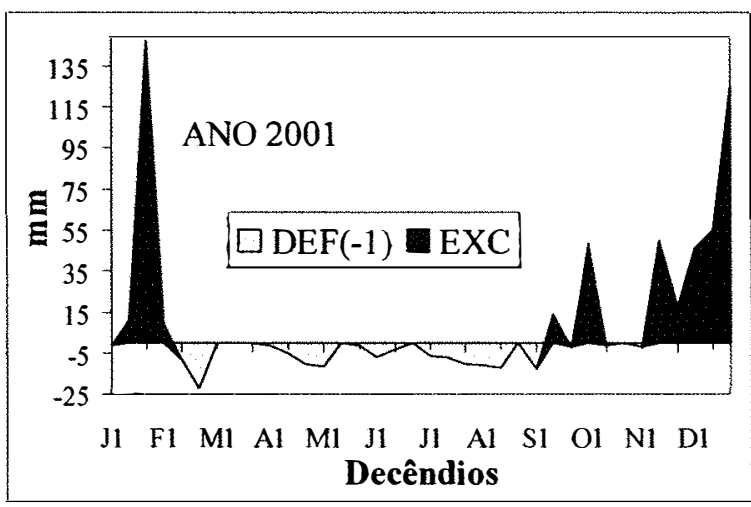

(b)

Figura 6 - Balanço hídrico seqüencial em 2000 (a) e em 2001 (b) 


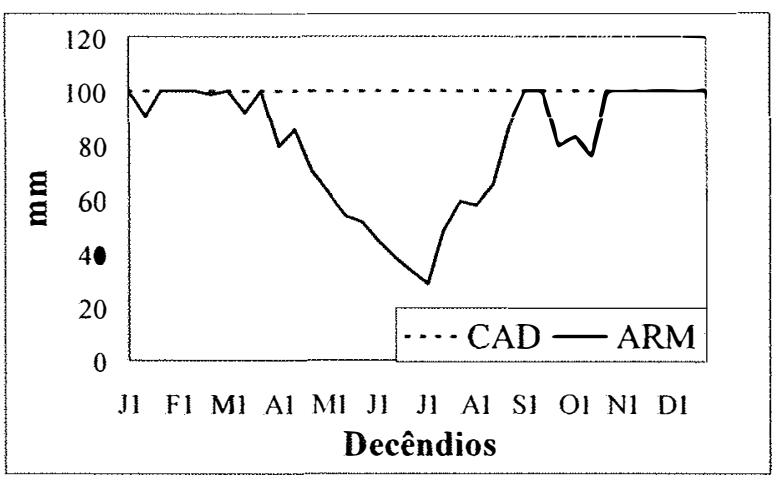

(a)

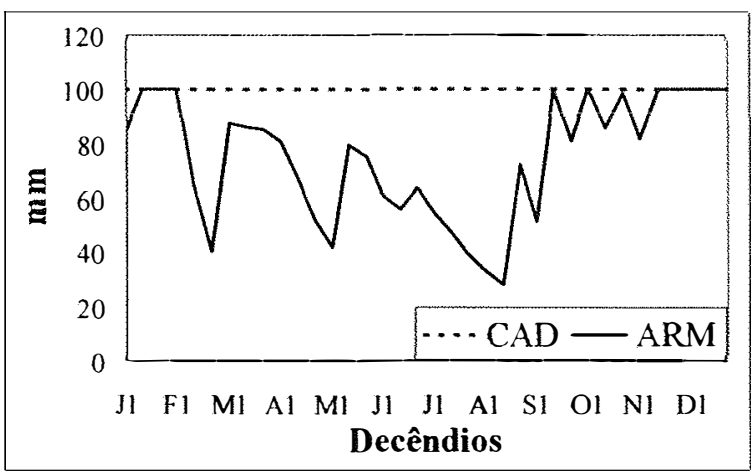

(b)

Figura 7 - Capacidade de água disponível (CAD) e armazenamento (ARM) mensal em 2000 (a) e em 2001 (b)

A idéia de que as condições climáticas foram decisivas para a variação temporal da produção ficou ainda mais fortalecida pelo fato de que em 2003, embora os dados não tenham sido coletados por árvore, a produção total foi de $86.309,2 \mathrm{~kg}$, ao passo que em 2002 foi de $187.147,2 \mathrm{~kg}$. Além disso, o clima pareceu ter contribuído para uma maior variabilidade em 2001, haja visto os coeficientes de variação (Tabela 1), que indicam maiores desvios relativos à média em 2001 do que em 2002. Parker \& Batchelor (1932) também encontraram maior coeficiente de variação (aproximadamente 28\%) num ano em que as condições climáticas para a produção foram adversas.

Já o gráfico do tipo probabilidade acumulada, apresentado na Figura 8, mostra que os dados de produção relativa em 2002 estiveram mais próximos da média (valor 1) do que em 2001. Daí, o maior coeficiente de variação em 2001. Também, em 2001, a diferença entre os grupos de árvores que produziram mais e menos foi mais proeminente. Shanmugasundaram \& Ramachander (1983) e Shamasundaran \& Ramachander (1983), ao acompanharem a produção em um pomar citrícola durante quatro anos, também verificaram grande variabilidade de produção entre os anos. 


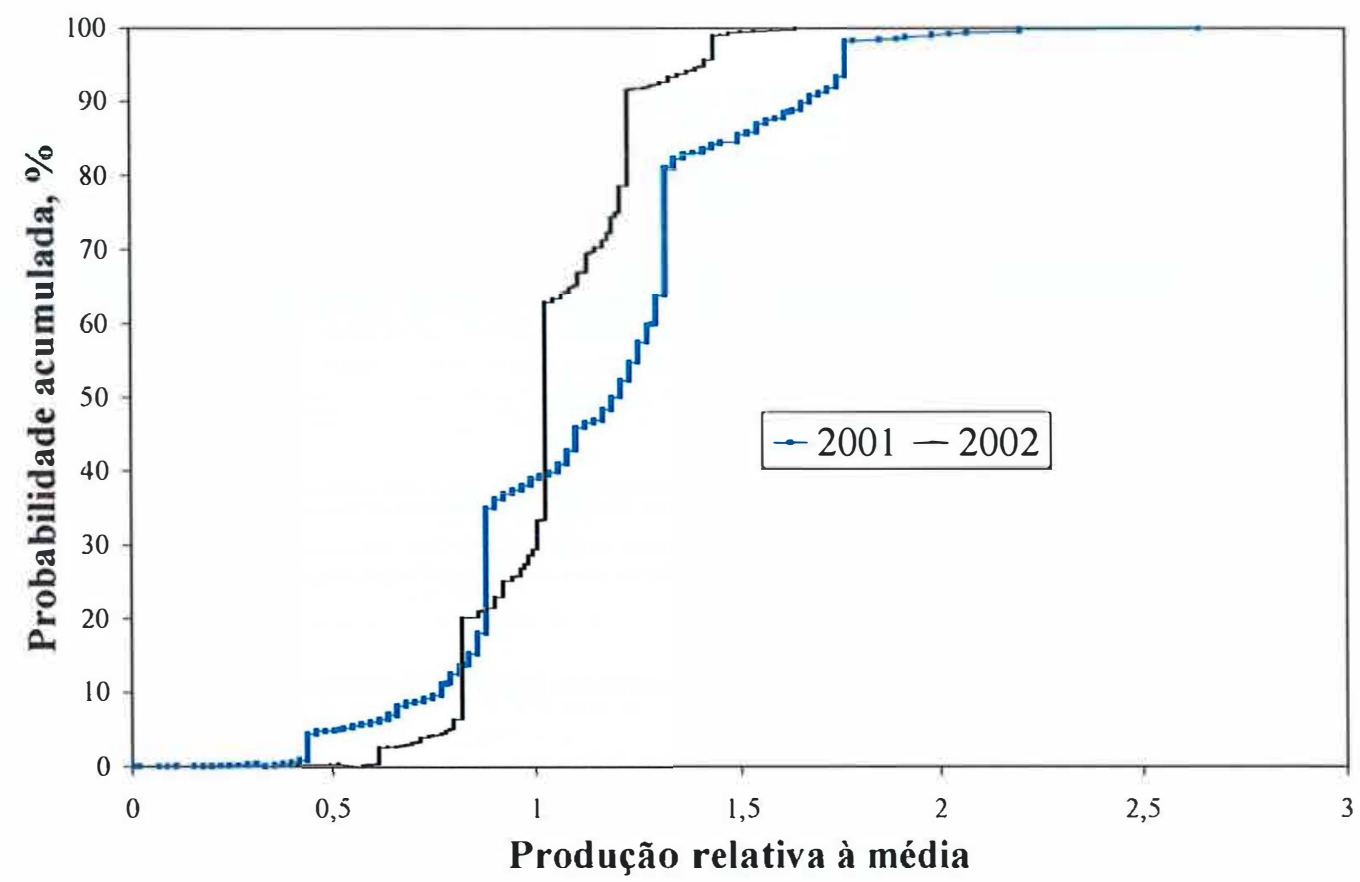

Figura 8 - Gráficos do tipo probabilidade acumulada em 2001 e em 2002

Em função das análises anteriores, é possível perceber uma dinâmica interessante na relação entre as características intrínsecas do terreno e das plantas e a variabilidade de produção. Em 2002, quando a expressão das características intrínsecas das plantas foi favorecida, houve menor variabilidade. O oposto ocorreu em 2001, quando as condições restringiram a expressão dessas características intrínsecas das plantas. Provavelmente, pode-se inferir daí que as características intrínsecas do terreno tenham tido um peso maior na variabilidade de produção em 2001. Para Parker \& Batchelor (1932), sob condições adversas, a variabilidade do solo poderia ser a principal responsável pela variabilidade sistemática. Afinal, constataram que a produção em algumas regiões do pomar foi mais prejudicada do que em outras, no ano em que o coeficiente de variação foi mais elevado.

Ao se relacionar as produções em 2001 e 2002 entre si, aquele comportamento produtivo notadamente desigual foi minimizado. Por exemplo, o coeficiente de correlação de Pearson evidencia que aproximadamente $43 \%$ dos valores de produção em 
2001 seguiram a mesma tendência em 2002, isto é, árvores mais ou menos produtivas em 2001 continuaram a ser mais ou menos produtivas em 2002. Também em Parker \& Batchelor (1932) correlações significativamente positivas foram obtidas, principalmente, entre anos consecutivos, chegando a aproximadamente 0,685 . No mesmo sentido, o coeficiente de Spearman mostra que aproximadamente $41 \%$ das árvores mantiveram a mesma posição na classificação gradual de produções em 2001 e em 2002.

A Figura 9 (a) mostra graficamente a correlação entre a produção em 2001 e em 2002. Ao passo que o gráfico da Figura 9 (b) é equivalente ao anterior, apenas diferencia-se por ser expresso em unidades referentes à diferença e divisão pela média geral de produção de cada ano. Ou seja, o valor de produção de cada árvore foi subtraído e posteriormente dividido pela média geral de produção de cada ano. Nesse último gráfico, o comportamento de produção das árvores, de manter ou alterar o nível produtivo, ficou ressaltado.

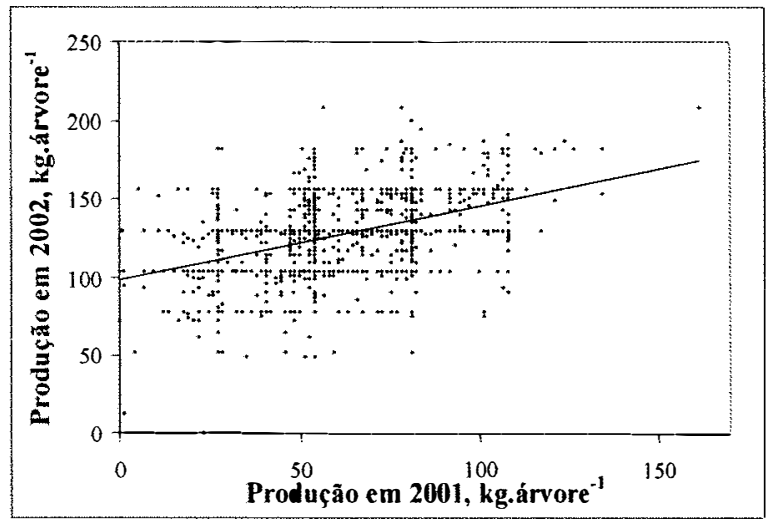

(a)

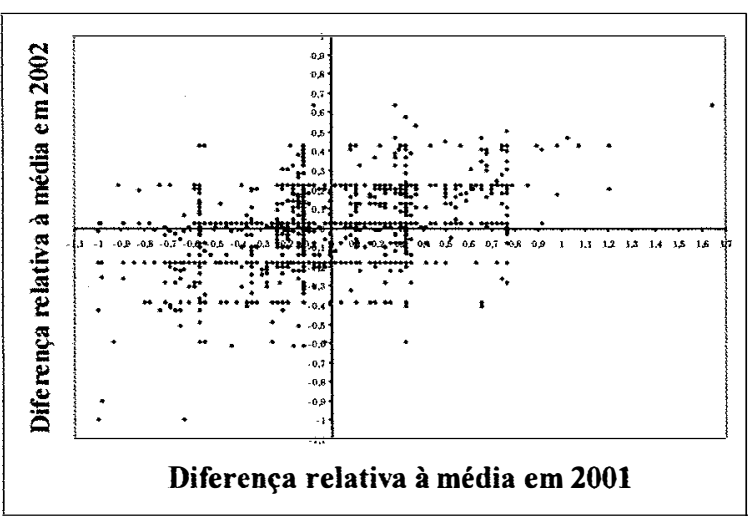

(b)

Figura 9 - Gráfico de correlação entre a produção absoluta (a) e relativa (b) em 2001 e em 2002

Clark Powell (1932) também verificou uma tendência de grupos de 50 (cinqüenta) árvores com diferentes níveis de produção manterem esses níveis durante quatro anos de estudo. Assim como Parker \& Batchelor (1932) constataram a tendência 
das parcelas de 8 árvores manterem sua produção relativa sempre dentro de um certo limite.

Ao se realizar uma análise de estabilidade temporal com os dados do presente estudo, constatou-se que das 1471 árvores pelo menos uma apresentou uma diferença média relativa que representasse um determinado nível produtivo e ainda um desvio médio baixo. O desvio médio baixo mostra que a produção é relativamente estável num determinado nível produtivo. Caso algumas árvores mantivessem esses desvios baixos, seria possível considerá-las como representativas daqueles níveis produtivos e, sendo representativas, auxiliar no direcionamento de futuras amostragens voltadas à estimativa de produção. Como exemplo, consideremos que o produtor pretenda, num futuro próximo, estimar a média de produção do pomar e tenha apenas os dados de dois anos de produção por árvore. O produtor poderia continuar coletando dados apenas daquelas árvores que apresentassem uma diferença média relativa próxima à média do pomar e desvio médio baixo, para selecionar aquelas que mantivessem esse desvio baixo e usálas, no futuro, para a estimativa da média de produção.

Ainda, é pertinente comentar que somente dez árvores não aumentaram sua produção de 2001 para 2002. As 1461 árvores restantes aumentaram sua produção em diversos graus de acréscimo. Na Figura 10, é possível observar a distribuição de freqüências da porcentagem de acréscimo de produção de 2001 para 2002.

\subsubsection{Descrição espacial}

Ao se referenciar no espaço os valores de produção em 2001 e em 2002, uma nova dimensão foi adicionada à análise da distribuição do comportamento produtivo que poderia ficar mascarada em função da variabilidade. 


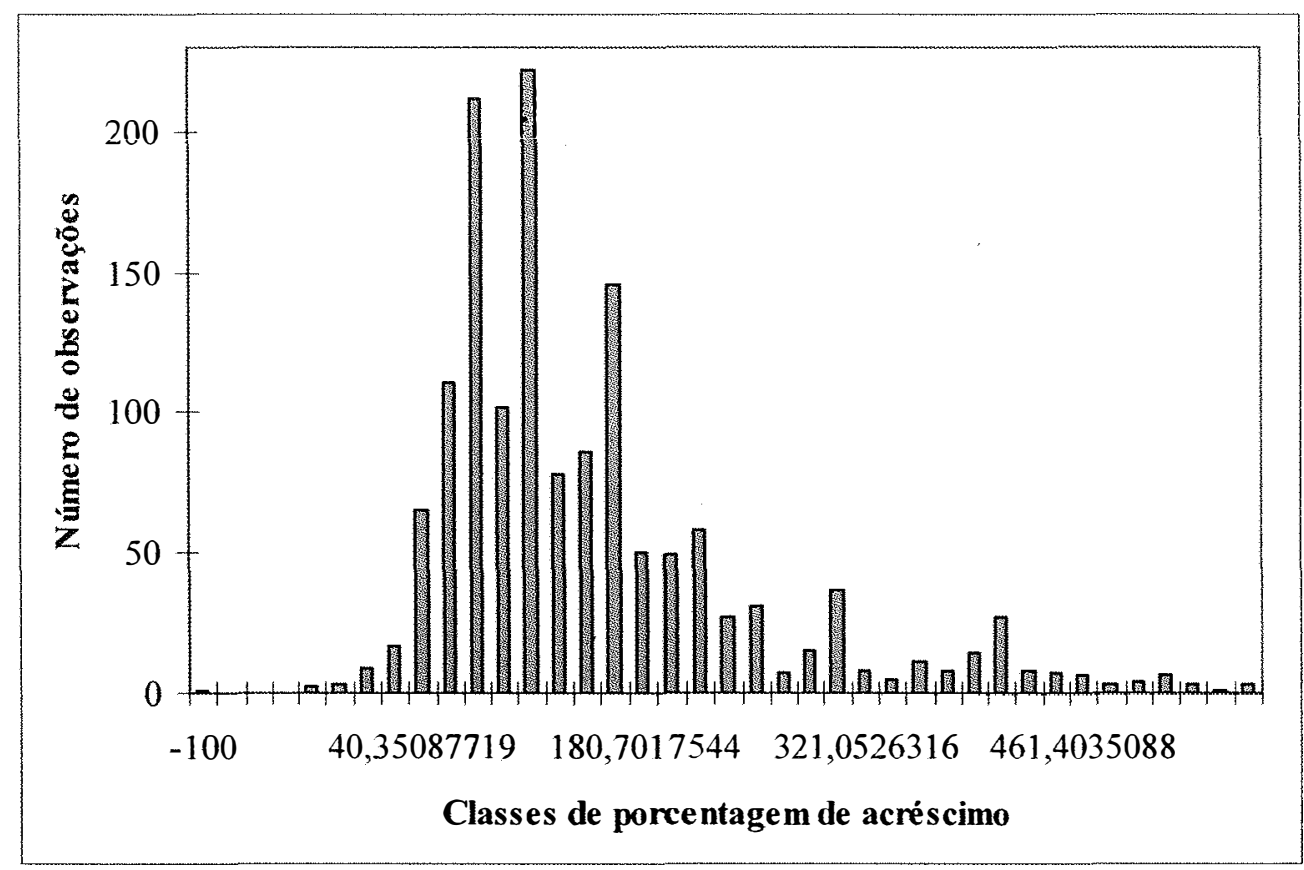

Figura 10 - Gráfico de distribuição de freqüências da porcentagem de acréscimo de produção de 2001 para 2002

Pelas Figuras 11 e 12, verifica-se que, em geral, a produção de árvores pertencentes a uma determinada classe estiveram próximas no espaço de árvores pertencentes a classes vizinhas. No entanto, em 2001 houve uma propensão das árvores mais produtivas estarem mais agrupadas e uma tendência de estarem distribuídas preferencialmente ao longo da direção NO/SE e N/S.

Ao se observar os semivariogramas representados na Figura 13, ficou comprovado que houve dependência espacial, tanto em 2001 como em 2002, e nos moldes mencionados anteriormente. Farias et al. (2003) também encontraram dependência espacial em dois pomares adultos de laranja Natal. Ainda, constatou-se que, em 2001, essa dependência se estendeu até maiores distâncias e a semivariância entre árvores mais próximas foi menor. Ou seja, em geral a produção das árvores foi mais agrupada no espaço e mais semelhante entre elas. Tal constatação pode ser visualizada com mais detalhe na Figura 14. Farias et al. (2003) também encontraram maior 


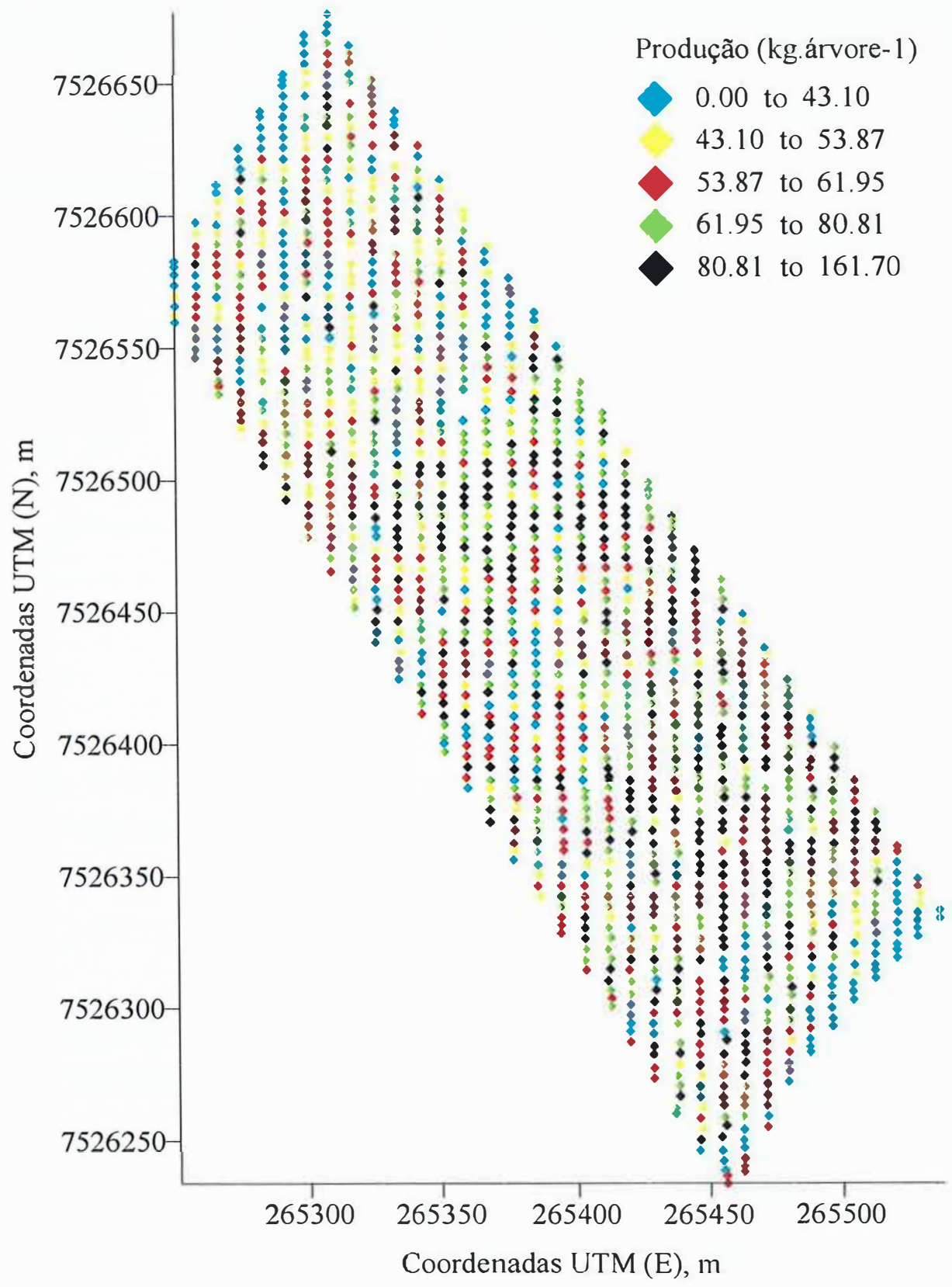

Figura 11 - Distribuição espacial dos dados de produção em 2001 de forma discreta 


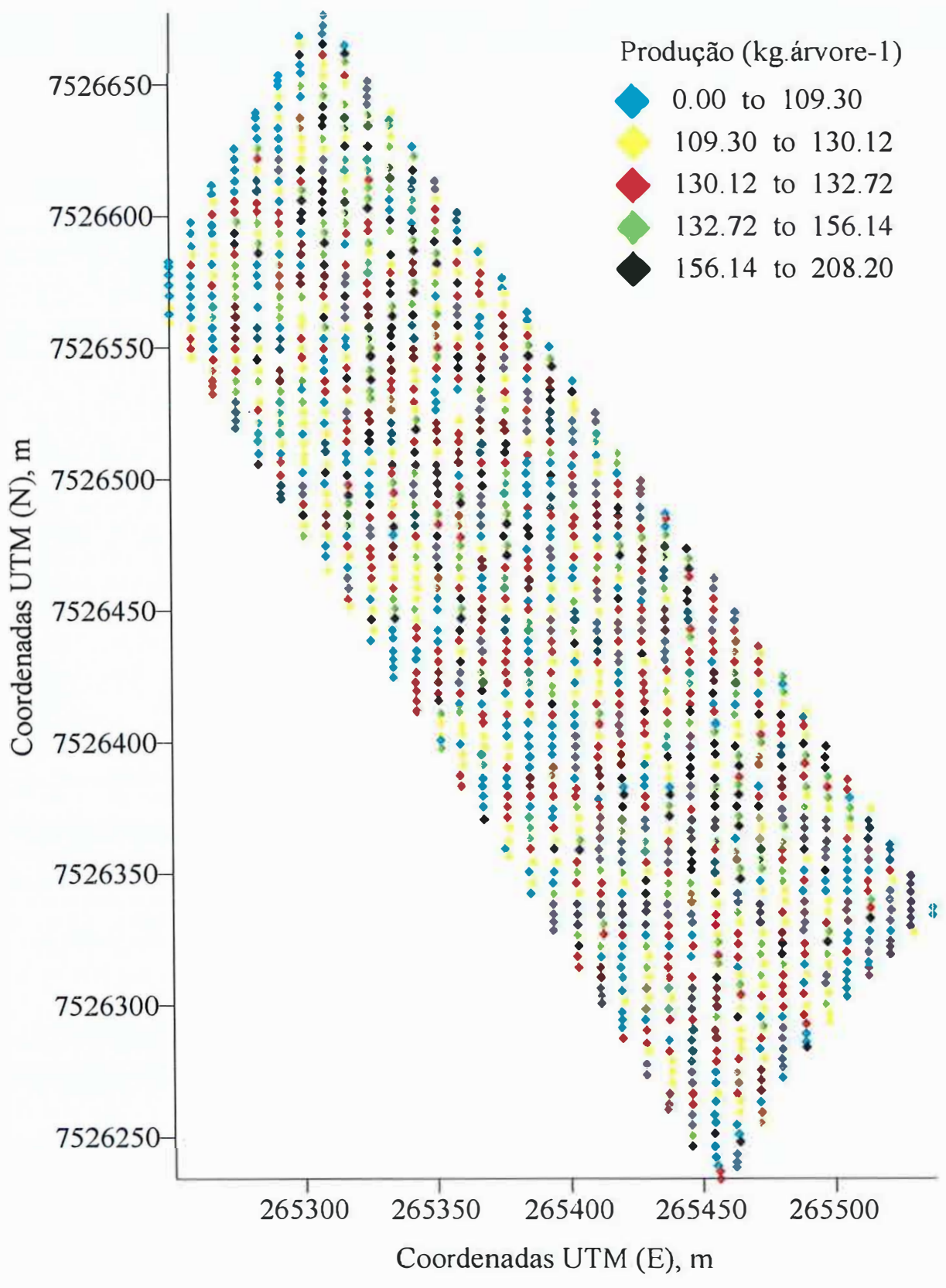

Figura 12 - Distribuição espacial dos dados de produção em 2002 de forma discreta 


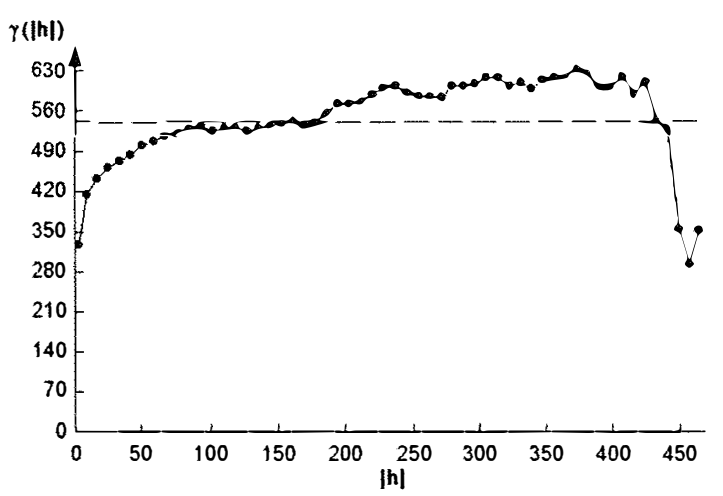

(a)

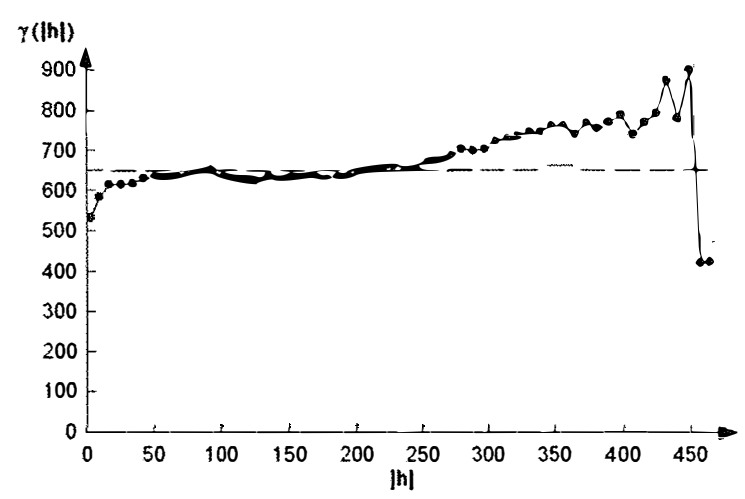

(b)

Figura 13 - Semivariogramas completos da produção em 2001 (a) e em 2002 (b)

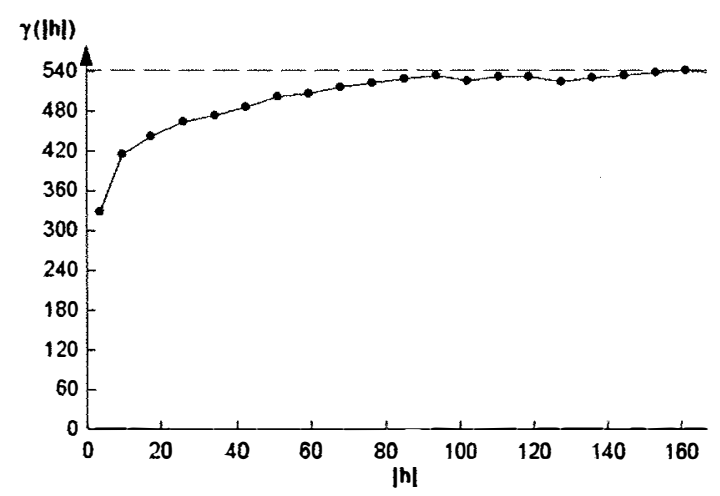

(a)

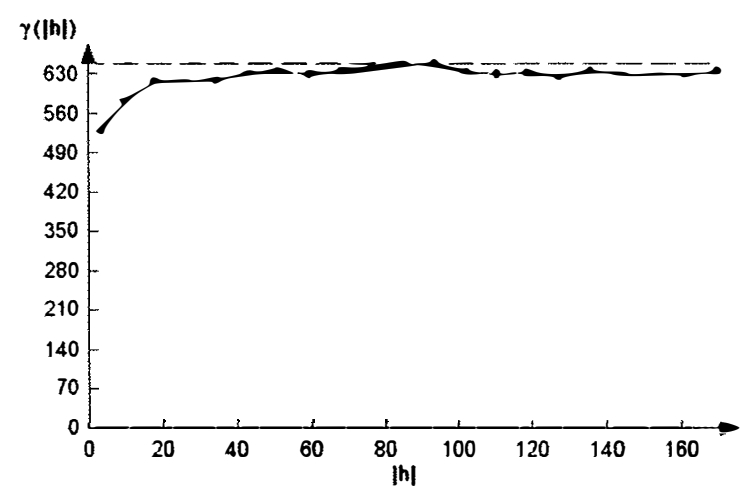

(b)

Figura 14 - Semivariogramas parciais da produção em 2001 (a) e em 2002 (b)

dependência espacial e menor semivariância entre árvores mais próximas num pomar não irrigado em comparação a um irrigado. Também Parker \& Batchelor (1932) encontraram maior correlação entre árvores vizinhas num ano em que as condições climáticas para a produção foram adversas. Eles sugeriram que a produção nesse ano foi influenciada de forma não usual por fatores que afetaram mais algumas regiões do que outras. Ao passo que Brar \& Mann (1986) não encontraram correlação entre árvores vizinhas e atribuíram essa variação árvore a árvore à alta variabilidade do solo. É interessante notar que, apesar de haver dependência espacial, as semivariâncias em 2001 à curta distância são elevadas, indicando que as produções das árvores mais próximas não foram tão semelhantes assim. Em Whitney et al. (2000), os mapas de produtividade 
em pomares citrícolas apresentaram, em sua maioria, considerável variabilidade. Os autores também atribuíram grande parte dessa variação de produtividade à variabilidade do solo.

Em 2002, a produção entre árvores próximas foi menos semelhante ainda, daí as semivariâncias maiores à curta distância em relação a 2001. É provável que o comportamento produtivo com menor coeficiente de variação em 2002 tenha realçado pequenas diferenças de produção entre árvores vizinhas. Também, é possível pensar que essa variabilidade foi mais influenciada em 2002 do que em 2001 por características intrínsecas das plantas, as quais não necessariamente apresentam uma grande dependência espacial. Para Batchelor \& Reed (1918), Brar et al. (1983) e Coelho Filho (1998), as características intrínsecas das plantas exercem papel importante em questões relacionadas à produção.

Ainda pela observação da Figura 13, verifica-se que, após uma determinada distância, as semivariâncias tenderam a subir. Tal comportamento sugere a presença de tendência nos dados. Em 2001, a causa da tendência se manifestou a uma menor distância, provavelmente ligada a fatores relacionados ao clima, como a capacidade de armazenamento de água no solo, e, também, conforme a posição das árvores em relação ao lençol freático. Em 2002, a tendência também esteve ligada a características intrínsecas do terreno, como por exemplo, fertilidade.

Ao se retirar as tendências pelo método do refinamento pelas medianas, percebe-se, pela Figura 15, que as semivariâncias tenderam a se estabilizar. No entanto, em 2001, a dependência espacial diminuiu. Afinal, o método do refinamento pelas medianas tendeu a diminuir as diferenças existentes entre as observações, a aumentar as diferenças entre observações vizinhas e, conseqüentemente, a aumentar as semivariâncias às curtas distâncias. Tal comportamento pode ser melhor visualizado na Figura 16. 


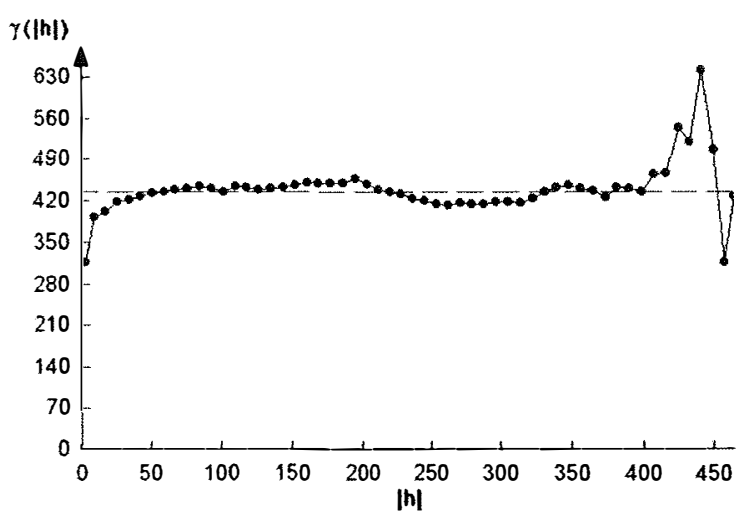

(a)

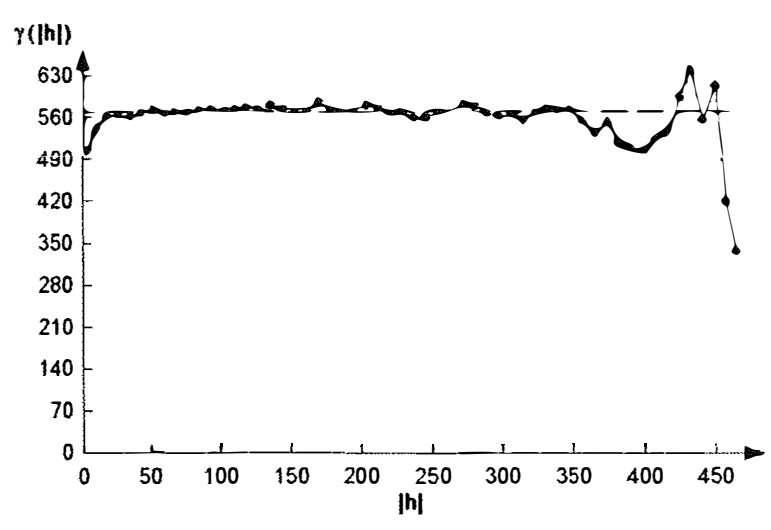

(b)

Figura 15 - Semivariogramas completos após a retirada das tendências em 2001 (a) e em 2002 (b)

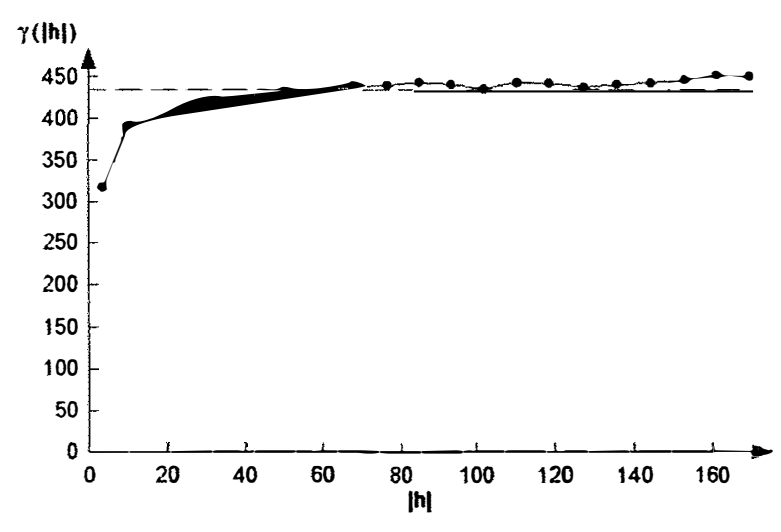

(a)

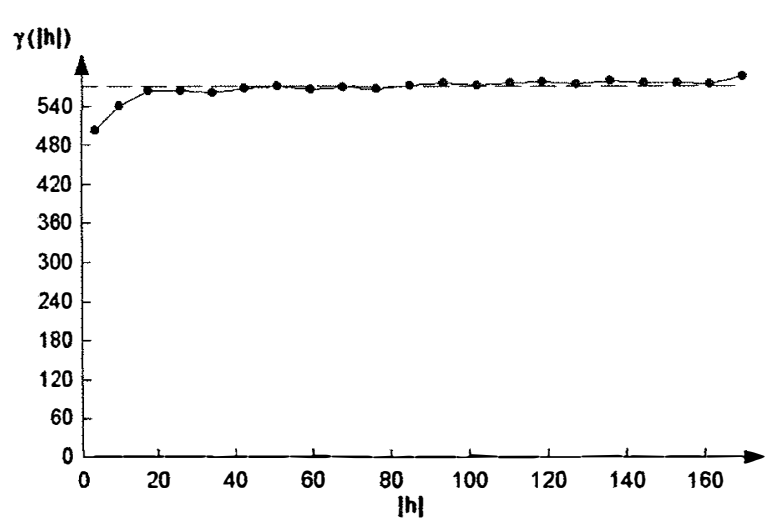

(b)

Figura 16 - Semivariogramas parciais após a retirada das tendências em 2001 (a) e em $2002(b)$

É interessante notar que, ao se retirar as tendências, os semivariogramas em 2001 e em 2002 tornaram-se mais semelhantes. Portanto, é possível inferir que as tendências encontradas em 2001 provocaram as diferenças entre os semivariogramas em 2001 e 2002. 
A idéia de que em pomares citrícolas a produção de árvores próximas foi mais semelhante é evidenciada ao se observar os mapas de classes de produção em 2001 e em 2002 obtidos pela análise de agrupamentos via lógica fuzzy. Pela observação das Figuras 17 e 18, constata-se que árvores pertencentes à mesma classe são próximas no espaço. Vale mencionar que as médias de produção das classes 1, 2, 3 e 4 em 2001 e 1, 2, 3, 4 e 5 foram, respectivamente, 25,27 kg.árvore ${ }^{-1} ; 104,53$ kg.árvore $^{-1}$; 77,67 kg.árvore ${ }^{-1}$ e 52,33 kg.árvore ${ }^{-1}$ e 180,91 kg.árvore ${ }^{-1}$; 153,76 kg.árvore ${ }^{-1}$; 129,52 kg.árvore ${ }^{-1}$; 104,30 kg.árvore ${ }^{-1}$ e 75,65 kg.árvore ${ }^{-1}$.

Tanto os mapas de classes de produção formados via lógica fuzzy, como os de produção relativa em 2001 e 2002, obtidos por interpolação dos dados de produção relativa originais via krigagem e representados nas Figuras 19 e 20 indicam a existência de continuidade espacial da produção. Ou seja, as classes de produção adjacentes em valor também o são no espaço.

Por outro lado, a representação espacial das classes de produção nos dois tipos de classificação, ou seja, via lógica fuzzy e arbitrária foi diferente, a despeito de existir algumas coincidências. A subjetividade na formação das classes via classificação arbitrária dificulta o processo de formação das classes, podendo comprometer sua confiabilidade.

Com relação ao número de classes formado pela análise de agrupamentos via lógica fuzzy, é possível inferir que em 2002 o número foi maior (cinco classes) graças a maior variância dentro das classes. Provavelmente, o comportamento produtivo com menor coeficiente de variação em 2002 pode ter realçado pequenas diferenças de produção entre as árvores. 


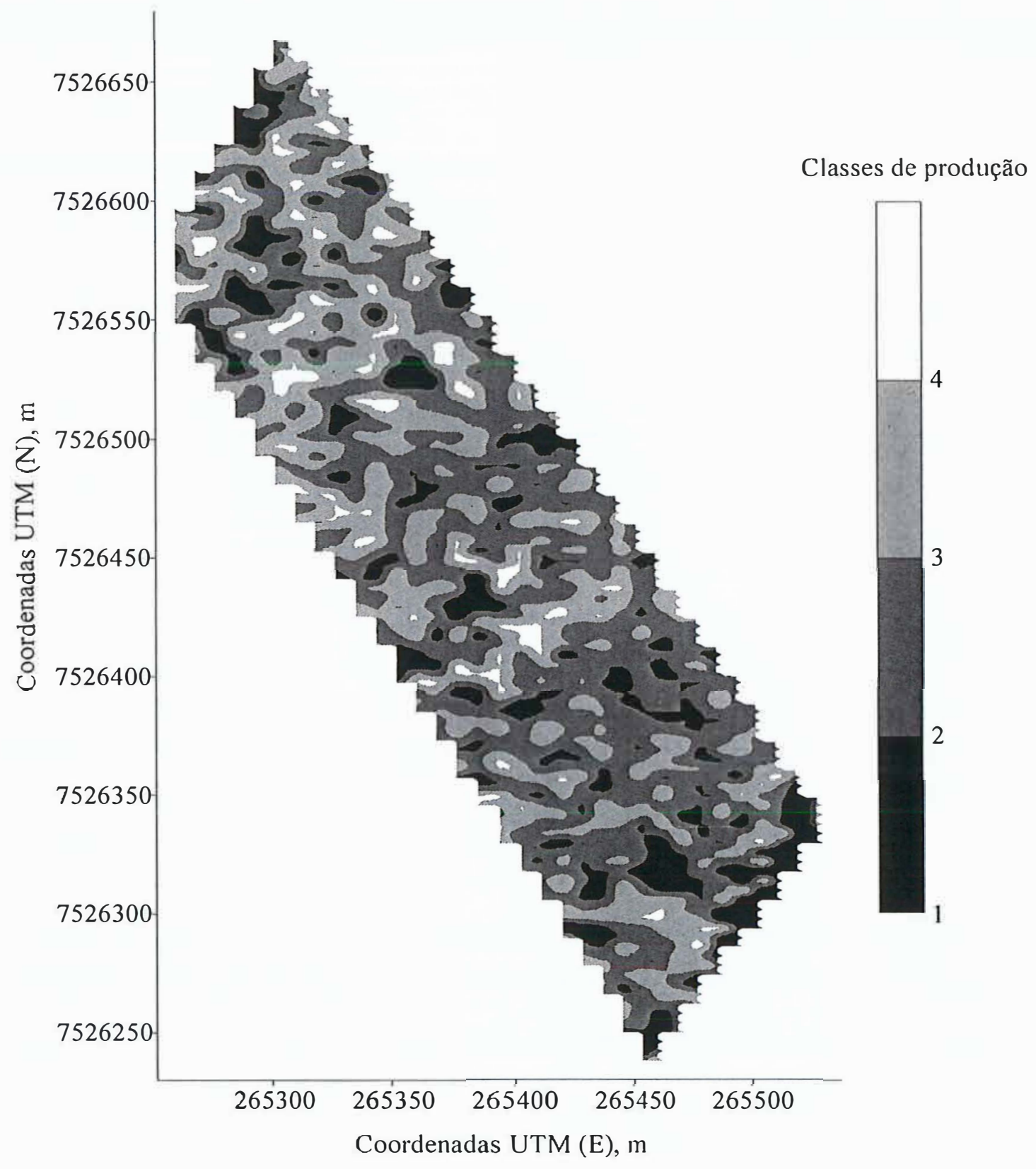

Figura 17 - Distribuição espacial das classes de produção em 2001 formadas pela análise de agrupamentos via lógica fuzzy 


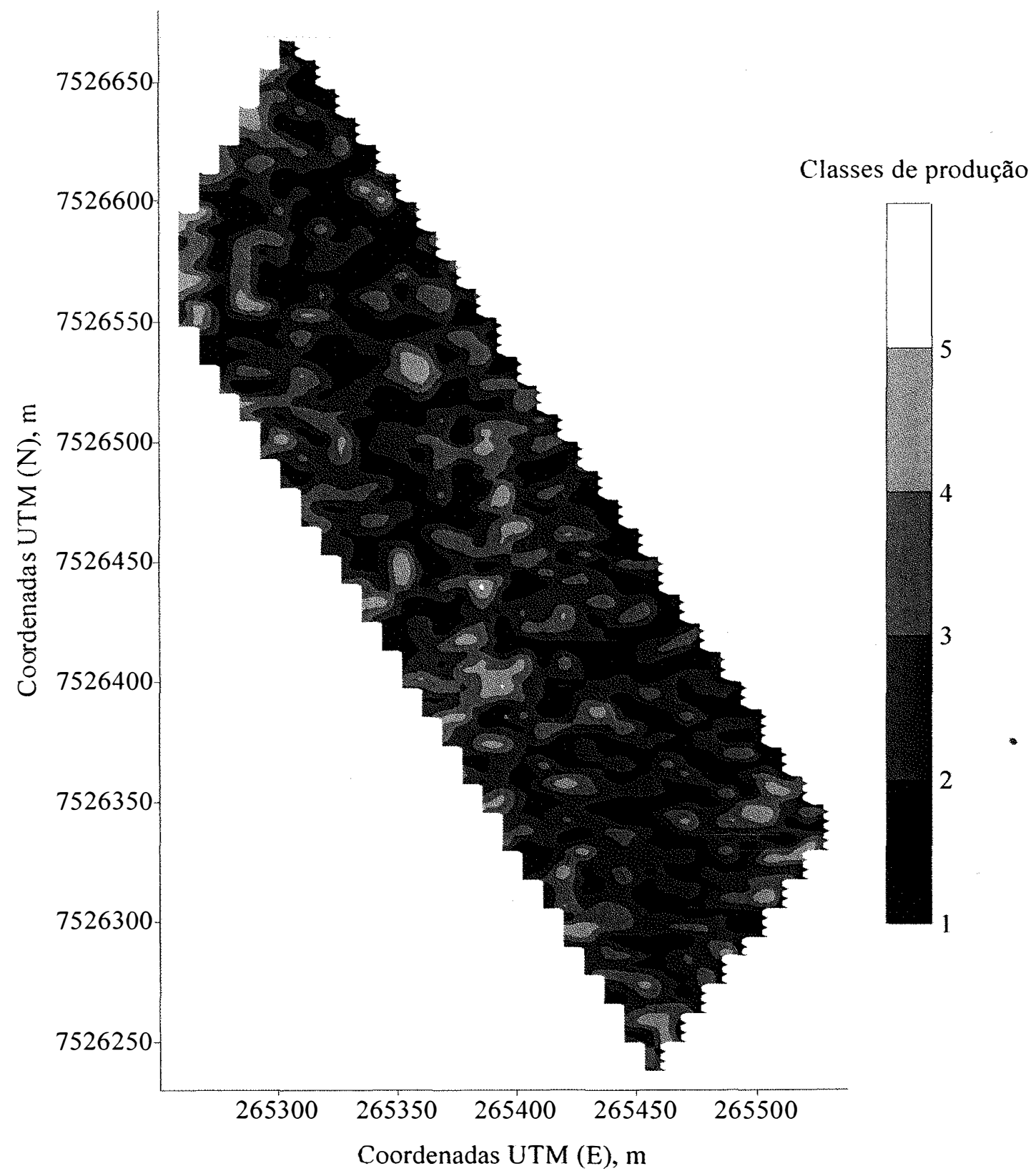

Figura 18 - Distribuição espacial das classes de produção em 2002 formadas pela análise de agrupamentos via lógica fuzzy 


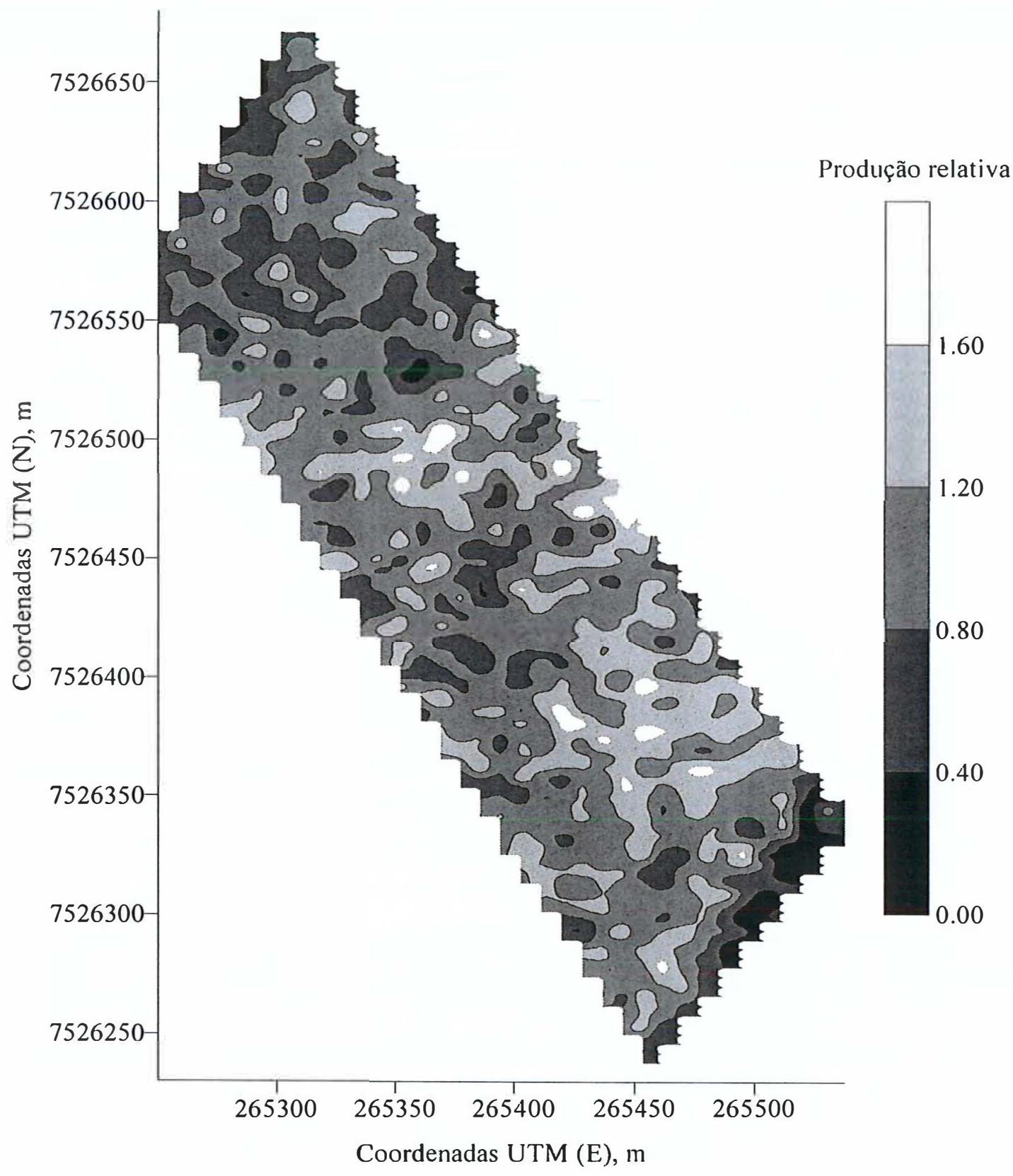

Figura 19 - Distribuição espacial das classes de produção relativa em 2001 formadas por classificação arbitrária 


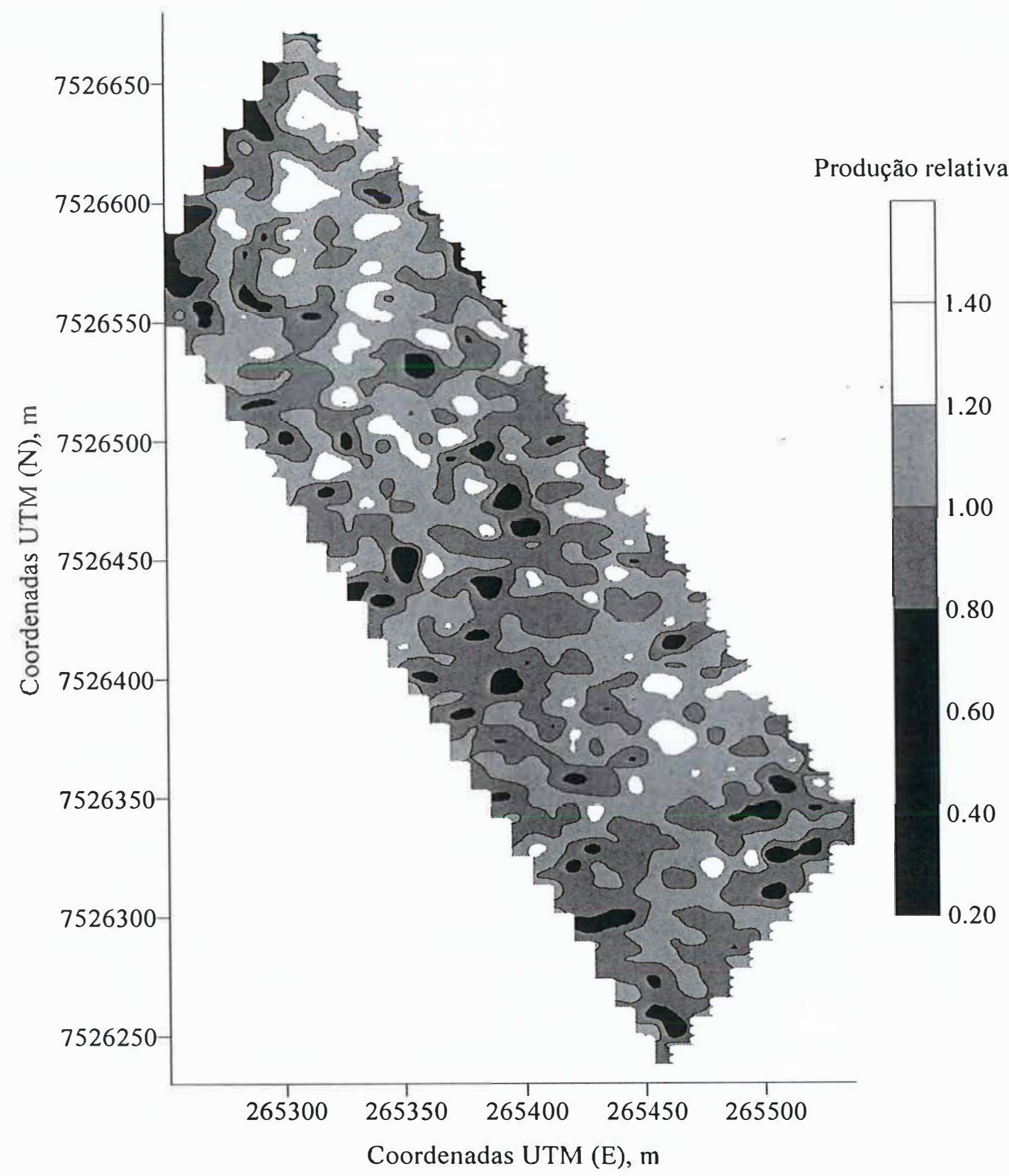

Figura 20 - Distribuição espacial das classes de produção relativa em 2002 formadas por classificação arbitrária 
A análise de agrupamentos via lógica fuzzy ainda permitiu constatar que algumas classes menos expressivas em 2001 e 2002 apresentaram pouca coerência espacial, ou seja, os grupos de árvores pertencentes a essas classes estavam mais dispersas no espaço. É bastante provável que as características intrínsecas das plantas tenham sido as maiores responsáveis por tal comportamento.

No que concerne a distribuição espacial da produção propriamente dita, em 2001, como é possível visualizar na Figura 19, houve uma tendência das classes mais produtivas se concentrarem mais da metade do pomar para direção $\mathrm{S}$ e uma boa parte das classes menos produtivas da metade para direção N. Em 2002, essa tendência não ocorreu, como é possível visualizar na Figura 20.

\subsubsection{Descrição espaço-temporal}

O estudo das variabilidades temporal e espacial permite a compreensão de alguns padrões produtivos e indicativos de outros que poderiam ser confirmados quando analisados conjuntamente. Ainda, devido à falta de repetição dos padrões de variabilidade em 2001 e 2002, também observados por Lark \& Stafford (1997) em seu estudo com culturas anuais, essas análises isoladas não seriam suficientes. Portanto, a abordagem espaço-temporal proporcionaria identificar padrões comuns, ou seja, padrões de variabilidade que poderiam se repetir.

Ao se comparar os semivariogramas padronizados de 2001 e 2002, representados na Figura 21, verifica-se que houve repetição do padrão de dependência espacial, embora ocorreram diferenças. Tal constatação pode ser melhor visualizada na Figura 21 (b). Ao se retirar as tendências, isso se evidencia ainda mais, como pode ser observado na Figura 22. Sobretudo, o semivariograma cruzado entre 2001 e 2002, representado na Figura 23, torna clara a dependência espacial da produção de árvores em $2001 \mathrm{com}$ as suas vizinhas em 2002, que é ainda melhor visualizada na Figura 23 (b). 


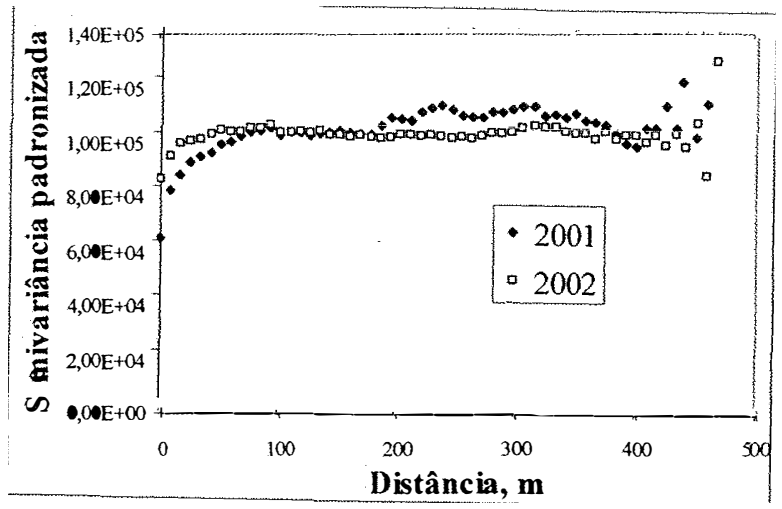

(a)

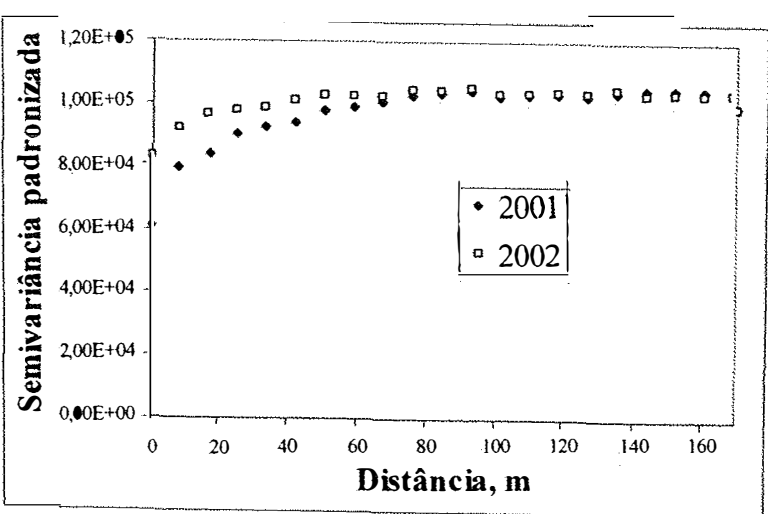

(b)

Figura 21 - Semivariogramas padronizados completos (a) e parciais (b) da produção em 2001 e 2002

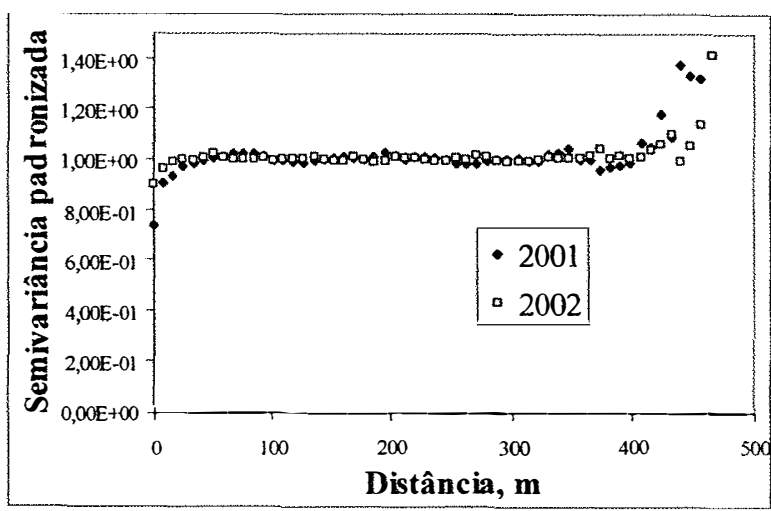

(a)

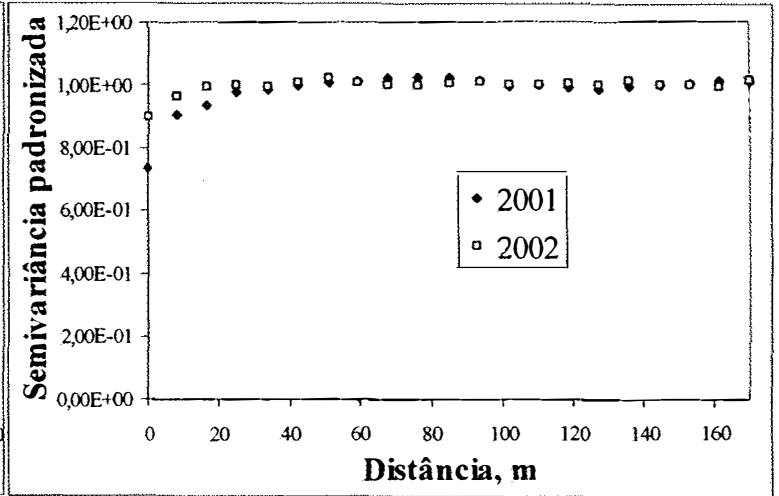

(b)

Figura 22 - Semivariogramas padronizados completos (a) e parciais (b) da produção em 2001 e 2002 após a retirada das tendências

Ao se analisar conjuntamente os dados de produção em 2001 e 2002 via lógica fuzzy, fica ainda mais evidenciada a tendência exposta acima. Pela observação das Figuras 24 a 33, constata-se que árvores pertencentes à mesma classe, ou seja, com grau de pertinência maior que 0,5 , tenderam a se agrupar no espaço. Os resultados apresentados por Lark \& Stafford (1997) e Lark (1998) também mostraram essa tendência em culturas anuais. 


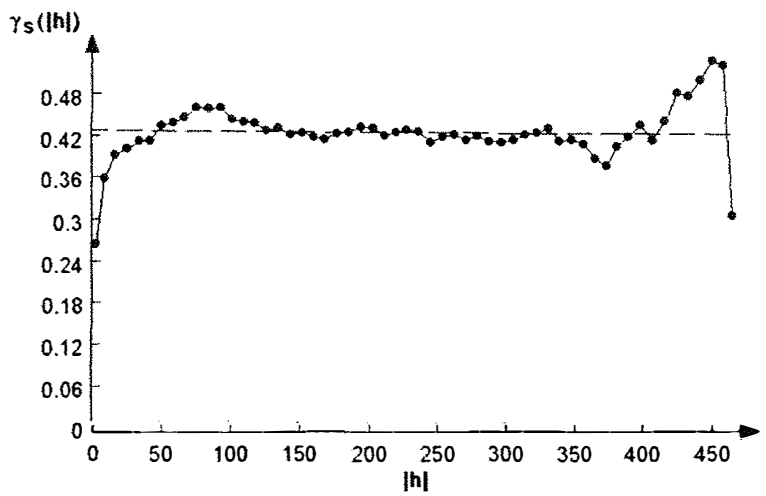

(a)

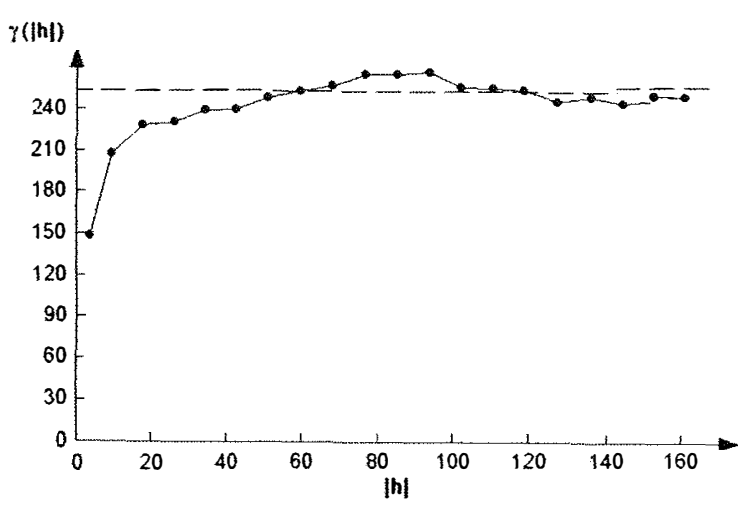

(b)

Figura 23 - Semivariogramas cruzados entre a produção em 2001 e 2002 completo (a) e parcial (b)

Com relação aos valores médios de produção relativa das 10 classes formadas pela análise de agrupamentos via lógica fuzzy em 2001 e 2002, é possível notar, pela observação da Figura 34, que por meio desse tipo de análise foi possível criar classes bem distintas de comportamento produtivo. Ademais, foi possível levantar as flutuações de produção das classes entre anos sucessivos. Cabe esclarecer ainda que o número de árvores pertencente às classes 1 a 10 foi, respectivamente, 98 árvores, 126 árvores, 267 árvores, 119 árvores, 257 árvores, 104 árvores, 161 árvores, 74 árvores, 179 árvores e 86 árvores.

A despeito das árvores pertencentes às mesmas classes tenderem a estarem agrupadas no espaço, é possível verificar ainda, pela observação das Figuras 24 a 33 que as classes de comportamento produtivo apresentaram baixa coerência espacial, muito menor que a encontrada por Lark \& Stafford (1997) e Lark (1998) em culturas anuais. Afinal, o número elevado de classes formadas e sua fragmentação não permitiriam um resultado melhor. Em Whitney et al. (1998), Whitney et al. (1999) e Whitney et al. (2000), considerando-se apenas um único ciclo de produção, as classes de produção também apresentaram menor coerência espacial do que em Lark \& Stafford (1997) e 


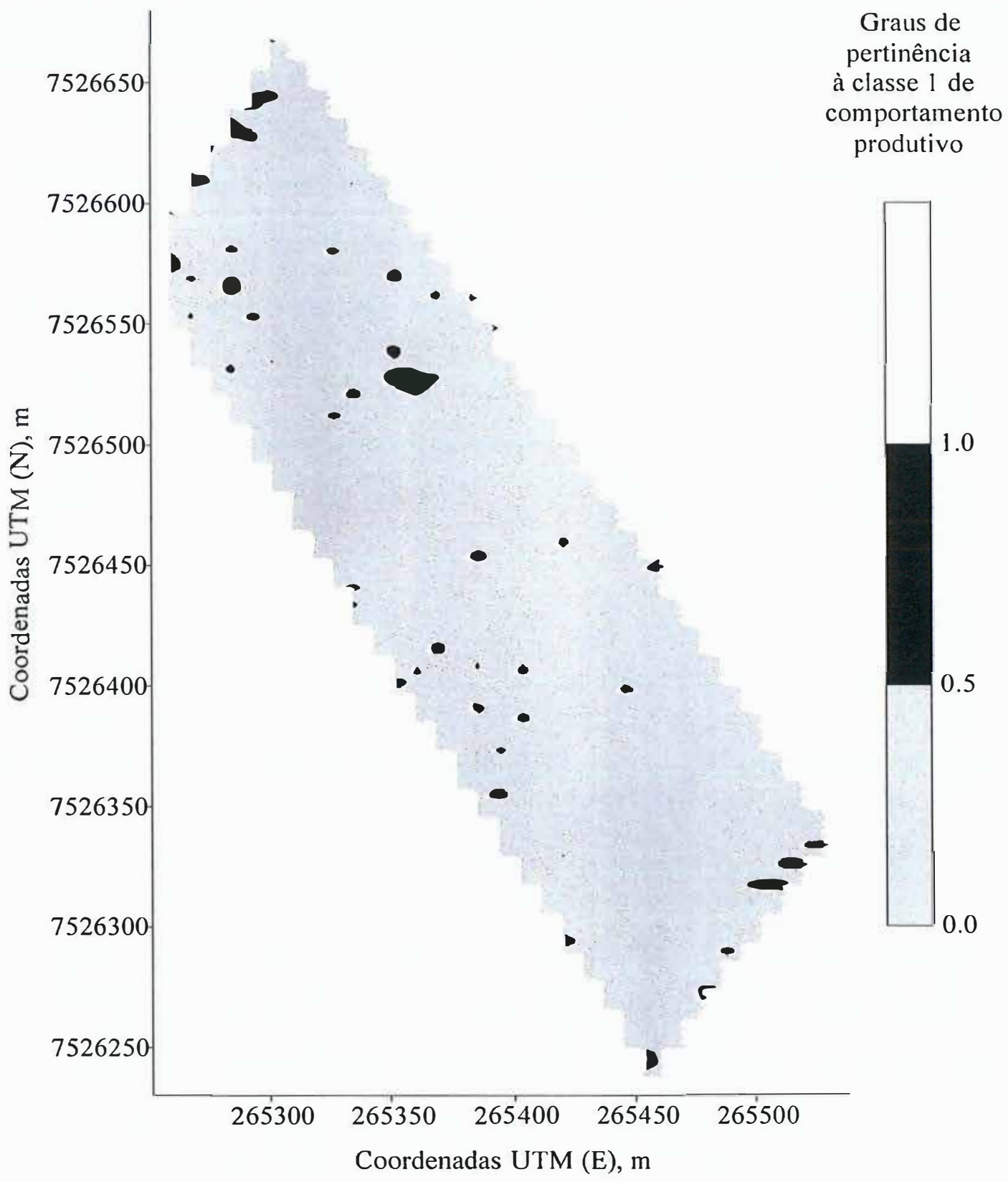

Figura 24 - Mapa de graus de pertinência à classe de comportamento produtivo 1 formada pela análise de agrupamentos via lógica fuzzy 


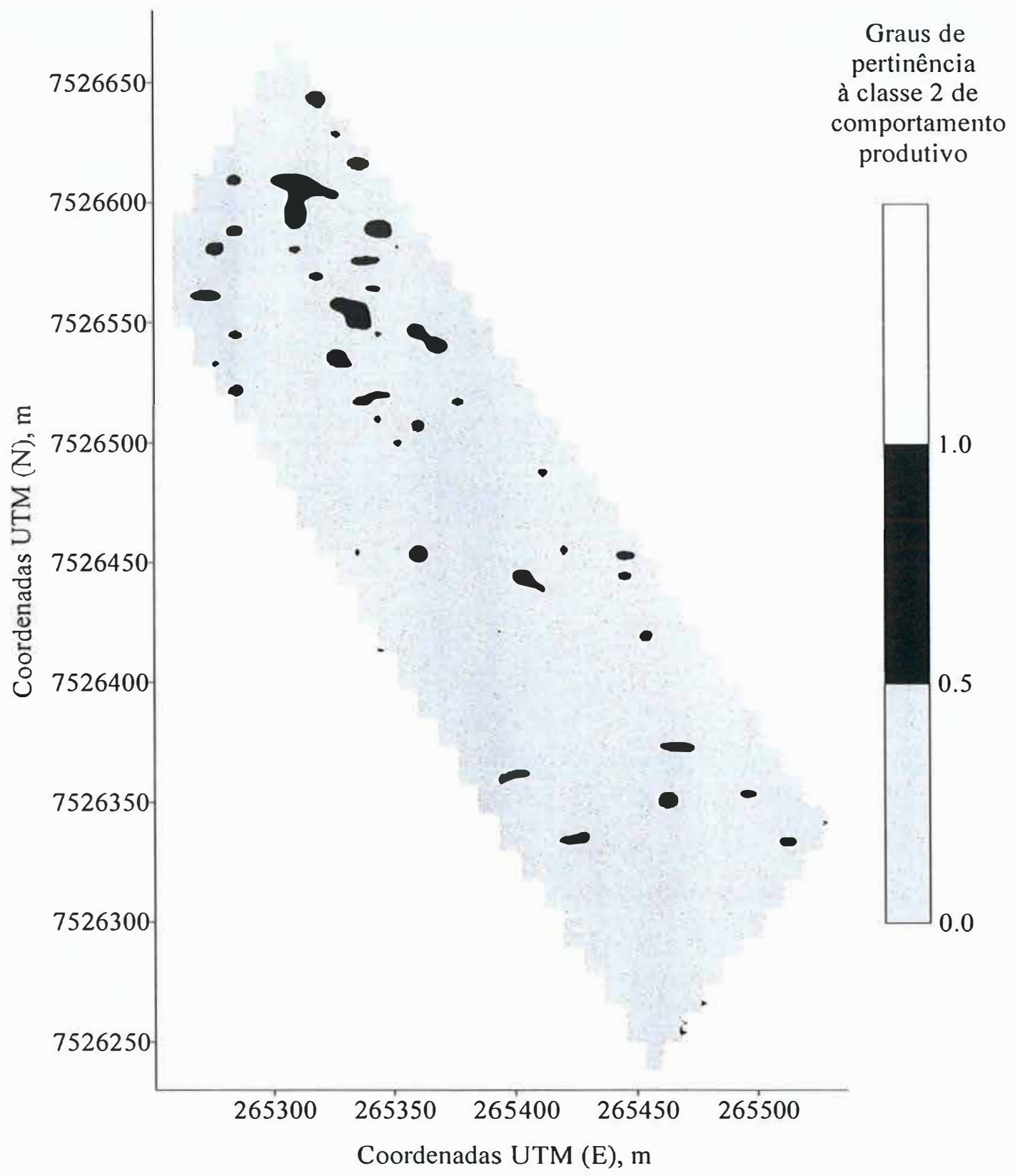

Figura 25 - Mapa de graus de pertinência à classe de comportamento produtivo 2 formada pela análise de agrupamentos via lógica fuzzy 


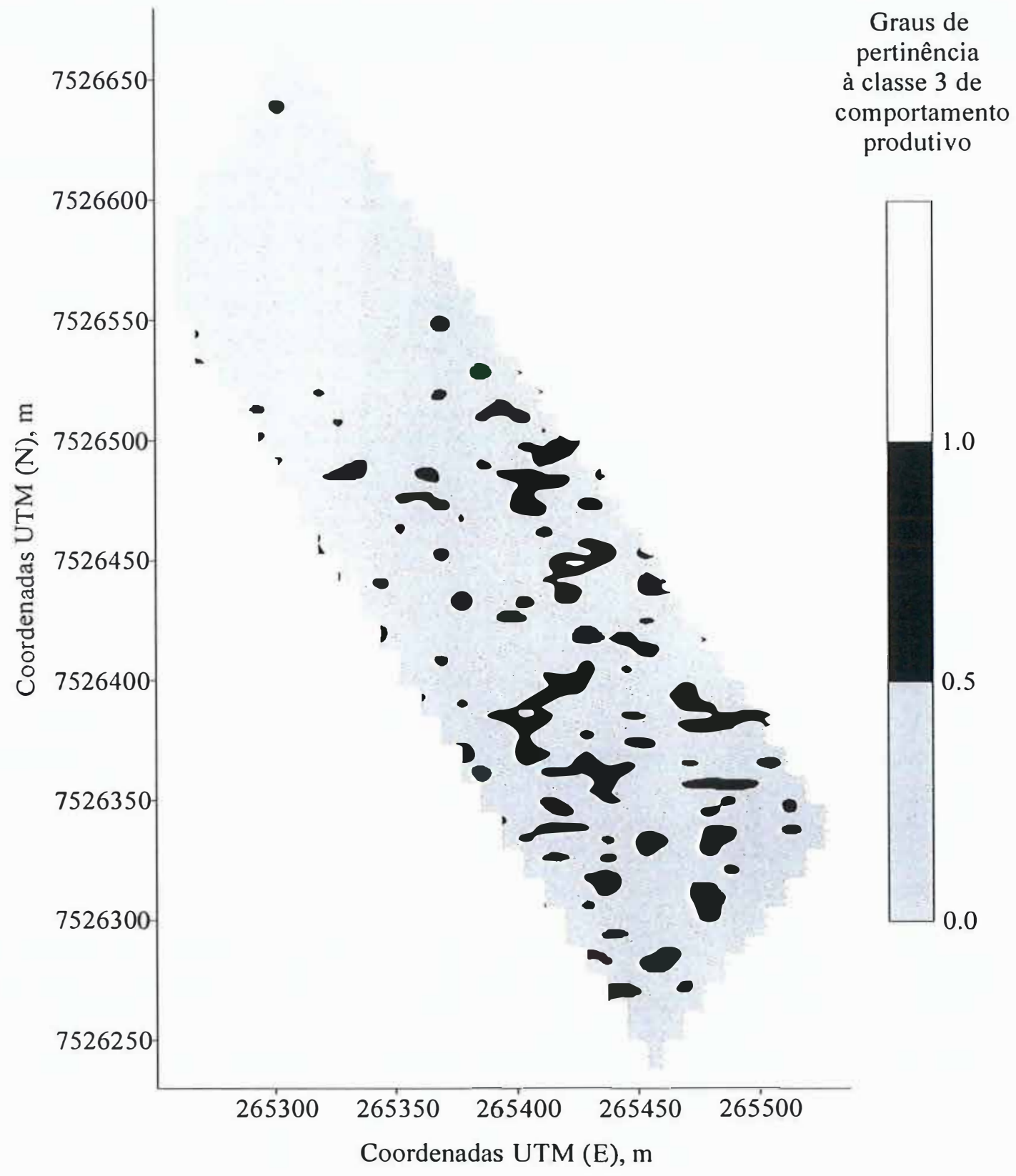

Figura 26 - Mapa de graus de pertinência à classe de comportamento produtivo 3 formada pela análise de agrupamentos via lógica fuzzy 


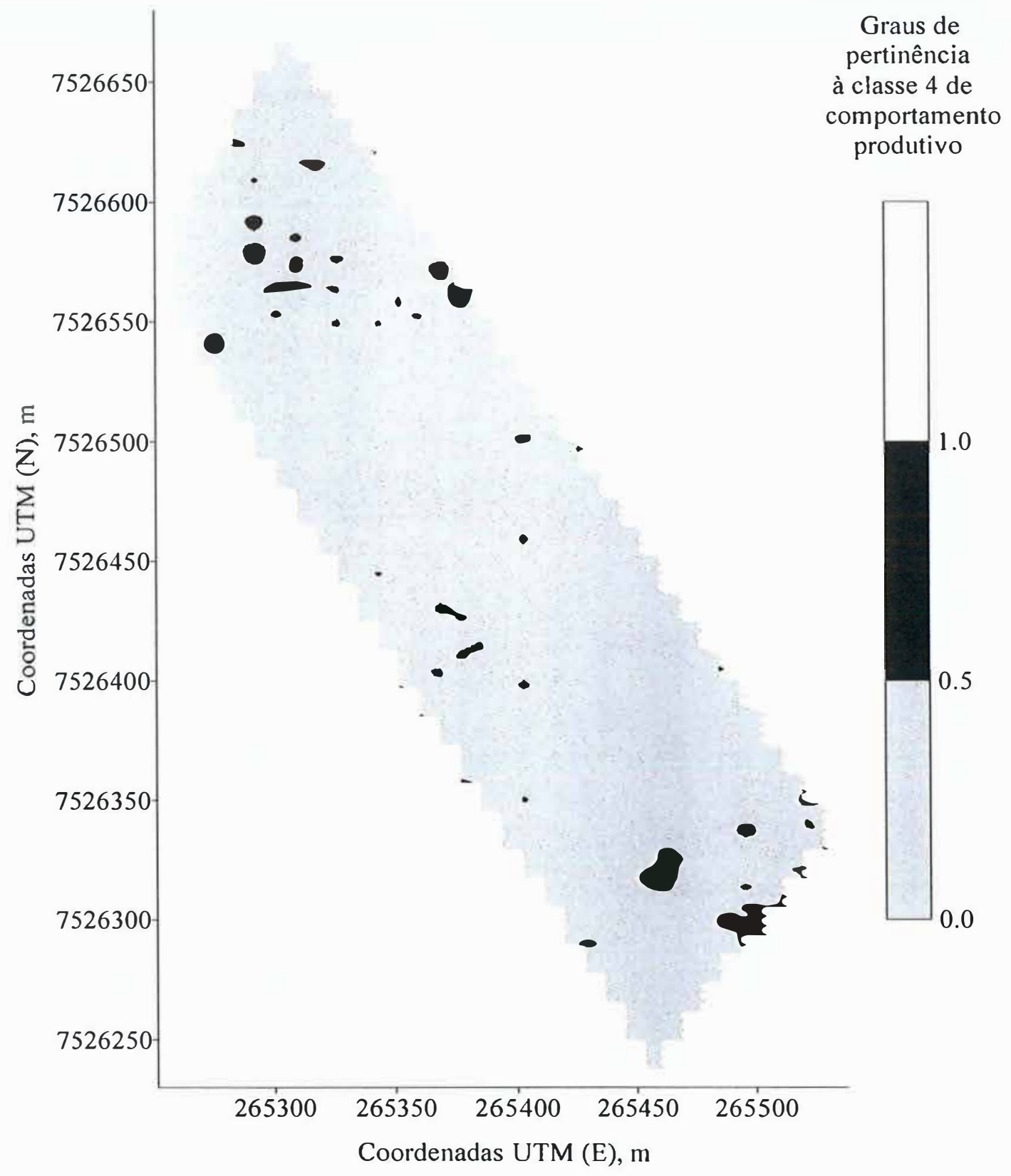

Figura 27 - Mapa de graus de pertinência à classe de comportamento produtivo 4 formada pela análise de agrupamentos via lógica fuzzy 


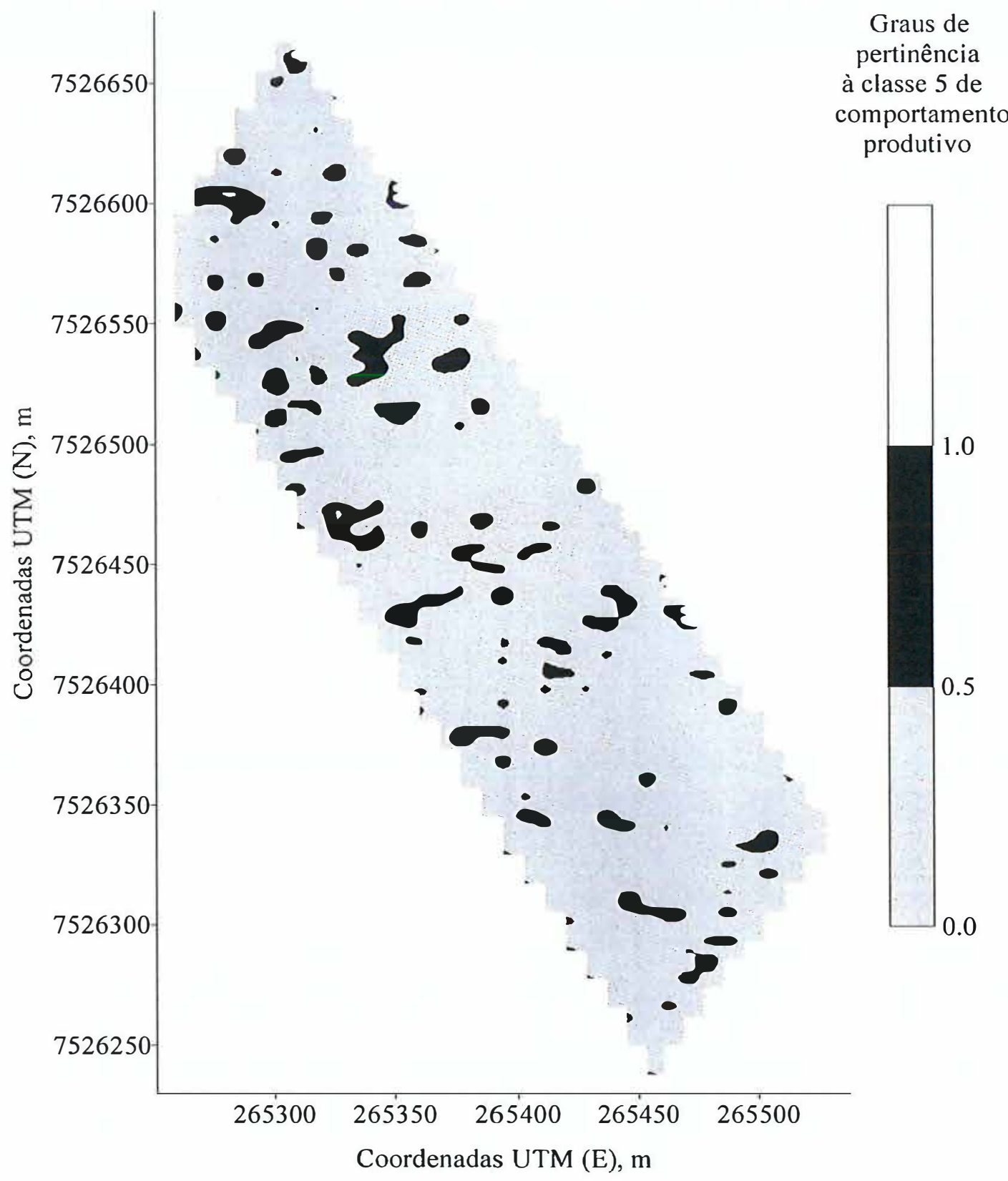

Figura 28 - Mapa de graus de pertinência à classe de comportamento produtivo 5 formada pela análise de agrupamentos via lógica fuzzy 


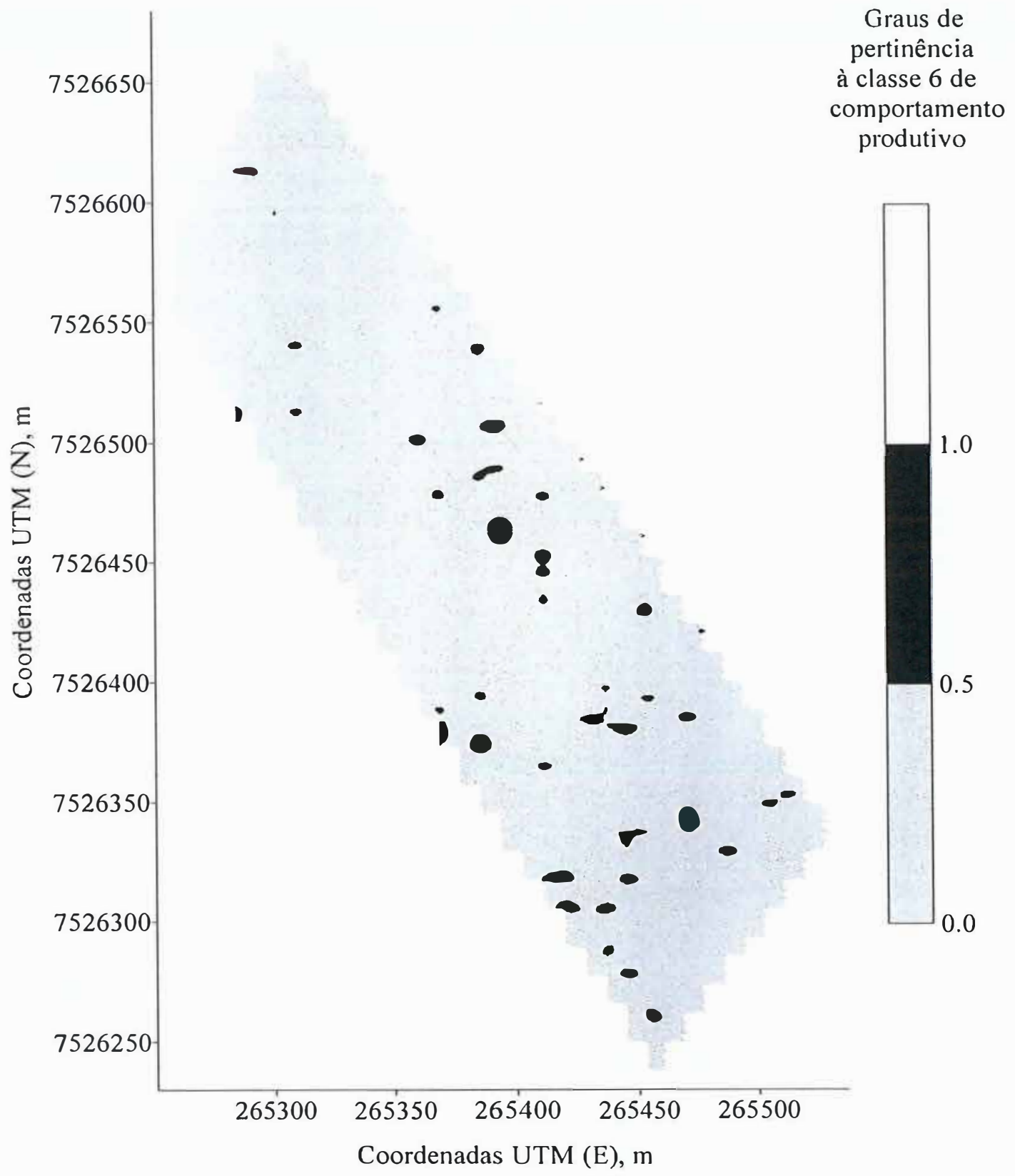

Figura 29 - Mapa de graus de pertinência à classe de comportamento produtivo 6 formada pela análise de agrupamentos via lógica fuzzy 


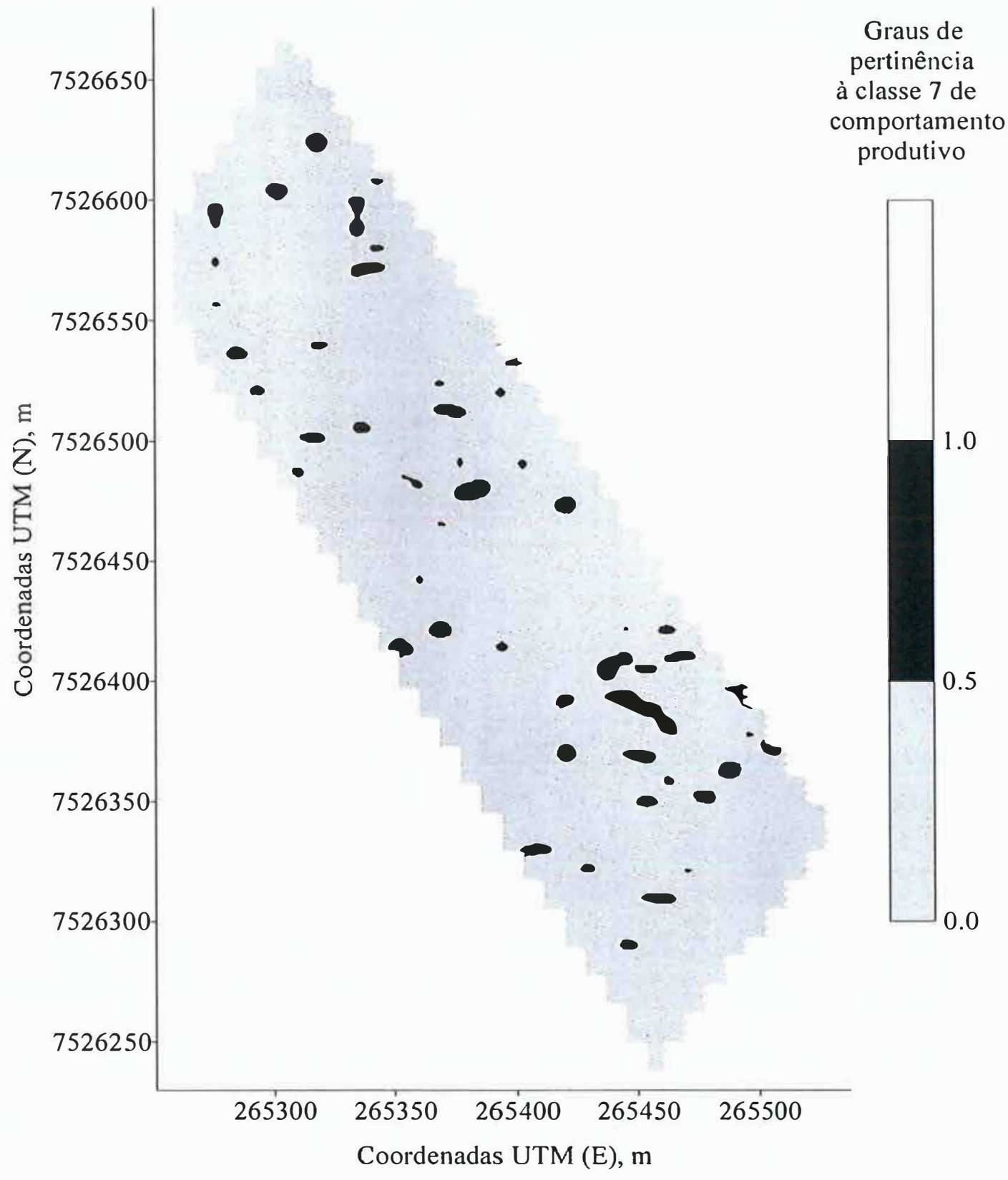

Figura 30 - Mapa de graus de pertinência à classe de comportamento produtivo 7 formada pela análise de agrupamentos via lógica fuzzy 


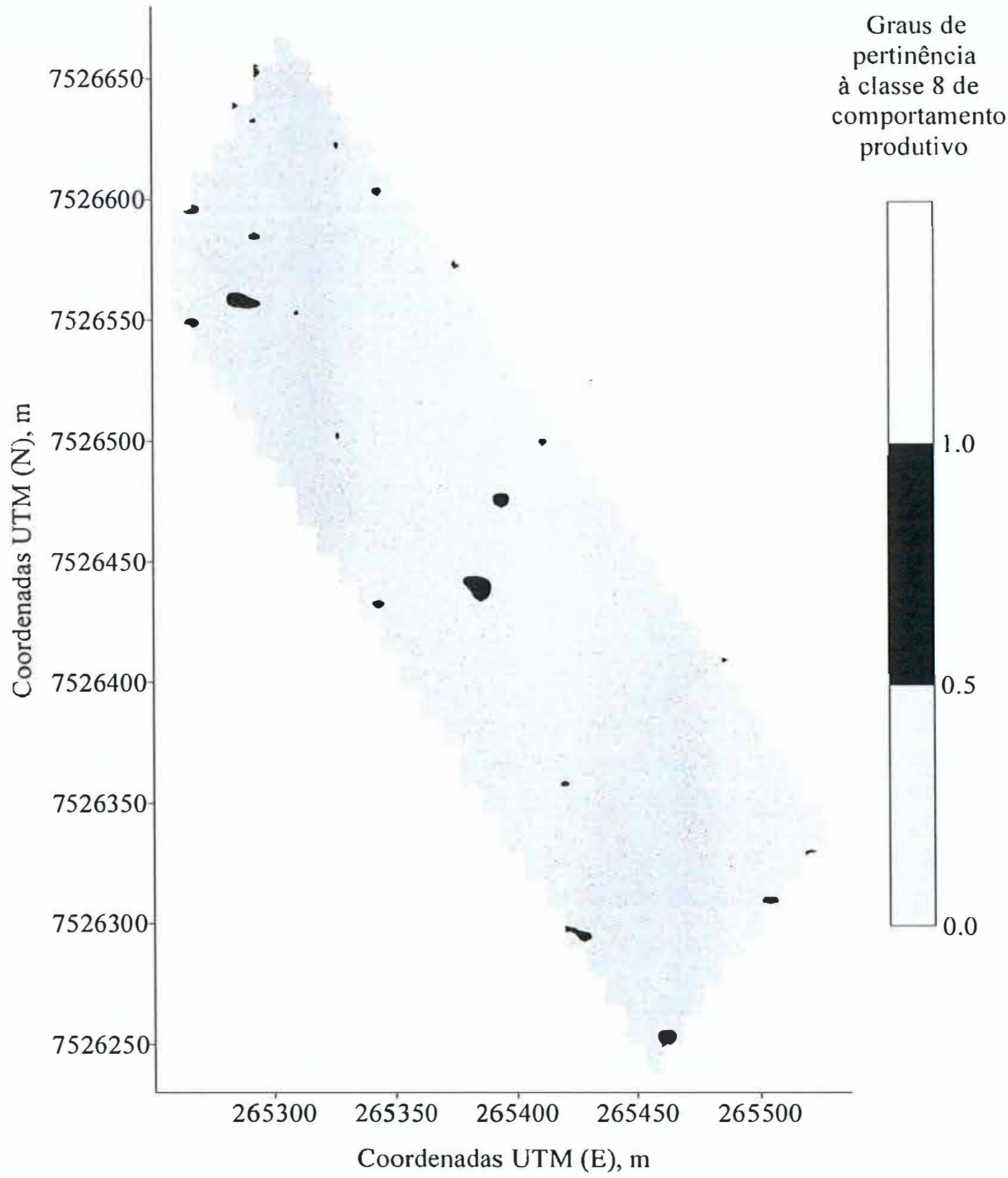

Figura 31 - Mapa de graus de pertinência à classe de comportamento produtivo 8 formada pela análise de agrupamentos via lógica fuzzy 


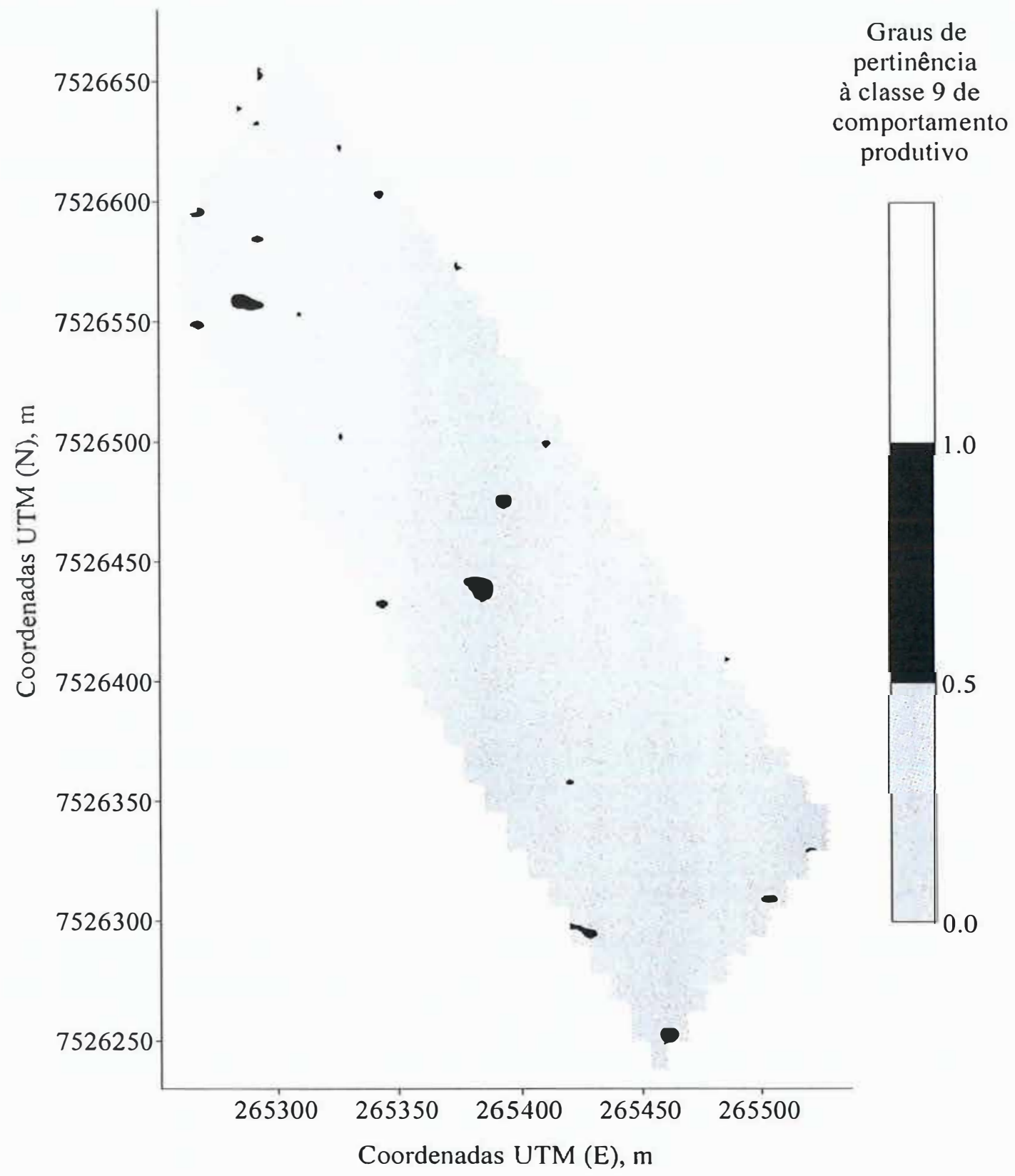

Figura 32 - Mapa de graus de pertinência à classe de comportamento produtivo 9 formada pela análise de agrupamentos via lógica fuzzy 


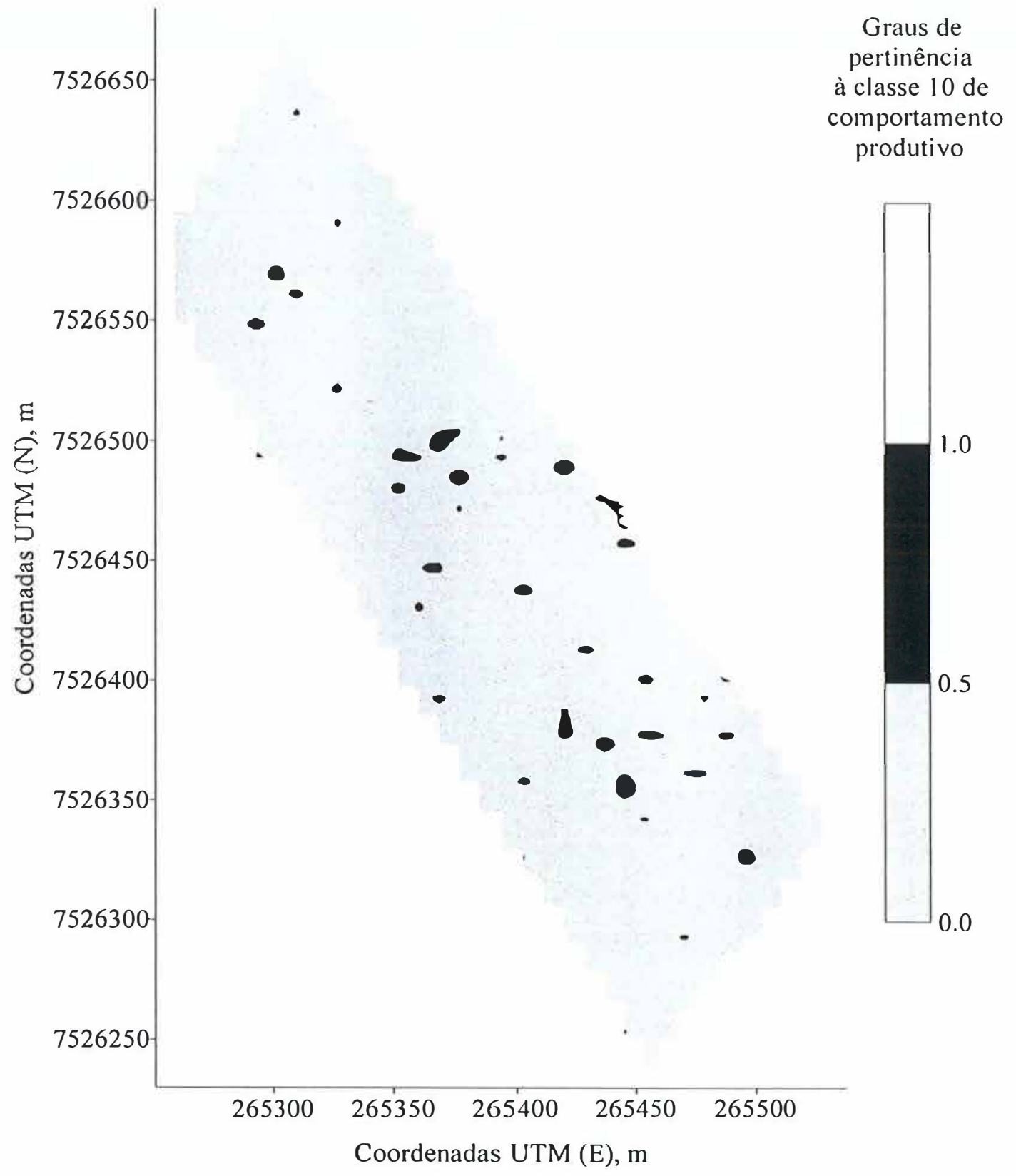

Figura 33 - Mapa de graus de pertinência à classe de comportamento produtivo 10 formada pela análise de agrupamentos via lógica fuzzy 


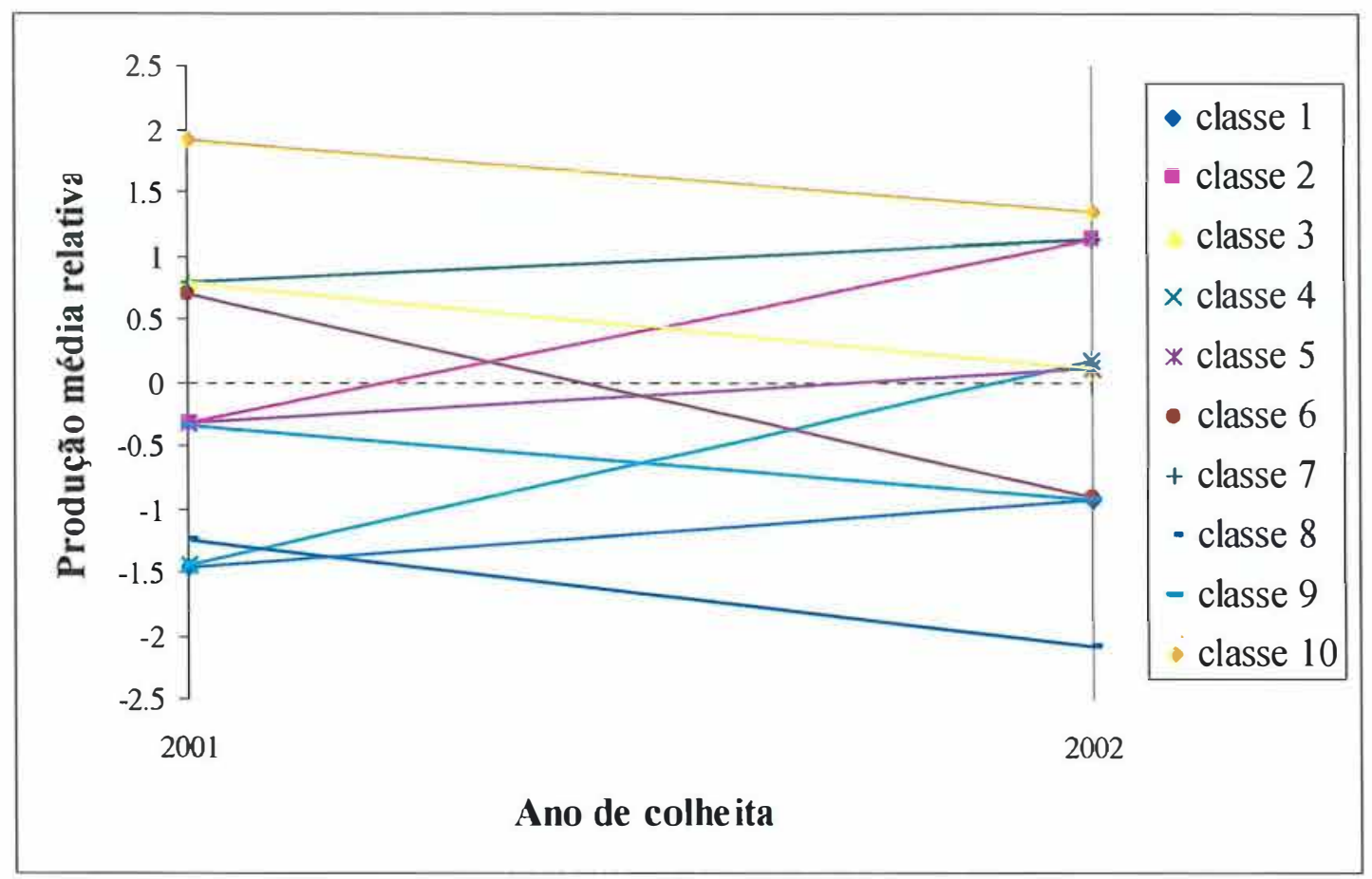

Figura 34 - Produção média relativa em 2001 e 2002 de cada classe de comportamento produtivo formada pela análise de agrupamentos via lógica fuzzy

Lark (1998). Whitney et al. (2000), face à considerável variabilidade encontrada nos mapas de produtividade, concluíram que ainda não existia uma solução óbvia para lidar com essa variabilidade em pomares citrícolas.

Também, ao se analisar conjuntamente os dados de produção em 2001 e 2002 conforme metodologia semelhante à proposta por Blackmore (2003), se encontrou dependência espacial entre as árvores e baixa coerência espacial (Figura 35). No entanto, como era esperado, a distribuição espacial representada nesse mapa, em geral, não coincidiu com a representada nos mapas de graus de pertinência às 10 classes formadas pela análise de agrupamentos via lógica fuzzy. Cabe comentar que a separação das classes de variância temporal foi dificultada pela arbitrariedade do método. 
No presente estudo, foi possível também observar que a resposta espectral explicou em boa parte a formação das classes de comportamento produtivo. Afinal, os valores de coeficiente de correlação intraclasse obtidos para resposta espectral e representados na Tabela 2 evidenciaram que a resposta espectral esteve significativamente relacionada às classes formadas pela análise de agrupamentos via lógica fuzzy, em pelo menos um tipo de imagem. Vale comentar que os valores negativos significam variâncias dentro das classes maiores que entre classes, portanto contrários aos resultados esperados de uma análise de correlação intraclasse. Whitney et al. (1999), ao investigar as potencialidades do gerenciamento localizado da produção em pomares citrícolas, concluíram que os primeiros mapas de produtividade obtidos em sua pesquisa mostraram que a variação da produtividade tendia a estar correlacionada ao tamanho de copa das árvores, estimado a partir da resposta espectral de fotografias aéreas.

Tabela 2. Valores de coeficiente de correlação intraclasse para resposta espectral

\begin{tabular}{ccccccccc}
\hline tipo de & \multicolumn{2}{c}{ vôo1 a } & \multicolumn{2}{c}{ vôo1 $\mathrm{b}$} & \multicolumn{3}{c}{ vôo 2} & \multicolumn{3}{c}{ vôo 3 } \\
imagem & somatório & 10 & somatório & 10 & somatório & 10 & somatório & 10 \\
\hline infravermelho & 0,19 & 0,42 & $-0,28$ & 0,34 & 0,31 & 0,31 & 0,06 & $-0,01$ \\
NDVI & 0,15 & $-0,06$ & 0,23 & 0,21 & 0,32 & 0,48 & 0,19 & 0,04 \\
SAVI & 0,14 & $-0,13$ & 0,15 & 0,21 & 0,13 & 0,24 & 0,17 & 0,05 \\
vermelho & 0,19 & $-0,07$ & $-0,33$ & 0,06 & 0,19 & $-0,08$ & 0,25 & 0,00 \\
\hline
\end{tabular}

Já em Lark \& Stafford (1997), foi a capacidade de armazenamento de água no solo que explicou em boa parte a formação das classes de comportamento produtivo. Esses autores encontraram coeficientes de correlação intraclasse para capacidade de armazenamento de água no solo de 0,35 em uma profundidade de solo e de 0,36 em outra. Provavelmente, a maior coerência espacial encontrada em Lark \& Stafford (1997) poderia ter sido atribuída à relação significativa entre as classes de comportamento produtivo e a capacidade de armazenamento de água no solo, cuja distribuição tende a ser mais coerente no espaço. 


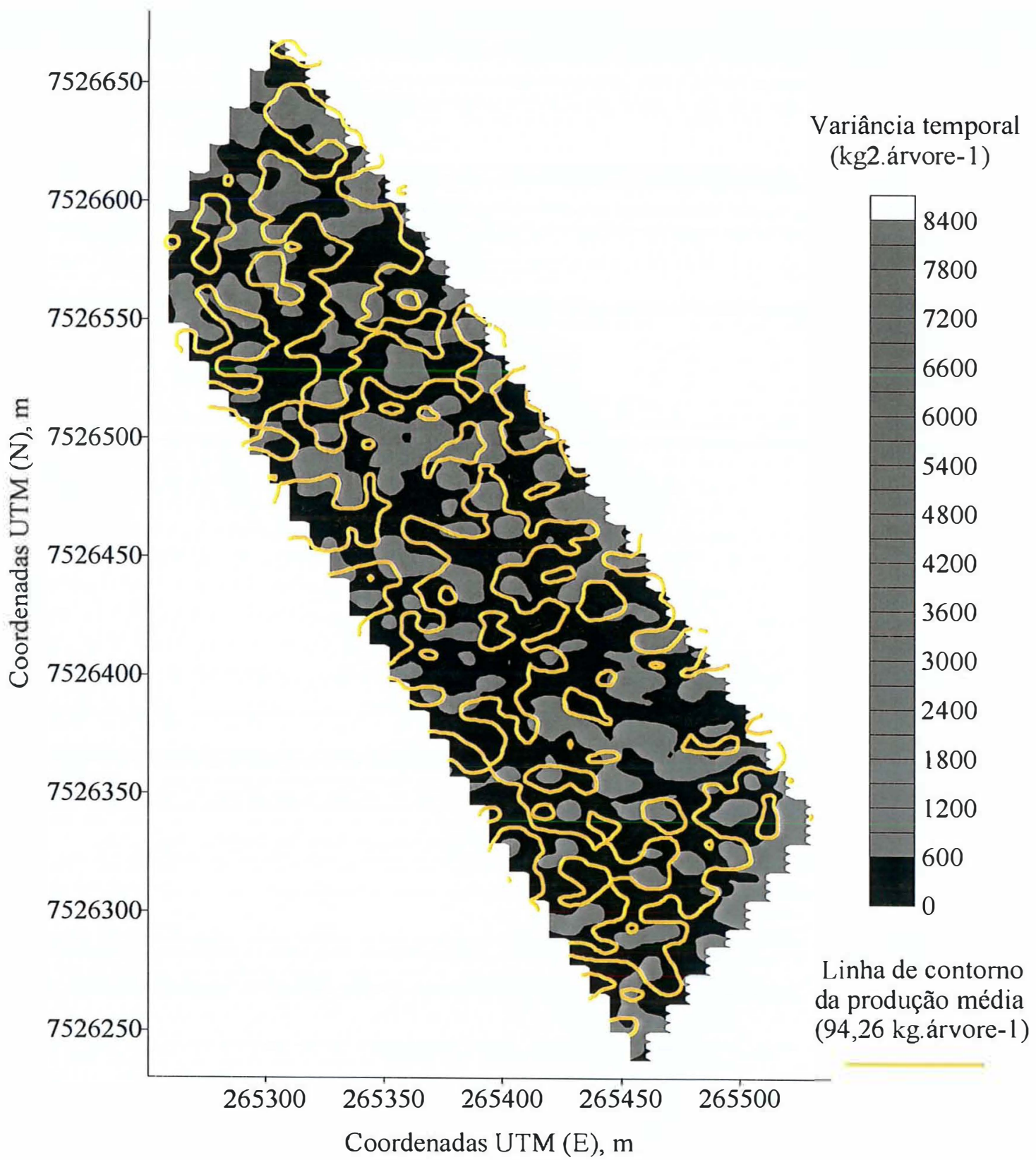

Figura 35 - Linha de contorno da produção média sobreposta às classes de variância temporal 
Existe a possibilidade de que as classes de comportamento produtivo se mantenham ao longo do tempo, pelo menos em parte, o que permitiria utilizá-las para prever aproximadamente o comportamento produtivo das árvores em ciclos de produção futuros. Afinal, a resposta espectral das árvores do vôo 1 a esteve altamente correlacionada com a do vôo 2. O coeficiente de correlação de Pearson foi de 0,73 para as imagens NDVI. Vale comentar que, na época do vôo 1 a, as árvores ainda não haviam passado pela fase de desenvolvimento vegetativo, ao passo que, na época do vôo 2 , essa fase fenológica já havia sido completada. Mataa \& Tominaga (1998) constataram que as árvores com maior ou menor desenvolvimento vegetativo, no primeiro ciclo produtivo, mantiveram esse mesmo comportamento no ciclo seguinte.

\subsection{Estudo das relações entre parâmetros de copa e produção}

Nas Tabelas 3 e 4, encontram-se os parâmetros de copa em 2001 que apresentaram maior relação com a produção em 2002. Cabe mencionar que as relações entre os parâmetros de copa em 2001 e a produção em 2001 e entre os parâmetros de copa em 2002 e a produção em 2002 foram altamente não significativas. Possivelmente, as condições climáticas desfavoráveis à produção em 2001 e problemas de determinação de parâmetros de copa em 2002 comprometeram melhores relações. Pela Tabela 3, constata-se que os parâmetros de copa em 2001 apresentaram baixos valores de $\mathrm{r}^{2}$ com a produção em 2002. É pertinente comentar que as condições climáticas para a produção em 2002 foram favoráveis, portanto, era de se esperar valores de $r^{2}$ mais elevados. Afinal, as árvores com maior área foliar poderiam expressar seu maior potencial produtivo. Porém, as diferenças de área foliar entre as árvores em 2001 não corresponderam mais plenamente às diferenças de produção em 2002. Conforme Mataa \& Tominaga (1998), árvores jovens de tangerina Ponkan, com maior capacidade produtiva, apresentaram um menor desenvolvimento vegetativo. Portanto, não necessariamente, árvores mais produtivas são maiores. Mas, e média, no estudo de Mataa \& Tominaga (1998), as árvores maiores produziram mais que as menores com a 
média, no estudo de Mataa \& Tominaga (1998), as árvores maiores produziram mais que as menores com a mesma capacidade produtiva. Além disso, as diferenças de produção entre árvores mais e menos produtivas diminuíram de um ciclo para o outro.

Tabela 3. Resumo das regressões entre parâmetros de copa de 2001 e a produção de 2002 (2 quadrantes)

\begin{tabular}{ccccccc}
\hline Pârametros de copa & \multicolumn{4}{c}{ 2 quadrantes } \\
& função & equação & $\mathrm{r}^{2}$ & erro padrão valor de p_ \\
\hline $\begin{array}{cccccc}\text { área de projeção de copa } \\
\text { densidade foliar }\end{array}$ & linear & $\mathrm{y}=0,0179 \mathrm{x}+4,5587$ & 0,09 & 26,25 & 0,031 \\
DLLAI & linear & $\mathrm{y}=0,014 \mathrm{x}+4,5418$ & 0,13 & 25,74 & 0,011 \\
área foliar & logarítmica & $\mathrm{y}=0,3184 \operatorname{Ln}(\mathrm{x})+3,8112$ & 0,08 & 26,39 & 0,042 \\
altura & potencial & $\mathrm{y}=2,576 \mathrm{x}^{0,69}$ & 0,09 & 0,22 & 0,030 \\
\hline
\end{tabular}

Tabela 4. Resumo das regressões entre parâmetros de copa de 2001 e a produção de 2002 (4 quadrantes)

\begin{tabular}{ccccccc}
\multicolumn{2}{c}{ Pârametros de copa } & \multicolumn{3}{c}{4 quadrantes } & & \\
& função & equação & $\mathrm{r}^{2}$ & erro padrão & valor de $\mathrm{p}$ \\
\hline área de projeção de copa exponencial & $\mathrm{y}=3,2538 \mathrm{e}^{0,1029 \mathrm{x}}$ & 0,11 & 0,22 & 0,019 \\
área foliar & linear & $\mathrm{y}=0,0414 \mathrm{x}+3,962$ & 0,10 & 26,18 & 0,027 \\
altura & potencial & $\mathrm{y}=2,6838 \mathrm{x}^{0,7735}$ & 0,11 & 0,22 & 0,015 \\
\hline
\end{tabular}

Para Di Giorgi et al. (1991), assim como para Martins (2000), o clima tem influência marcante na produção. Entretanto, conforme os autores citados, a explicação da produtividade somente pelos fatores hídricos e térmicos apresenta limitações, afinal os processos de florescimento e frutificação não estão somente relacionados a esses fatores.

Segundo Martins (2000), o estado fitossanitário das plantas, com certeza, é outro fator também relacionado aos processos de florescimento e frutificação. Ainda um fator adicional de extrema importância para explicação da produtividade é o estado nutricional das plantas. 
Cabe comentar que o pomar analisado no presente trabalho foi bem conduzido, com tratos culturais os mais uniformes possíveis. No entanto, não foi irrigado. Pode-se argumentar que pequenas diferenças de disponibilidade hídrica poderiam prejudicar a relação entre parâmetros de copa e produção. Além da existência de diferenças de outros fatores, como o estado nutricional das plantas e a arquitetura de copa, a qual está relacionada à captação da energia solar.

Shamasundaran et al. (1983) e Shamasundaram (1984) também não encontraram relação significativa de variáveis como volume, altura e área de superfície de copa, com a produção de árvores de tangerina Coorg (Citrus reticulata Blanco). Da mesma forma, Albrigo et al. (1975), ao avaliarem a aplicabilidade da medida de superfície e volume de copa em árvores de laranja Valência, não encontraram relações significativas entre aquelas medidas e a produção em árvores individuais. Ao passo que Shamasundaran et al. (1983) e Shamasundaram (1984) encontraram relação significativa entre a produção e as variáveis extensão Leste-Oeste da copa e raio de copa. No entanto, esses autores não deixaram claro sob que condições esses resultados foram obtidos.

Parker \& Batchelor (1932), Menon \& Tyagi (1971), Brar \& Mann (1986), Ono et al. (1987), Brar et al. (1988), Tachibana \& Nakai (1989), Brar et al. (1990) e Mataa \& Tominaga (1998) observaram que existia uma tendência das árvores maiores, com maior área foliar, produzirem mais. Porém, esses estudos não estabeleceram relações entre área foliar e produção em nível de árvores individuais.

Ainda, pela observação da Tabela 4, nota-se que nem sempre o método de se utilizar as coordenadas do contorno de quatro quadrantes da copa para o cálculo dos parâmetros de copa apresentou melhores relações que o de se utilizar apenas as de dois quadrantes (Tabela 3). 
Também, os parâmetros de copa em 2001 não apresentaram dependência espacial ao correlacioná-los por meio de semivariogramas cruzados com a produção em 2002.

\subsection{Estudo das relações entre resposta espectral e parâmetros de copa}

Nas Tabelas 5, 6 e 7 encontram-se apenas os parâmetros de copa que apresentaram maior relação com a resposta espectral. Ao se observar as Tabelas 5, 6 e 7 constatou-se que as melhores relações entre resposta espectral e parâmetros de copa foram obtidas a partir dos dados extraídos das imagens tomadas em 2001. Em 2001, as árvores eram menores, portanto, mais individualizadas e os dados para análise foram extraídos de duas imagens ao invés de uma (caso dos segundo e terceiro vôos). Ou seja, as regressões foram obtidas com menos dados, conseqüentemente, menos graus de liberdade. Ademais, é possível argumentar que a determinação dos parâmetros de copa em 2001 tenha sido mais exata, especialmente, quanto à tomada dos dados de coordenadas do contorno das árvores e localização do aparelho LAI-2000 na árvore, afinal as árvores eram menores.

Cabe comentar ainda, que apesar das árvores não terem crescido no período entre o segundo vôo e a determinação dos parâmetros de copa em 2002, seus estados eram diferentes, pois ocorreu queda de folhas. Com relação ao terceiro vôo realizado na mesma época da determinação dos parâmetros de copa em 2002, é possível alegar que, provavelmente, esse vôo apresentou problemas de configuração da câmara, diminuindo o contraste entre os níveis de cinza. A Figura 36 ilustra a distribuição dos níveis de cinza na faixa do infravermelho próximo. É possível notar a concentração dos valores num estreito intervalo entre 0 e 255 , que seriam os dois extremos, caso o contraste fosse máximo. Face esses resultados obtidos, é possível afirmar que aumentar o tempo de exposição da câmara, para permitir maior entrada de energia refletida pelo alvo, é uma medida necessária. 
Tabela 5. Resumo das regressões entre resposta espectral e parâmetros de copa em 2001 calculados a partir de dados de coordenadas de contorno de copa de 2 quadrantes

Parâmetros de copa em 2001

2 quadrantes

parâmetro tipo de imagem função equação $\quad$ g.l. $\mathrm{r}^{2}$ erro padrão valor de $\mathrm{p}$

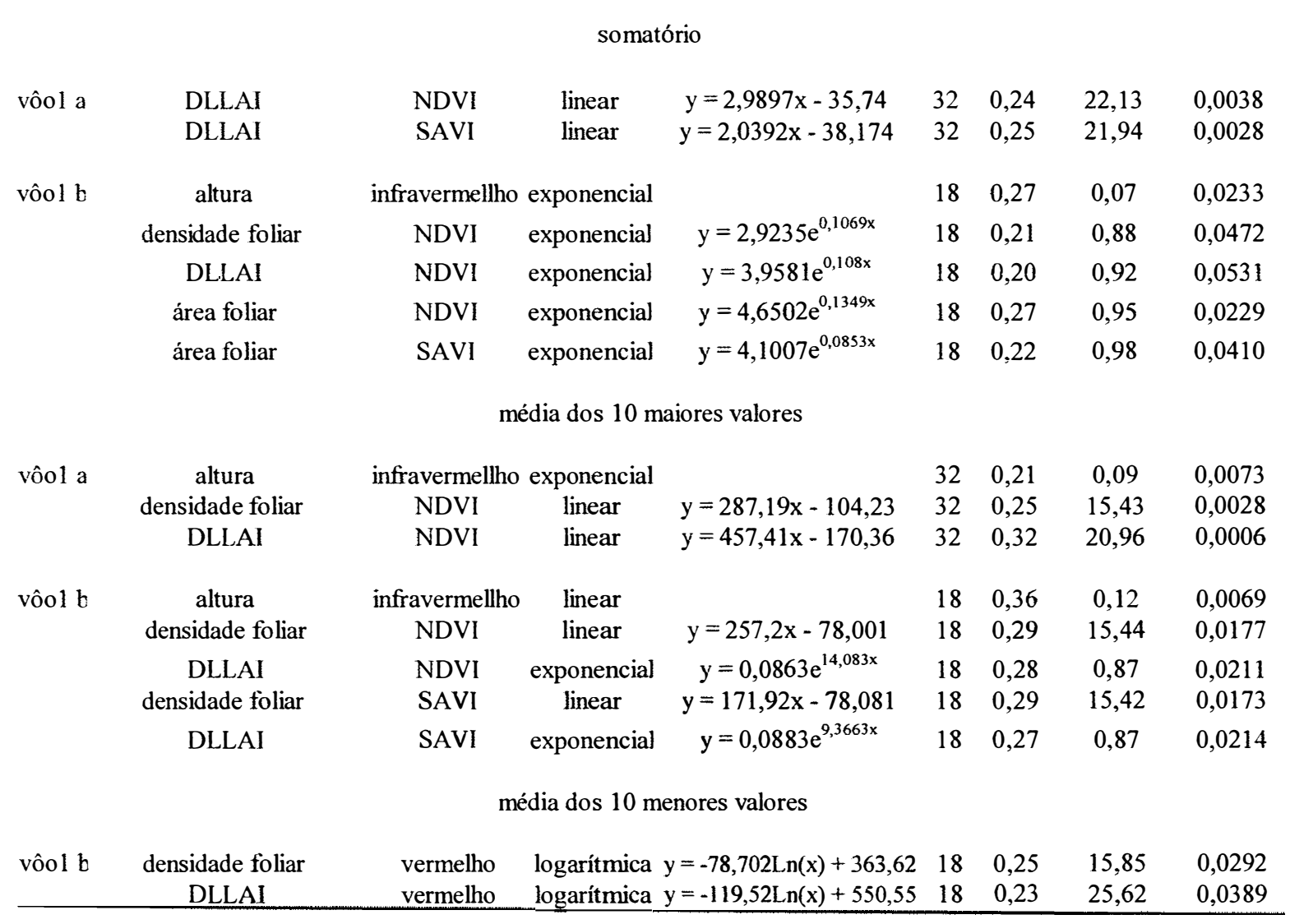

Em média, os parâmetros área e volume foram aqueles que apresentaram as melhores relações com a resposta espectral na forma de somatório dos níveis de cinza dos pixels. Craig et al. (2000) também encontraram relação significativa entre NDVI e volume, embora a relação não tenha sido uma simples relação linear $\left(r^{2}=0,339\right)$. No presente estudo, a relação entre resposta espectral e área foliar também teve destaque, especialmente entre os valores de NDVI e SAVI obtidos a partir das imagens tomadas em 2001 e área foliar calculada com os valores de coordenadas dos quatro quadrantes. 
Tabela 6. Resumo das regressões entre resposta espectral e parâmetros de copa em 2001 calculados a partir de dados de coordenadas de contorno de copa de 4 quadrantes

\begin{tabular}{|c|c|c|c|c|c|c|c|c|}
\hline \multicolumn{9}{|c|}{$\begin{array}{c}\text { Parâmetros de copa em } 2001 \\
4 \text { quadrantes } \\
\end{array}$} \\
\hline & parâmetro & tipo de imagem & função & equação & g.l. & $r^{2}$ & erro padr & valor de $\mathrm{p}$ \\
\hline \multicolumn{9}{|c|}{ somatório } \\
\hline \multirow[t]{6}{*}{ vôola } & área de projeção de copa & infravermellho & exponencial & $y=1,78 e^{4 E-05 x}$ & 32 & 0,47 & 0,14 & 0,00001 \\
\hline & $\begin{array}{c}\text { volume } \\
\text { área foliar } \\
\text { área de projeção de copa }\end{array}$ & $\begin{array}{l}\text { infravermellho } \\
\text { infravermellho } \\
\text { NDVI }\end{array}$ & $\begin{array}{l}\text { exponencial } \\
\text { linear } \\
\text { linear }\end{array}$ & $\begin{array}{c}y=1,9409 e^{5 E-05 x} \\
y=0,0012 x+1,6989 \\
y=0,1243 x+1,1956\end{array}$ & $\begin{array}{l}32 \\
32 \\
32\end{array}$ & $\begin{array}{l}0,41 \\
0,25 \\
0,48\end{array}$ & $\begin{array}{l}0,18 \\
6,70 \\
0,54\end{array}$ & $\begin{array}{l}0,00006 \\
0,00305 \\
0,00001\end{array}$ \\
\hline & volume & NDVI & potencial & $y=0,5443 x^{0,6999}$ & 32 & 0,45 & 0,18 & 0,00002 \\
\hline & $\begin{array}{c}\text { área foliar } \\
\text { área de projeção de copa }\end{array}$ & $\begin{array}{l}\text { NDVI } \\
\text { SAVI }\end{array}$ & $\begin{array}{l}\text { exponencial } \\
\text { linear }\end{array}$ & $\begin{array}{c}y=7,6443 e^{0,0512 x} \\
y=0,0843 x+1,1087\end{array}$ & $\begin{array}{l}32 \\
32\end{array}$ & $\begin{array}{l}0,39 \\
0,50\end{array}$ & $\begin{array}{l}6,06 \\
0,53\end{array}$ & $\begin{array}{l}0,00011 \\
0,00000\end{array}$ \\
\hline & $\begin{array}{c}\text { volume } \\
\text { área foliar } \\
\text { área de projeção de copa }\end{array}$ & $\begin{array}{c}\text { SAVI } \\
\text { SAVI } \\
\text { vermelho }\end{array}$ & $\begin{array}{l}\text { potencial } \\
\text { linear } \\
\text { linear }\end{array}$ & $\begin{array}{c}y=0,3816 x^{0,7168} \\
y=0,7739 x-1,0122 \\
y=0,0005 x+0,7977\end{array}$ & $\begin{array}{l}32 \\
32 \\
32\end{array}$ & $\begin{array}{l}0,45 \\
0,39 \\
0,37\end{array}$ & $\begin{array}{l}0,18 \\
6,03 \\
0,59\end{array}$ & $\begin{array}{l}0,00002 \\
0,00010 \\
0,00018\end{array}$ \\
\hline & $\begin{array}{l}\text { volume } \\
\text { área foliar }\end{array}$ & $\begin{array}{l}\text { vermelho } \\
\text { vermelho }\end{array}$ & $\begin{array}{l}\text { exponencial } \\
\text { linear }\end{array}$ & $\begin{array}{c}y=1,5917 e^{0,0002 x} \\
y=0,0043 x-4,3607\end{array}$ & $\begin{array}{l}32 \\
32\end{array}$ & $\begin{array}{l}0,46 \\
0,30\end{array}$ & $\begin{array}{l}0,18 \\
6,46\end{array}$ & $\begin{array}{l}0,00002 \\
0,00090\end{array}$ \\
\hline \multirow[t]{2}{*}{ vôol b } & área foliar & NDVI & potencial & $y=3,4851 x^{0,7051}$ & 18 & 0,31 & 0,35 & 0,01270 \\
\hline & \multicolumn{8}{|c|}{ média dos 10 maiores valores } \\
\hline \multirow[t]{5}{*}{ vôol a } & densidade foliar & NDVI & potencial & $y=20,388 x^{1,6395}$ & 32 & 0,22 & 0,23 & 0,00533 \\
\hline & DLLAI & NDVI & potencial & $y=42,16 x^{2,2593}$ & 32 & 0,33 & 0,25 & 0,00049 \\
\hline & densidade foliar & SAVI & potencial & $y=11 x^{1,7218}$ & 32 & 0,21 & 0,23 & 0,00680 \\
\hline & DLLAI & SAVI & potencial & $y=18,904 x^{2,4715}$ & 32 & 0,34 & 0,24 & 0,00038 \\
\hline & altura & vermelho & potencial & $y=97,981 x^{-0,9097}$ & 32 & 0,23 & 0,10 & 0,00495 \\
\hline \multirow[t]{4}{*}{ vôo1 b } & densidade foliar & NDVI & potencial & $y=63,632 x^{2,774}$ & 18 & 0,51 & 0,28 & 0,00061 \\
\hline & DLLAI & NDVI & exponencial & $y=101,31 x^{2,9795}$ & 18 & 0,61 & 0,25 & 0,00007 \\
\hline & densidade foliar & SAVI & potencial & $y=20,838 x^{2,7797}$ & 18 & 0,51 & 0,28 & 0,00057 \\
\hline & DLLAI & SAVI & potencial & $y=30,479 x^{2,9819}$ & 18 & 0,62 & 0,25 & 0,00007 \\
\hline \multicolumn{9}{|c|}{ média dos 10 menores valores } \\
\hline vôo1 a & DLLAI & vermelho & exponencial & $y=927810 x^{-2,8256}$ & 32 & 0,31 & 0,25 & 0,00075 \\
\hline \multirow[t]{2}{*}{ vôol b } & densidade foliar & vermelho & exponencial & $y=50,913 e^{-0,0311 x}$ & 18 & 0,53 & 0,28 & 0,00041 \\
\hline & DLLAL & vermelho & exponencial & $y=65,925 e^{-0,031 x}$ & 18 & 0,55 & 0,26 & 0,00026 \\
\hline
\end{tabular}


Tabela 7. Resumo das regressões entre resposta espectral e parâmetros de copa em 2002

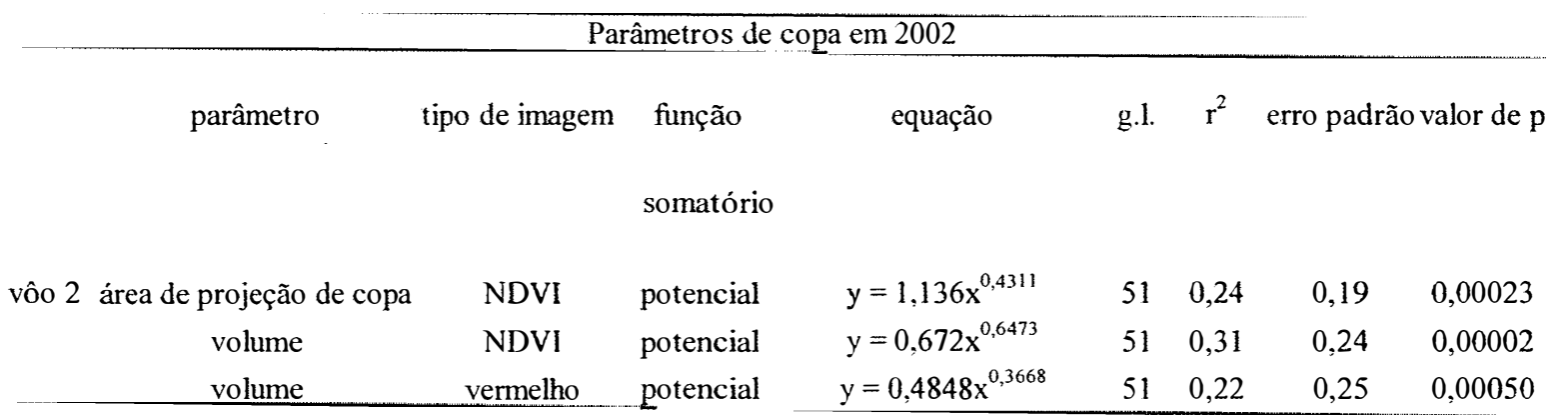

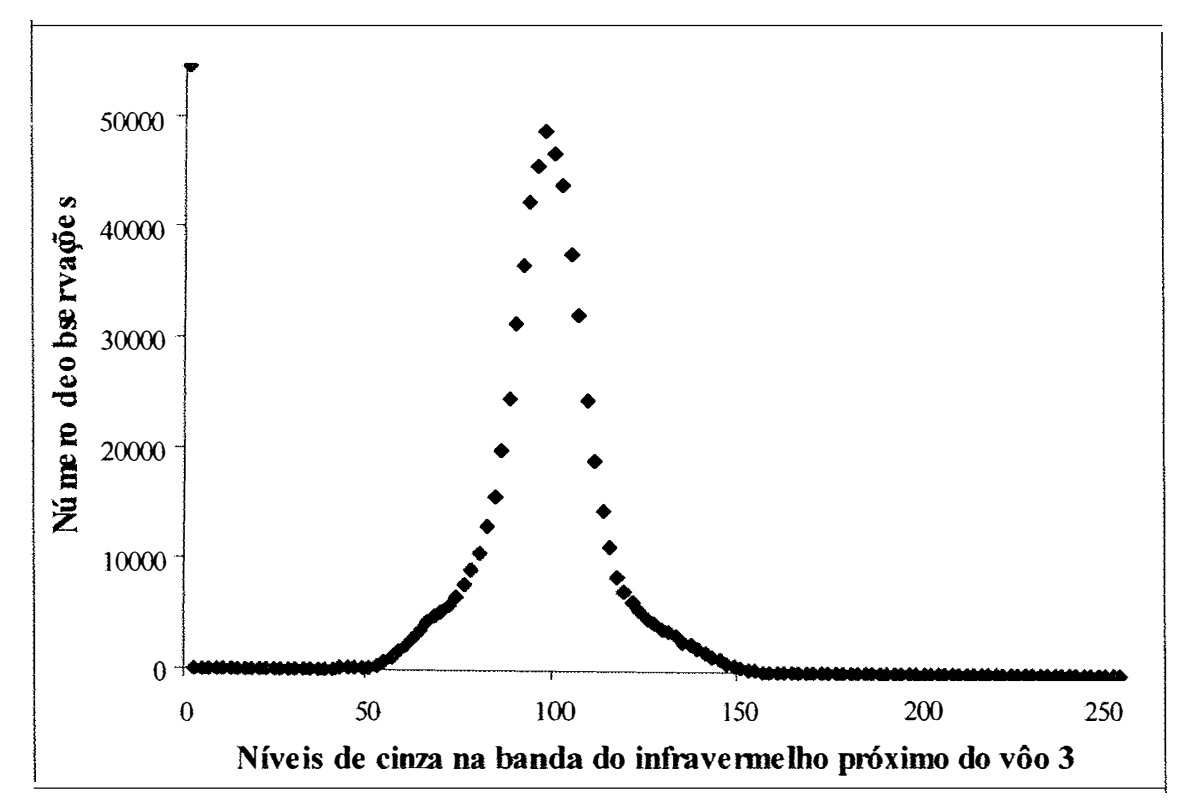

Figura 36 - Distribuição dos níveis de cinza na faixa do infravermelho próximo do vôo 3

Já, a resposta espectral na forma de média dos 10 maiores valores, no caso do NDVI e SAVI, e menores, no caso da faixa do vermelho, apresentou as melhores relações com DLLAI, especialmente na faixa do vermelho, NDVI e SAVI obtidos a partir das imagens do vôo 1. É interessante notar que as relações entre os valores na faixa do infravermelho próximo com os parâmetros de copa foram menores, até mesmo comparadas às da faixa do vermelho. Afinal, na faixa do infravermelho próximo, a amplitude de resposta à quantidade de folhas é maior. É possível sustentar que a 
saturação da resposta espectral nessa faixa, graças ao maior tempo de exposição do alvo à energia radiante, tenha comprometido melhores resultados. Xavier (2002) também encontrou menores relações entre IAF e resposta espectral na faixa do infravermelho próximo para eucalipto e floresta ripária, e atribuiu isso aos comportamentos espectrais distintos das folhas nesse comprimento de onda e a maior possibilidade de sombreamento no dossel devido a sua estrutura.

No entanto, alguma relação $\left(r^{2}=0,21\right)$ foi obtida entre altura e a resposta espectral na forma de média dos 10 maiores níveis de cinza na faixa do infravermelho próximo extraídos de uma das duas imagens do vôo 1. Para Craig et al. (2000), a relação entre NDVI e altura apresentou um coeficiente de determinação $\left(\mathrm{r}^{2}\right)$ de 0,487 , ou seja, quase metade da variação na altura foi explicada pela variação no NDVI.

Ainda, vale destacar os valores de $\mathrm{r}^{2}$ obtidos entre a média dos 10 maiores valores de NDVI e SAVI e dos 10 menores níveis de cinza na faixa do vermelho, extraídos da imagem b do vôo1, e IAF e DLLAI. No entanto, é pertinente comentar que as regressões foram obtidas com apenas 18 graus de liberdade.

Em geral, os parâmetros de copa calculados a partir dos dados de coordenadas de contorno de copa de 4 quadrantes apresentaram valores de $\mathrm{r}^{2}$ superiores. É interessante notar que os tipos de imagem que melhor expressaram a relação entre densidade foliar, que, na verdade, é um tipo de IAF, calculada a partir dos dados de coordenadas de contorno de copa de 4 quadrantes, e resposta espectral foram NDVI e SAVI. Ademais, a função que melhor expressou essa relação foi a potencial. Os resultados obtidos por Xavier (2002) também mostraram que o NDVI e a função potencial melhor expressaram a relação entre IAF e resposta espectral. No entanto, Xavier (2002), ao relacionar conjuntamente o IAF das coberturas vegetais cana-deaçúcar, milho, pastagem, eucalipto e floresta ripária com a resposta espectral, encontrou coeficientes de determinação superiores aos encontrados nesse estudo. 
Colombo et al. (2003) também encontraram coeficientes de determinação superiores ao relacionar separadamente resposta espectral e IAF de milho, soja, uva e um tipo de árvore utilizada como madeira. Por outro lado, não encontraram coeficientes de determinação superiores para as relações entre resposta espectral e IAF de florestas. Colombo et al. (2003) atribuíram tal comportamento à alta heterogeneidade interna desse tipo de cobertura, com diferentes alturas e arquiteturas de copa.

É pertinente considerar que as condições exploradas em Xavier (2002) e Colombo et al. (2003) foram bem diferentes às exploradas no presente estudo. Por exemplo, nos estudos de Xavier (2002) e Colombo (2003), as resoluções espaciais foram aproximadamente 10 e 3 vezes inferiores às exploradas no presente estudo. Ademais, a determinação do IAF em campo nos estudos de Xavier (2002) e Colombo (2003) foi bem diferente da do presente estudo. Xavier (2002) e Colombo (2003) estimaram o IAF das coberturas vegetais como dosséis contínuos, ao passo que no presente estudo as árvores foram consideradas entidades isoladas. Em nível de árvores isoladas, a determinação de IAF em pomares é dificultada pela proximidade das árvores vizinhas, o que diminui a área amostrada pelo aparelho LAI-2000.

Ainda, um ponto a destacar é a variabilidade de resposta espectral dentro de uma mesma árvore, em função da variabilidade de iluminação. Vale mencionar que os vôos foram realizados quando o sol estava mais próximo do zênite. No entanto, na época em que foram realizados os vôos, havia ainda alguma inclinação solar.

Ademais, a resposta espectral das árvores sofreu influência do substrato, das sombras e da casca do tronco e dos galhos. Segundo Xavier (2002), Formaggio (1989) e Guyot (1990), o substrato, as sombras e a casca do tronco e dos galhos exercem influência marcante sobre a resposta espectral. Também, diferenças nutricionais e sanitárias entre as árvores podem ter contribuído para diminuir os valores de $\mathrm{r}^{2}$, afinal, de acordo com Guyot (1990), a resposta espectral das plantas nas faixas do vermelho e 
do infravermelho próximo pode variar também em função de deficiências nutricionais e do ataque de pragas e doenças.

Ao se considerar a resposta espectral na forma de somatório dos valores de níveis de cinza e índices de vegetação, leva-se em conta toda a variabilidade de condições às quais a resposta espectral está submetida. Por outro lado, ao se considerar a reposta espectral na forma de média dos 10 maiores valores, no caso da faixa do infravermelho próximo, do NDVI e do SAVI, e menores, no caso da faixa do vermelho, restringe-se a área amostrada da árvore a aquela região compreendida pelos 10 pixels.

\subsection{Estudo das relações entre resposta espectral e produção}

Pela observação das Tabela 8, 9 e 10, fica evidente que as melhores relações ocorreram entre os dados de resposta espectral e a produção em 2002. Na época mais importante para a produção em 2002, as condições climáticas foram mais favoráveis, propiciando às árvores expressarem mais plenamente seu potencial produtivo. Conseqüentemente, a resposta espectral, ao permitir estimar o vigor das árvores (Blazquez et al., 1978; Blazquez et al., 1979; Blazquez et al., 1984; Edwards \& Blazquez, 1985; Blazquez, 1988a; Blazquez, 1988b; Blazquez, 1989; Wickland, 1989; Blazquez, 1991; Blazquez, 1993; Campbell, 1996; Blazquez et al., 1998) e mesmo o potencial produtivo (Blazquez et al., 1984; Wickland, 1989; Ippoliti-Ramilo et al., 1999 e Weepener et al., 2000), aumenta sua relação com a produção. Nesse estudo, portanto, foi possível comprovar que, quando as condições climáticas para a produção foram mais favoráveis, a resposta espectral tendeu a estar mais relacionada ao vigor das árvores citrícolas jovens da variedade Hamlin e ao seu potencial produtivo. Whitney et al. (1999) e Whitney et al. (2000) também encontraram relação significativa entre o tamanho de copa das árvores, estimado a partir de sua resposta espectral em fotografias aéreas, e a produtividade $(\mathrm{r}=0,45$; valor de $\mathrm{p}=0,0001)$. 
Tabela 8. Resumo das regressões entre dados de resposta espectral extraída da imagem a do vôo 1 e produção em 2001

$$
\text { Produção em } 2001
$$

tipo de imagem função equação $\quad$ g.l. $\quad r^{2}$ erro padrão valor de $p$ média dos 10 maiores valores

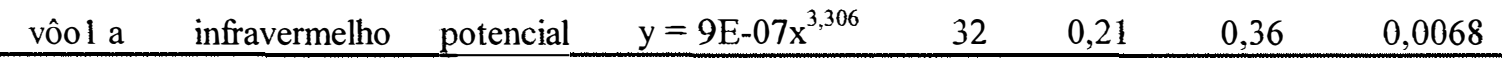

Tabela 9. Resumo das regressões entre dados de resposta espectral extraída das imagens a e b do vôo 1 e produção em 2002

Produção em 2002

tipo de imagem função equação $\quad$ g.l. $\quad r^{2}$ erro padrão valor de $\mathrm{p}$

somatório

$\begin{array}{ccccccc}\text { vôol a infravermellho } & \text { potencial } & \mathrm{y}=0,1977 \mathrm{x}^{0,6656} & 31 & 0,33 & 0,20 & 0,0005 \\ \text { NDVI } & \text { potencial } & \mathrm{y}=17,138 \mathrm{x}^{0,6823} & 31 & 0,41 & 0,19 & 0,0001 \\ \text { SAVI } & \text { potencial } & \mathrm{y}=11,717 \mathrm{x}^{0,7091} & 31 & 0,42 & 0,19 & 0,0001 \\ \text { vermelho } & \text { linear } & & 31 & 0,33 & 24,06 & 0,0006\end{array}$

$\begin{array}{cccccccc}\text { vôo1 b infravermelho } & \text { potencial } & \mathrm{y}=7,3824 \mathrm{x}^{0,3079} & 18 & 0,21 & 0,18 & 0,0498 \\ \text { NDVI } & \text { exponencial } & \mathrm{y}=84,996 \mathrm{e}^{0,0289 \mathrm{x}} & 18 & 0,37 & 0,16 & 0,0057 \\ \text { SAVI } & \text { potencial } & \mathrm{y}=29,836 \mathrm{x}^{0,4645} & 18 & 0,39 & 0,16 & 0,0042\end{array}$

média dos 10 maiores valores

vôo1 a infravermelho potencial $y=5 \mathrm{E}-05 \mathrm{x}^{2,7107} \quad 31 \quad 0,39 \quad 0,19 \quad 0,0001$

vôol b infravermelho potencial $y=3 \mathrm{E}-06 \mathrm{x}^{3,2227} \quad 18 \quad 0,36 \quad 0,16 \quad 0,0065$

$\begin{array}{llllll}\text { NDVI linear } y=326,65 x+5,4817 & 18 & 0,24 & 22,48 & 0,0350\end{array}$

$\begin{array}{llllll}\text { SAVI linear } y=216,93 x+6,1781 & 18 & 0,23 & 22,51 & 0,0358\end{array}$


Tabela 10. Resumo das regressões entre dados de resposta espectral extraída da imagem do vôo 2 e produção em 2002.

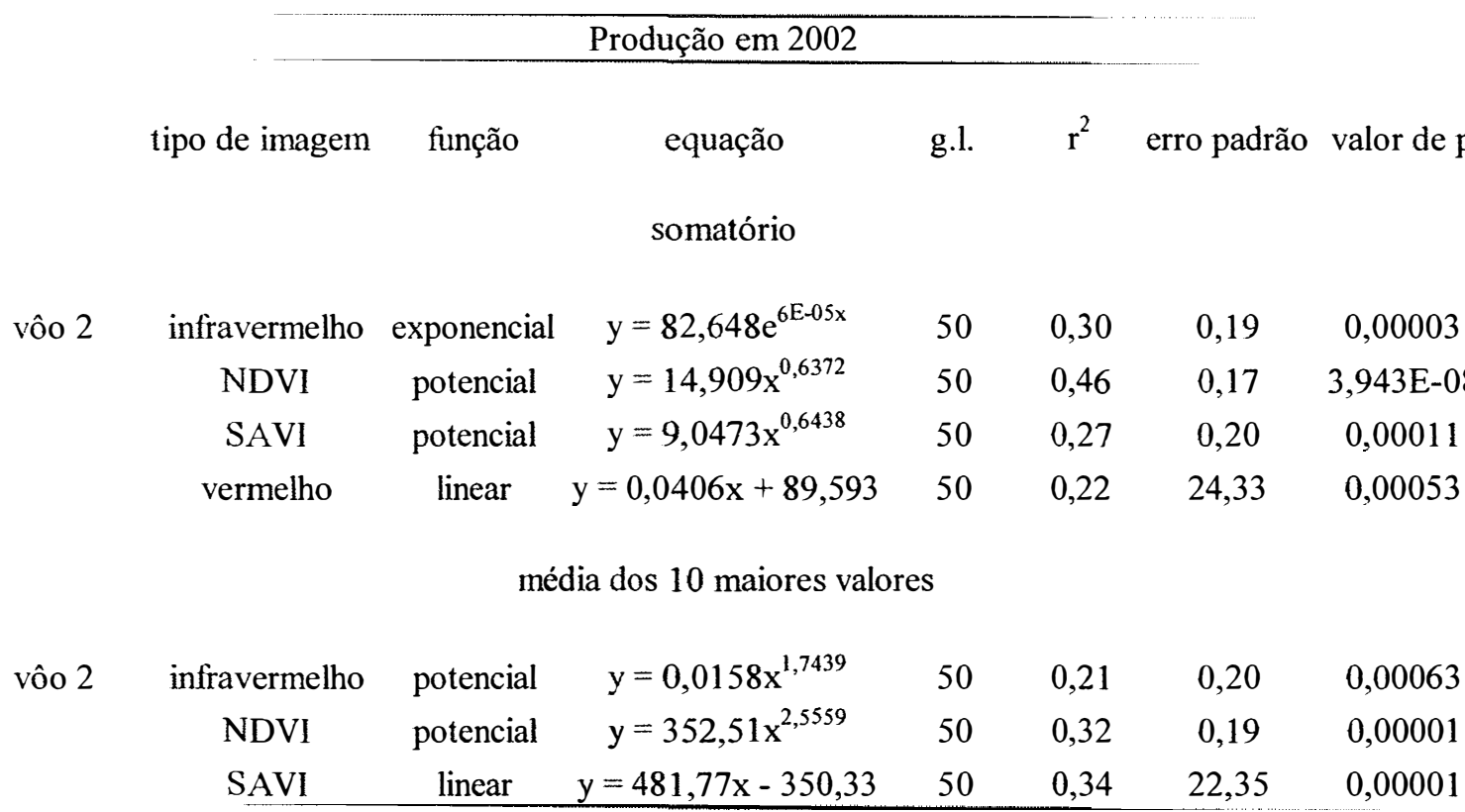

No entanto, é importante também considerar que a diferença entre as condições fenológicas das árvores para a produção em 2001 e as condições fenológicas das árvores na época de realização dos vôos tenha comprometido melhores relações entre os dados de resposta espectral e a produção em 2001.

Além disso, ficou comprovado que, acima do vigor das árvores, a resposta espectral dá uma idéia da energia radiante que está sendo capturada pelas plantas, que está diretamente relacionada à produção Afinal, as relações encontradas entre resposta espectral e produção foram muito mais superiores às encontradas entre parâmetros de copa e produção.

Ainda, as relações encontradas entre a resposta espectral extraída das imagens do vôo 1 e do vôo 2 e produção foram bastante superiores às encontradas entre a do vôo 3 e produção. Vale lembrar que a imagem do vôo 3 apresentou problemas relacionados à 
configuração da câmara e foi tomada em época diferente à época de formação e maturação dos frutos para a produção em 2002.

Já quando se comparam as relações encontradas entre a resposta espectral extraída das imagens do vôo 1 e produção em 2002 com a da imagem do vôo 2 e produção em 2002, verifica-se uma ligeira vantagem numérica do vôo 1. No entanto, é preciso lembrar que as relações encontradas entre a resposta espectral extraída das imagens do vôo 1 e produção em 2002 foram obtidas com menos graus de liberdade. Por outro lado, para o vôo 2 foi obtido o maior valor de $\mathrm{r}^{2}$, entre NDVI e produção em 2002.

Ainda com relação aos vôos 1 e 2, é interessante notar que, nas épocas desses vôos, as árvores estavam sob condições fenológicas bem diferentes. Por exemplo, durante o vôo 1, as árvores eram menores e não carregavam frutos, ao passo que durante o vôo 2 as árvores já haviam ultrapassado a fase de desenvolvimento vegetativo, portanto apresentavam maior área foliar, e estavam carregadas de frutos.

Ao se comparar os valores de $r^{2}$ das relações entre a resposta espectral na forma de somatório e a produção com os das relações entre a resposta espectral na forma de média dos 10 maiores valores, no caso da faixa do infravermelho próximo, NDVI e SAVI, e menores, no caso do vermelho, e a produção, observou-se, em geral, valores maiores de $\mathrm{r}^{2}$ entre a resposta espectral na forma de somatório e a produção. No entanto, na faixa do infravermelho próximo das imagens do vôo 1 e SAVI da imagem do vôo 2, os valores de $\mathrm{r}^{2}$ entre a resposta espectral na forma de média dos 10 maiores valores e a produção foram superiores. No caso de NDVI da imagem do vôo 2 , os valores de $\mathrm{r}^{2}$ foram próximos.

A vantagem de se trabalhar com a resposta espectral na forma de média dos 10 maiores ou menores valores é não precisar identificar todos os pixels que fazem parte da copa da árvore. Em pomares adultos, a identificação desses pixels é impossível, uma vez que as copas das árvores estão unidas, formando um contínuo na linha de plantio. 
Quanto ao tipo de função matemática que melhor se ajustou aos dados de resposta espectral e produção, constatou-se que a função potencial tendeu a expressar melhor a relação entre resposta espectral e produção, afinal apresentou, em geral, os melhores resultados de $\mathrm{r}^{2}$.

Já quanto à explicação dos baixos valores de $\mathrm{r}^{2}$ encontrados, é possível inferir que, tanto problemas espectrais, como aqueles relacionados à própria produção podem ter comprometido melhores resultados. Por exemplo, no caso de problemas espectrais, é possível associar os baixos valores de $r^{2}$ a causas semelhantes dos baixos valores de $r^{2}$ obtidos entre resposta espectral e parâmetros de copa, ou seja, variabilidade de iluminação e a contribuição de sombras, substrato e casca do tronco e dos galhos. No caso de problemas relacionados à própria produção, diferenças hídricas, nutricionais, sanitárias e fisiológicas entre as árvores podem ser destacadas. É pertinente comentar que, nas faixas do espectro eletromagnético avaliadas no presente estudo, dificilmente, as diferenças hídricas seriam captadas por completo pelos sensores. Afinal, segundo Guyot (1990), em condições naturais, as plantas precisam sofrer um estresse hídrico extremamente severo para alterar sua resposta nas faixas do vermelho e do infravermelho próximo. Com relação às diferenças nutricionais e sanitárias, não se pôde inferir se os sensores captaram por completo essas diferenças, assim como, as fisiológicas, por exemplo, a alternância de produção.

Os resultados obtidos por Blazquez et al. (1978), Blazquez et al. (1979), Blazquez et al. (1984), Edwards \& Blazquez (1985), Blazquez (1988a), Blazquez (1988b), Blazquez (1989), Blazquez (1991) e Blazquez (1993) indicaram que a resposta espectral na faixa do infravermelho próximo permitiu levantar as condições gerais das árvores, nos três primeiros trabalhos, e o nível de estresse das plantas, nos outros, muito provavelmente, graças mais às diferenças nutricionais e sanitárias, que causam impactos mais permanentes, do que hídricas, que tendem a ser mais provisórias em culturas permanentes. 
Ainda quanto aos problemas relacionados à própria produção, é interessante comentar que as árvores mais vigorosas, com maior resposta espectral, conseqüentemente, maior potencial produtivo, não necessariamente produziram mais, caso tenha faltado água nas fases mais importantes à produção. Ou seja, eram árvores que, provavelmente, estavam sustentadas em solo com menor capacidade de armazenamento de água, portanto, podem ter apresentado desenvolvimento vegetativo acentuado na época em que o armazenamento de água foi alto, mas que produziram menos quando as precipitações foram insuficientes na época de fixação dos frutos.

Ficou claro, portanto, no presente estudo, que a explicação da produtividade em pomares jovens de laranja Hamlin por meio de sua resposta espectral depende do levantamento de outros fatores, especialmente daqueles relacionados ao solo, como já haviam sugerido Weepener et al. (2000). Assim, as análises de regressão seriam separadas, por exemplo, por tipo de solo. Martins (2000) também sugeriu a inclusão da produção do ano anterior na parametrização de modelos de previsão de safra citrícola. 


\section{CONCLUSÕES}

1 Sob condições climáticas adversas, a variabilidade de produção entre árvores próximas é menor, muito provavelmente, devido a maior influência das características intrínsecas do terreno;

2 Em pomares jovens de laranja Hamlin, em nível de árvores individuais, é possível criar classes distintas de comportamento produtivo por meio da análise de agrupamentos via lógica fuzzy;

3 Em pomares jovens de laranja Hamlin, em nível de árvores individuais, o gerenciamento localizado da produção, seja na forma de estimativa de produção como na de manejo, é dificultado pela alta variabilidade espaço-temporal da produção e baixa coerência espacial das classes de comportamento produtivo;

4 No pomar estudado, a resposta espectral das árvores explica em boa parte a formação das classes de comportamento produtivo;

5 Os parâmetros área de projeção de copa, volume, altura, densidade foliar, DLLAI e área foliar, por si só, não são bons indicadores de produção, em pomares jovens de laranja Hamlin; 
6 A resposta espectral, na forma de níveis de cinza nas faixas do vermelho e do infravermelho próximo e dos índices de vegetação NDVI e SAVI, em imagens de alta resolução espacial, apresenta relação significativa com a produção e com os parâmetros área de projeção de copa, volume, altura, densidade foliar, DLLAI e área foliar em pomares jovens de laranja Hamlin;

7 O índice de vegetação NDVI é o que melhor expressa a relação entre resposta espectral, parâmetros biofísicos e produção em pomares jovens de laranja Hamlin;

8 Para estudos relacionados ao gerenciamento localizado da produção em pomares jovens de laranja Hamlin, a tomada de imagens aéreas multiespectrais tanto na época anterior como posterior à fase de desenvolvimento vegetativo apresenta desempenho semelhante;

9 A explicação da produtividade em pomares jovens de laranja Hamlin por meio de sua resposta espectral depende do levantamento de outros fatores, especialmente daqueles relacionados ao solo. 


\section{REFERÊNCIAS BIBLIOGRÁFICAS}

ALBRIGO, L.G.; ANDERSON, C.A.; EDWARDS, G.J.; BISTLINE, F.W.; HEPBURN, W.J.; CARY, T. Yield estimation of "Valencia" orange research plots and groves. Proceedings of the Florida State Horticultural Society, v.88, p.44-49, 1975.

AMAMI, S. El Contribuition a l'étude de la evolution des pousses de l'année et des inflorescences chez oranger "Maltaise de Tunisie" et son effet sur le calibre du fruit. Annales de l'Institut National de la Recherche Agronomique de Tunisie, v.47, n.1, 25p, 1974. /Resumo 858 em Horticultural Abstracts, v.47, n.1, p.90, Jan. $1977 /$

AUTODESK INC. AUTOCAD2000 (software). San Rafael: Autodesk Inc., 1999.

BATCHELOR, L.D.; REED, H.S. Relations of the variability of yields of fruit trees to the accuracy of field trials. Journal of Agricultural Research, v.12, n.5, p.245283, Feb. 1918.

BEN-MECHLIA, N.; CARROLL, J.J. Agroclimatic modeling for the simulation of phenology, yield and quality of crop production. International Journal of Biometeorology, v.33, n.1, p.36-51, 1989.

BLACKMORE, S. The role of yield maps in precision farming. Cranfield, 2003. 170p. Thesis (Ph.D.) - Cranfield University. 
BLAZQUEZ, C.H. Comparisons between densitometric measurements, image analysis, and photointerpretation readings of aerial color infrared photographs of citrus trees. Proceedings of the Florida State Horticultural Society, v.101, p.66-69, 1988a.

BLAZQUEZ, C.H. Use of aerial color infrared photography, dual color video, and a computer system for property appraisal of citrus groves. Photogrammetric Engineering and Remote Sensing, v.54, n.2, p.233-236, Feb. 1988b.

BLAZQUEZ, C.H. Densitometry, image analysis, and interpretation of aerial color infrared photographs of citrus. HortScience, v.24, n.4, p.691-693, Aug. 1989.

BLAZQUEZ, C.H. Measurements of citrus tree health with a scanning densitometer from aerial color infrared photographs. Plant Disease, v.75, n.4, p.370-372, Apr. 1991.

BLAZQUEZ, C.H. Correlation of densitometric measurements of aerial color infrared photography with visual grades of citrus groves. Plant Disease, v.77, n.5, p.477479, May 1993.

BLAZQUEZ, C.H.; EDWARDS, G.J.; HORN JR., F.W. Citrus grove mapping with colored infrared aerial photography. Proceedings of the Florida State Horticultural Society, v.91, p.5-8, 1978.

BLAZQUEZ, C.H.; EDWARDS, G.J.; HORN JR., F.W. Aerial color infrared photography - a management tool. Proceedings of the Florida State Horticultural Society, v.92, p.13-15, 1979.

BLAZQUEZ, C.H.; EDWARDS, G.J.; MURARO, R.P. The role of maps, aerial photography, and image analysis in citrus grove surveillance and appraisal. Proceedings of the Florida State Horticultural Society, v.97, p.69-73, 1984. 
BLAZQUEZ, C.H.; ADAIR, R.C.; DENNIS, G.D.; BUTTS, J.; BRADY, D.; WHITTAKER, H.M. Application of aerial photography and videography to citrus tree inventory. Proceedings of the Florida State Horticultural Society, v.111, p.173-177, 1998.

BRAR, W.S.; MANN, M.S. Optimum plot size in experiment with Kinnow mandarin. Punjab Horticultural Journal, v.26, n.1/4, p.25-30, 1986.

BRAR, W.S.; CHAHAL, B.S.; GILL, D.S. Optimum plot size for experiments on sweet orange (Citrus sinensis Osbeck) cv. Jaffa. South Indian Horticulture, v.31, n.2/3, p.99-100, 1983.

BRAR, W.S.; MANN, S.S.; CHAHILL, B.S. Single tree sampling scheme for estimating plot yield in Kinnow mandarin. South Indian Horticulture, v.36, n.6, p.293-296, 1988.

BRAR, W.S.; MANN, S.S. MANN, M.S. Single tree sampling scheme for estimating plot yield in Kinnow mandarin. Punjab Horticultural Journal, v.30, n.1/4, p.3337, 1990.

BURROUGH, P.A. Principles of geographical information systems for land resources assessment. New York: Oxford University Press, 1989. 194 p.

BURROUGH, P.A.; MCDONNELL, R.A. Principles of geographical information systems. Oxford: Oxford University Press, 2000. 333 p.

BUSTAN, A.; GOLDSCHMIDT, E.E. Estimating the cost of flowering in a grapefruit tree. Plant, Cell and Environment, v.21, p.217-224, 1998. 
BUSTAN, A.; GOLDSCHMIDT, E.E.; ERNER, Y. Progress in the development of "Citros" - a dynamic model of citrus productivity. Acta Horticulturae, n.499, p.6980, Oct. 1999.

CAMARGO, M.B.P de; ORTOLANI, A.A.; PEDRO JUNIOR, M.J.; ROSA, S.M. Modelo agrometeorológico de estimativa de produtividade para o cultivar de laranja Valência. Bragantia, v.58, n.1, p.171-178, 1999.

CAMPBELL, J.B. Introduction to remote sensing. 2.ed. New York: The Guilford Press, 1996. 622p.

CHING, T.H. Coeficiente de correlação intraclasse: planejamento com alocação ótima e aplicação no estudo de confiabilidade de medidas. São Paulo, 1995. 103p. Dissertação (Mestrado) - Instituto de Matemática e Estatística, Universidade de São Paulo.

CLARK POWELL, H. The continuity of high and low yielding tendencies in citrus trees. Journal of Pomology And Horticultural Science, v.10, p.295-300, 1932.

CLARK UNIVERSITY. Clark Labs, The Idrisi Project. IDRISI32: version I32.11 (software). Worcester: Clark Labs, The Idrisi Project/Clark University, 2000.

COELHO FILHO, M.A. Variabilidade espacial aplicada ao manejo da irrigação por microaspersão em lima ácida "Tahiti" (Citrus latifolia TANAKA). Piracicaba, 1998. 152p. Dissertação (Mestrado) - Escola Superior de Agricultura "Luiz de Queiroz", Universidade de São Paulo.

COLOMBO, R.; BELLINGERI, D.; FASOLINI, D.; MARINO, C.M. Retrieval of leaf area index in different vegetation types using high resolution satellite data. Remote Sensing of Environment, v. 86, p.120-131, 2003. 
COVRE, M. Influência de parâmetros culturais de citros sobre os dados TM/Lansat. São José dos Campos, 1989. 241p. Dissertação (Mestrado) - Instituto Nacional de Pesquisas Espaciais, Ministério da Ciência e Tecnologia.

CRAIG, J.C.; SHIH, S.F.; BOMAN, B.J.; CARTER, G.A. Multispectral aerial imagery for detection of salinity stress in citrus. In: INTERNATIONAL CONFERENCE ON GEOSPATIAL INFORMATION IN AGRICULTURE AND FORESTRY, 2., Lake Buona Vista, 2000. Proceedings. Ann Arbor: Veridian Erim International, 2000. v.2. p. $97-103$.

DHILON, J.S.; SINGH, K.K.; BAKHSHI, J.C. Investigations on flowering and fruiting problems in sweet lime (Citrus limettioides Tanaka) I Flowering and fruiting characteristics. Punjab Horticultural Journal, v.2, p.153-166, 1962. /Resumo 7979 em Horticultural Abstracts, v.33, n.4, p.797, Dec. 1963/

DI GIORGI, F.; IDE, B.Y.; DIB, K.; MARCHI, R.J.; TRIBONI, H.R.; WAGNER, R.L.; ANDRADE, G. Influência climática na produção de laranja. Laranja, v.12, n.1, p.163-192, 1991.

DOWMAN, I. Fundamentals of digital photography. In: ATKINSON, K.B. (Ed.) Close range photogrammetry and machine vision. Caithness: Whittles Publishing, 1996. cap.3, p.52-77.

DUNCAN TECHNOLOGIES INC. CameraLink camera control software user's manual (software). Auburn: Duncan Technologies Inc., 1999. 33p.

\section{DUNCAN TECHNOLOGIES INC. MS2100, MS2150 \& MS3100 digital} multispectral camera user's manual. Auburn: Duncan Technologies Inc., 1999. $32 \mathrm{p}$. 
EDWARDS, G.J.; BLAZQUEZ, C.H. Analysis of ACIR transparencies of citrus trees with a projecting spectral densitometer. Photogrammetric Engineering and Remote Sensing, v.51, n.1, p.95-98, Jan. 1985.

EMPRESA BRASILEIRA DE PESQUISA AGROPECUÁRIA. Centro Nacional de Pesquisa de Solos. Sistema brasileiro de classificação de solos. Brasília: EMBRAPA Produção de Informação; Rio de Janeiro: EMBRAPA Solos, 1999. $412 \mathrm{p}$.

FARIAS, P.R.S.; NOCITI, L.A.; BARBOSA, J.C.; PERECIN, D. Agricultura de precisão: mapeamento da produtividade em pomares cítricos usando geoestatística. Revista Brasileira de Fruticultura, v.25, n.2, p.235-241, Ago. 2003.

FORMAGGIO, A.R. Características agronômicas e espectrais para sensoriamento remoto de trigo e feijão. Piracicaba, 1989. 163p. Tese (Doutorado) - Escola Superior de Agricultura "Luiz de Queiroz", Universidade de São Paulo.

GALLO, J.R.; RODRIGUEZ, O.; CAMARGO, A.P. de; IGUE, T. Variações anuais na produção de frutos e concentração de macronutrientes em folhas de citros, relacionados ao balanço hídrico meteorológico e a adubação, no período de 1957 a 1975. Bragantia, v.36, p.271-290, 1977.

GOLDEN SOFTWARE INC. SURFER(WIN32): version 6.01 (software). Golden: Golden software Inc., 1995.

GOLDSCHMIDT, E.E.; MONSELISE, S.P. Physiological assumptions toward the development of a citrus fruiting model. In: INTERNATIONAL CITRUS CONGRESS, 2., Orlando, 1977. Proceedings. Orlando: International Society of Citriculture, 1978. v.2. p.668-672. 
GONÇALVES, A.C.A. Variabilidade espacial de propriedades físicas do solo para fins de manejo da irrigação. Piracicaba, 1997. 118p. Tese (Doutorado) - Escola Superior de Agricultura "Luiz de Queiroz", Universidade de São Paulo.

GUARDIOLA, J.L. Frutificação e crescimento. In: SEMINÁRIO INTERNACIONAL DE CITROS, 2 ., Bebedouro, 1992. Anais. Campinas: Fundação Cargill, 1992. p.1-26.

GUYOT, G. Optical properties of vegetation canopies. In: STEVEN, M.D.; CLARK, J.A. (Ed.) Applications of Remote Sensing in Agriculture. London: Butterworths, 1990. cap.2, p.19-43.

HAMLETT, J.M.; HORTON, R.; CRESSIE, N.A.C. Resistant and exploratory techniques for use in semivariogram analyses. Soil Science Society of America Journal, v.50, p.868-875, 1986.

HUETE, A.R. Soil influences in remotely sensed vegetation-canopy spectra. In: ASRAR, G. (Ed.) Theory and applications of optical remote sensing. New York: John Wiley \& Sons Inc., 1989. cap.4, p.107-141. (Wiley series in remote sensing)

IAFFE, A. Avaliação da disponibilidade hídrica no solo na produção de laranjas Baianinha e Hamlin em Pindorama, SP. Campinas, 1996. 98p. Dissertação (Mestrado) - Faculdade de Engenharia Agrícola, Universidade Estadual de Campinas.

IKEDA, F. Estimation methods of yield of citrus fruit by sap analysis and computer image processing of tree crown. Journal of Agricultural Science, v.47, n.3, p.97101, Mar. 1992. 
IKEDA, F.; MORINAGA, K.; NAGATA, K. Estimation methods of yield of citrus fruit by sap analysis or computer image processing of tree crown. Bulletin of the Shikoku National Agricultural Experiment Station, n.54, p.111-120, Mar. 1991.

IPPOLITI-RAMILO, G.A.; EPIPHANIO, J.C.N.; SHIMABUKURO, Y.E.; FORMAGGIO, A.R. Sensoriamento remoto orbital como meio auxiliar na previsão de safras. Agricultura em São Paulo, v.46, n.1, p.89-101, 1999.

ISAAKS, E.H.; SRIVASTAVA, R. M. An introduction to applied geostatistics. New York: Oxford University Press, 1989. 561p.

LARK, R.M. Forming spatially coherent regions by classification of multi-variate data: an example from analysis of maps of crop yield. International Journal of Geographical Information Science, v.12, n.1, p 83-98, 1998.

LARK, R.M.; STAFFORD, J.V. Classification as a first step in the interpretation of temporal and spatial variation of crop yield. Annals of Applied Biology, v.130, p.111-121, 1997.

LI-COR. LAI-2000 plant canopy analyser: instruction manual. Lincoln: LI-COR Inc., 1992a. 166p.

LI-COR. 2000-90 support software for the LAI-2000 plant canopy analyser: version 2.15 (software). Lincoln: LI-COR Inc., 1992b. 19p.

MARTINS, A.N. Avaliação de fatores hídricos e térmicos na produção de laranjeiras (Citrus sinensis L. Osbeck) "Valência" e "Hamlin". Piracicaba, 2000. 115p. Tese (Doutorado) - Escola Superior de Agricultura "Luiz de Queiroz", Universidade de São Paulo. 
MATAA, M.; TOMINAGA, S. Reproductive-vegetative shoot growth interactions and relationship to non-structural carbohydrates in immature ponkan mandarin (Citrus reticulata Blanco). Journal of Horticultural Science \& Biotechnology, v.73, n.2, p.189-194, Mar., 1998.

MCBRATNEY, A.B.; MOORE, A.W. Application of fuzzy sets to climatic classification. Agricultural and Forest Meteorology, v.35, p.165-185, 1985.

MENON, T.C.M.; TYAGI, B.N. Optimum site and shape of plots in experiments with mandarin orange (Citrus reticulata Blanco). Indian Journal of Agricultural Sciences, v.41, n.10, p.857-861, 1971.

MINASNY B.; MCBRATNEY, A.B. FuzME: version 3.5 (software). Sydney: Australian Centre for Precision Agriculture/The University of Sydney, 2002. http://www.usyd.edu.au/su/agric/acpa. (5 dec. 2003).

MORINAGA, K; IKEDA, F. The use of information on the structure of citrus trees in forecasting yields. Agriculture-and-Horticulture, v.66, n.6, p.723-726, 1991.

MYERS, V.I. (Ed.) Remote sensing applications in agriculture. In: COLWELL, R.N. (Ed.); ESTES, J.E.; THORLEY, G.A. Manual of remote sensing: interpretation and applications. v.2. 2.ed. Falls Church: American Society of Photogrammetry, 1983. cap.33, p.2111-2228.

ONO, S.; IWAGAKI, I., TAKAHARA, T. Studies on the yield components in citrus orchards. Bulletin of the Fruit Tree Research Station, D., n. 9, p. 51-62, 1987.

OLIVEIRA, J.B.; MENK, J.R.F.; BARBIERI, J.L.; ROTTA, C.L.; TREMOCOLDI, W. Levantamento pedológico semidetalhado do Estado de São Paulo: Quadrícula de Araras. Campinas: Instituto Agronômico, 1982. 180p. (Boletim técnico, 71). 
PANNATIER, Y. Variowin: software for spatial data analysis in 2D, v.2.2. New York: Springer-Verlag, 1996. 93p.

PARKER, E.R.; BATCHELOR, L.D. Variation in the yields of fruit trees in relation to the planning of the future experiments. Hilgardia, v.7, n.2, p.81-161, 1932.

PAULINO, S.E.P.; VOLPE, C.A. Relações entre a produção de laranjeira "Pêra" e algumas variáveis meteorológicas, em Limeira, SP. Revista Brasileira de Fruticultura, v.23, n.1, p.130-133, 2001.

PETERSON, D.L.; RUNNING, S.W. Applications in forest science and management. In: ASRAR, G. (Ed.) Theory and applications of optical remote sensing. New York: John Wiley \& Sons, Inc., 1989. cap.10, p.429-473. (Wiley series in remote sensing)

PLESSIS, S.F. du Crop forecasting for navels in South Africa. Proceedings of Florida State Horticultural Society, v. 96, p.40-43, 1984.

ROLIM, G.S.; SENTELHAS, P.C.; BARBIERI, V. Planilhas no ambiente EXCEL para os cálculos de balanços hídricos: normal, seqüencial, de cultura e de produtividade real e potencial. Revista Brasileira de Agrometeorologia, v.6, p.133-137, 1998.

SANIKIDZE, I.S.; MAMULAISHVILI, I. N. The effect of metereological factors on madarin cropping. Subtropicheskie Kul'tury, n.3, p.65-71. /Resumo 5213 em Horticultural Abstracts, v.62, n.6, p.612, Jun. 1992/

SHAMASUNDARAM, K.S. Forecasting yield in Coorg mandarin (Citrus reticulata Blanco). South Indian Horticulture, v.32, n.3, p.125-126, 1984. 
SHAMASUNDARAN, K.S.; RAMACHANDER, P.R. Optimum sample size for the estimation of yield in Coorg mandarin. South Indian Horticulture, v.31, n.4/5, p.223-224, 1983.

SHANMUGASUNDARAM, K.S.; RAMACHANDER, P.R. Optimum sample size for the estimation of Coorg mandarin ( $C$. reticulata Blanco). South Indian Horticulture, v.31, n.6, p.291-292, 1983.

SHAMASUNDARAN, K.S.; MISRA, A.K.; RAMACHANDER, P.R. Prediction of yield in Coorg mandarin (C. reticulata Blanco) by using multiple linear regression. Progressive Horticulture, v.15, n.1/2, p. 161-162, 1983.

STATSOFT INC. STATISTICA FOR WINDOWS: release 4.3 (software). Tulsa: Statsoft Inc., 1993.

TACHIBANA, S.; NAKAI, S. Relationships between crown density, yield and leaf area index in different planting densities in Wase satsuma mandarins (Citrus unshiu Marc. var. praecox Tanaka). Journal of the Japanese Society for Horticultural Science, v.58, n.1, p.91-96, 1989. /Resumo em CAB Abstracts on CD-ROM, 1988-89/

TRIANTAFILIS, J.; ODEH, I.O.A.; MINASNY, B.; MCBRATNEY, A.B. Elucidation of physiographic and hydrogeological features of the lower Namoi valley using fuzzy k-means classification of EM34 data. Environmental Modelling \& Software, v.18, p.667-680, 2003.

TUBELIS, A.; SALIBE, A.A. Relações entre a produção de laranjeira "Hamlin" e as precipitações mensais no altiplano de Botucatu. Pesquisa Agropecuária Brasileira, v.24, n.7, p.801-806, 1989. 
VAN NOORT, G. Determining the potential production of citrus trees in a given environment. In: INTERNATIONAL CITRUS SYMPOSIUM, 1., Riverside, 1968. Proceedings. Riverside: University of California, 1969. p.345-350.

VACHAUD, G.; DE SILANS, A.P. ; BALABANIS, P.; VAUCLIN, M. Temporal stability of spatially measured soil water probability density function. Soil Science Society of America Journal, v.49, p.822-827, 1985.

VETTORAZZI, C.A. Sensoriamento remoto orbital. Piracicaba: ESALQ/Departamento de Engenharia Rural, 1992. 134p. (Série Didática 2)

VETTORAZZI, C.A.; COUTO, H.T.Z. do; FERRAZ, S.F.B.; POMPERMAYER NETO, P. Videografia aérea como fonte de dados para a tomada de decisões em agricultura. In: BALASTREIRE, L.A. O estado-da-arte da agricultura de precisão no Brasil. Piracicaba: L.A. Balestreire, 2000. p.197-200.

XAVIER, A.C. Estimativa da dinâmica do índice de área foliar em uma microbacia hidrográfica por meio de técnicas de sensoriamento remoto. Piracicaba, 2002. 111p. Tese (Doutorado) - Escola Superior de Agricultura "Luiz de Queiroz", Universidade de São Paulo.

WEEPENER, H.L.; NARCISO, G.; LYON, T. Monitoring citrus plantations with airborne imagery. In: INTERNATIONAL CONFERENCE ON GEOSPATIAL INFORMATION IN AGRICULTURE AND FORESTRY, 2., Lake Buona Vista, 2000. Proceedings. Ann Arbor: Veridian Erim International, 2000. v.2. p.132139. 
WHITNEY, J.D.; WHEATON, T.A.; MILLER, W.M. Citrus geospatial information gathering. In: INTERNATIONAL CONFERENCE ON GEOSPATIAL INFORMATION IN AGRICULTURE AND FORESTRY, 2., Lake Buona Vista, 2000. Proceedings. Ann Arbor: Veridian Erim International, 2000. v.2. p.167173.

WHITNEY, J.D.; WHEATON, T.A.; MILLER, W.M.; SALYANI, M.; SCHUELLER, J.K. Site-specific yield mapping for Florida citrus. Proceedings of Florida State Horticultural Society, v. 111, p.148-150, 1998.

WHITNEY, J.D.; MILLER, W.M.; WHEATON, T.A.; SALYANI, M.; SCHUELLER, J.K. Precision farming applications in Florida citrus. Applied Engineering in Agriculture, v.15, n.5, p.399-403, 1999.

WICKLAND, D.E. Future directions for remote sensing in terrestrial ecological research. In: ASRAR, G. (Ed.) Theory and applications of optical remote sensing. New York: John Wiley \& Sons, Inc., 1989. cap.18, p.691-724. (Wiley series in remote sensing) 